Review

\title{
Supramolecular Based Membrane Sensors
}

\section{Mohammad Reza Ganjali ${ }^{1, *}$, Parviz Norouzi $^{1}$, Morteza Rezapour ${ }^{2}$, Farnoush Faridbod ${ }^{1}$ and Mohammad Reza Pourjavid ${ }^{1}$}

1 Center of Excellence in Electrochemistry, Faculty of chemistry, University of Tehran, Tehran, Iran E-mails: ganjali@khayam.ut.ac.ir (Ganjali), Norouzi@khayam.ut.ac.ir (Norouzi), faridbod@khayam.ut.ac.ir (Faridbod), pourjavid@khayam.ut.ac.ir (Pourjavid)

2 Research Institute of Petroleum Industry, Pazhooheshgah Bulevard, Khairabad Junction, Old Qom Road, Tehran, Iran.

E-mail: Rezapourm@ripi.ir (Rezapour)

* Author to whom correspondence should be addressed. E-mail: ganjali@khayam.ut.ac.ir

Received: 9 May 2006 / Accepted: 28 July 2006 / Published: 24 August 2006 / Uploaded after modification: 6 January 2007

\begin{abstract}
Supramolecular chemistry can be defined as a field of chemistry, which studies the complex multi-molecular species formed from molecular components that have relatively simpler structures. This field has been subject to extensive research over the past four decades. This review discusses classification of supramolecules and their application in design and construction of ion selective sensors.
\end{abstract}

Keywords: Supramolecular, Potentiometry, Sensors, Ion selective.

\section{Introduction}

Supramolecular chemistry can be defined as a field of chemistry, which studies the complex multimolecular species formed from molecular components that have relatively simpler structures. This field has been subject to extensive research over the past four decades. Scientists involved in supramolecular science design and study new chemical systems that are bound together reversibly by intermolecular forces, rather than by conventional covalent bonds (shared electrons). The field exploded when three of the pioneers of the field namely, Jean-Marie Lehn, Donald Cram and Charles Pedersen won the 1987 Nobel Prize in chemistry for synthesizing molecules and compounds with cavities and cages within which metal ions and other molecules could be bound. Research teams have also presented their pioneering works on the syntheses in the field. The syntheses majorly focus on 
specific groups of compounds, which, although a bit frightening for those out of the field, are invaluable to the experienced researcher.

One can also find examples of other synthetic methods in a number of undergraduate practical guides; however, these are not usually counted as being related to the supramolecular context. Other routine methods for the synthesis of supramoleculs are available in the organic syntheses literature.

What is "Supramolecular" Chemistry? The origin of supra molecular chemistry is closely linked to Pederson's pioneering works on crown ethers. He discovered dibenzo [18] crown-6 in 1967, while he was trying to prepare a flexible phenol terminated polyether. He wanted the polyether to use it to support the catalytic activity of vanadyl ion, by binding to it [1]. Although the importance of this new class of compounds was globally recognized, scientists were still interested in the potential of polyethers to act as metal binding ligands. Most of the scientists started synthesizing new compounds using polyethylene glycols and tried to modify them. Further experiments by Vögel and Weber led them to suggest the term podants for the family of compounds they synthesized [2].

Since a very ling time ago, the term "Supramolecular" has been used to refer to complicated biostructures. The application of this terminology for refering to molecular interactions has uts roots in Lehn's Nobel Prize (1987). He described this word as as "chemistry beyond the molecule" [3].

Scientists have analyzed natural systems and extracted two major principles involved in supramolecular chemistry molecular recognition and self-assembly.

In molecular recognition, a molecule "host" will combine with a molecule "guest". In selfassembly, molecular structures of a defined geometry add complementary molecular components, becoming ever-larger arrays. Chemists, biologists, engineers, physicists, optical scientists and materials scientists are effectively "architects" who apply the fundamental principles involved in the biological processes to design and fabricate artificial supramolecular systems. Because of this approach, supramolecular chemistry will have a major impact on materials science in the next century.

Supramolecular chemistry has been refered to, using other names including "host-guest chemistry", "molecular recognition", and "inclusion phenomena" [4].

Although the mentioned terms maybe a useful key words for searching in the literature they are not the answer one may require to the question of what exactly makes a particular aspect of chemistry "supramolecular".

Here, due to the focus of this article on specific applications of supramolecular chemistry, in the construction of potentiometric sensors, host-guest aspect of supramolecular chemistry is taken into consideration.

Host-guest chemistry, as mentioned above, describes complexes that are composed of two or more molecules or ions that are held together in unique structural relationships by either or a combination of hydrogen bonding or by ion pairing or by Van der Waals force, or forces other than those of full covalent bonds.

The host component is defined as an organic molecule or ion, whose binding sites converge in the complex and the guest component, is defined as any molecule or ion whose binding sites diverge in the complex. To make it more clear let us give an example. In an immunological process, the host is the antibody and the guest the antigen. 


\section{Classification of Supramolecular Families}

Compounds that are usually encountered in supramolecualr chemistry can be classified regarding different aspects. Here, we try to give a general classification based on the structure of the compounds.

\subsection{Linear Components for Supramolecular Networks}

\subsubsection{Podands}

As mentioned, the first compounds, the synthesis of which developed now call supramolecular chemistry were podants (Figure 1). These linear compounds are well known for their abbility ti wrap around metal ions of representative and lanthanide ions [5].

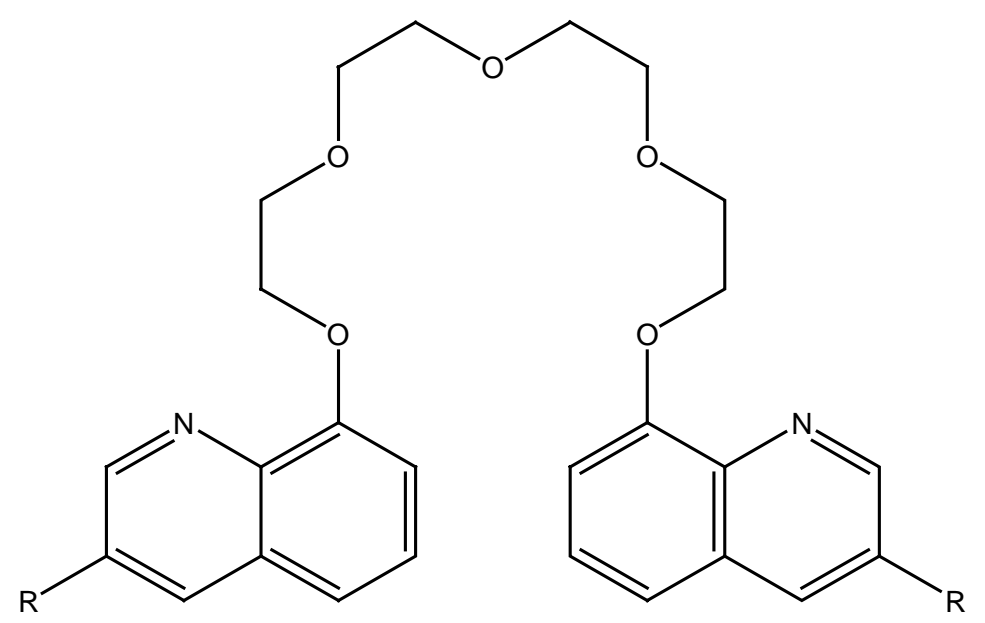

Figure 1. Podand.

\subsubsection{Rigid Components from Schiff's Bases}

Despite the fact that flexiblity may be a virtue for a ligand, pre-organized ligands like Sexipyridines, can also form complexes with metal ions $[5,6]$. 


\subsubsection{Flexible Tripod Ligands}

As mentioned above the preorganization of the donor groups leads to better complexation between the ligand and metal complexes. This can be exploited if the complexation constants are required to be high [5]. Tripod molecules are a group of compound in which three arms (which usually contain the donor groups) are connected to a nitrogen atom. This makes the molecule resemble a tripod. The tripods can be either symmetrical or non-symmetrical. Figure 2 is an example of a symmetrical tripod.

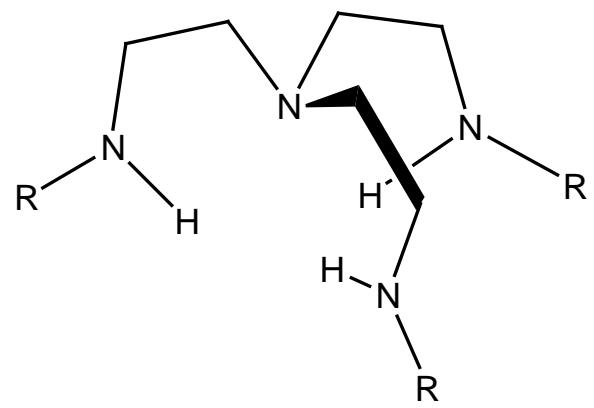

Figure 2. A symetrical tripodal ligand.

\subsubsection{Rigid Tripod Ligands}

Rigid tripodal ligands (3,5-bis(aminomethyl)-2,4,6-triethylphenyl)methanamine (Figure 3) and their derivatives fit in this family.

\subsubsection{Guandinium Based Linear Anionic Hosts}

The recognition and transport of some anions (e. g. sulfate, phosphate, carbonate and chloride) is of vital importance to the methabolism of the body. If these processes are interrupted, the living organisms will undergo severe problems [7]. Arginine reside, containing a terminal guadinium group, is one of the species that play the roll of an anion transferring species in biological systems. Terminal phosphate groups of phosphotyrosine residues on proteins are removed by a protein (tyrosine) containing several convergent arginine residues [5]. Figure 4, depicts some of these compounds. 


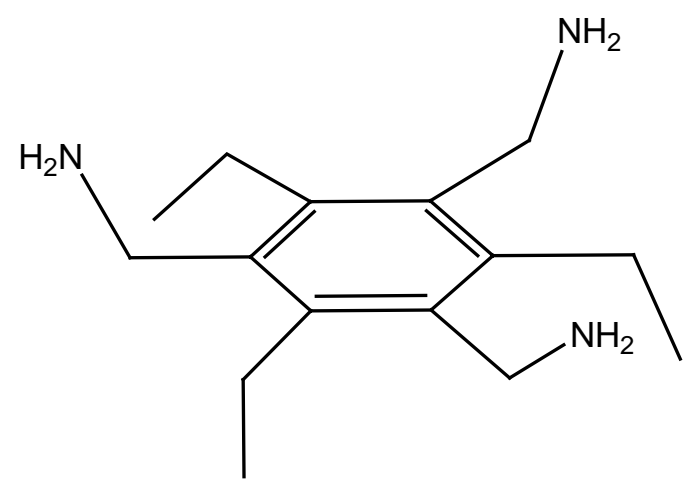

Figure 3. A Rigid tripodal ligand ((3,5-bis(aminomethyl)-2,4,6-triethylphenyl)methanamine).<smiles>Cc1nn(-c2ccccc2)c2c1CN1CCN3C=CN=C(N2)NC31</smiles><smiles></smiles>

Figure 4. Guanidinium-based receptors.

\subsection{Cyclic Compounds}

\subsubsection{Naturally Occurring Planar Microcycles}

One of the most common examples of this family is porphyrin, and its derivatives, which bind magnesium, manganese, cobalt, and nickel cations, in natural processes [8].

\subsubsection{Synthetic Planar Microcycles}

The first phthalocyanines (Figure 5) were formed due to the accidental addition of a templating reagent. These compounds are the major representative of this group. Tetralactam (Figure 6) and its derivatives are other members of this family. 


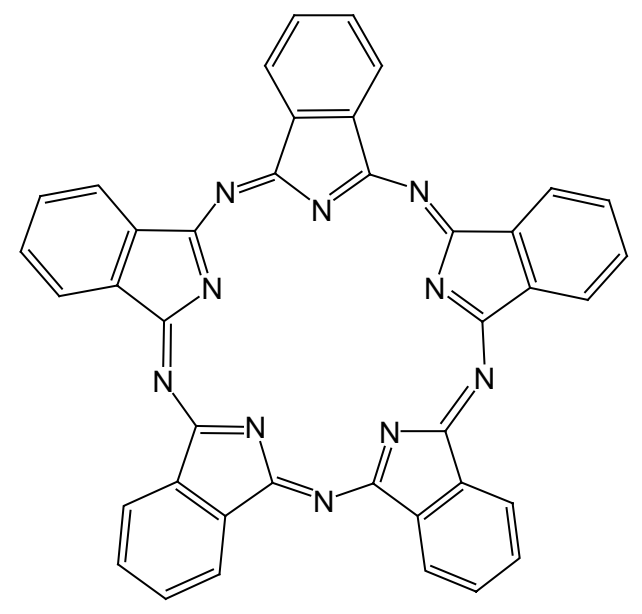

Figure 5. Phthalocyanine.

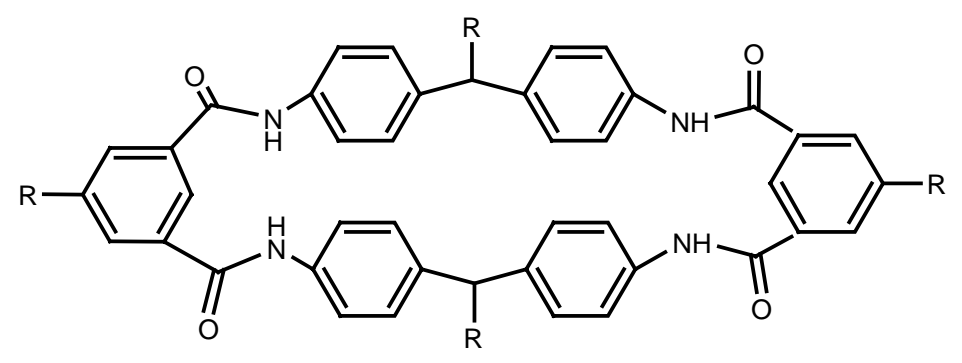

Figure 6. Tetralactam.

\subsubsection{Catananes and Rotaxanes}

Molecular knots are compound in which two molecular rings pass through one another. One of the most famous examples of these structures is the family of catananes. Rotaxanes on the other hand are composed of a dumble-shaped molecule that has penetrated a ring. These compounds are interesting in the field of molecular electronics (Figure 7). 


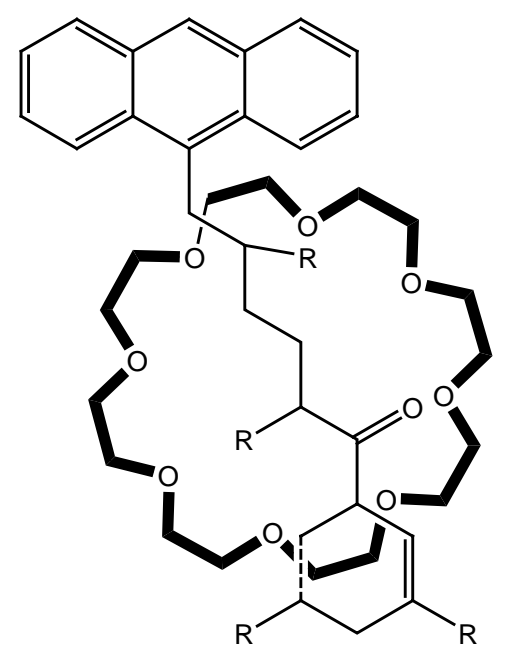

Figure 7. Rotaxane.

\subsubsection{Other Macrocycles}

The field of supramplecular chemistry was born with the synthesis of an azacrown ether ether namely dibenzo[18]crown-6. Other derivatives of crown ethers are also important this area. Like any other family of compounds, inserting other atoms (than oxygen) may improve the functionality of these compounds. Greene synthesized the first mono-azacrown ether (aza[18]crown-6) [9]. Figure 8, shows a sample structure of azacrown ether.

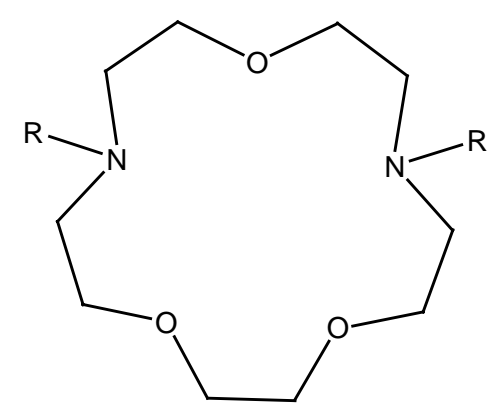

Figure 8. Azacrown ether.

Azacrowns with side arms are another modification of the family. The arms will increase the binding ability of the crowns to cations. The arms can be added to either the carbon or the nitrogen atoms of the crown (Figure 9). The addition of the arms to nitrogen atoms, however, is preferred [5]. 
<smiles>[R]c1ccc2c(c1)OCCOCCOc1cc([R])ccc1OCCOCCO2</smiles><smiles>[R]N1CCOCCOCCN([R])CCOCCOCC1</smiles>

Figure 9. The arms can be added to either the carbon or the nitrogen atoms of the crown.

Another example may be cyclodexterines. These water soluble compounds were formed in very little amounts as a result of the degradation of starch by Bacillus amylobacter. Cyclodxtrins including different numbers of D-glucopyranoside units linked by 1,4-glycosidic bonds are shown in Figure 10. Different properties of these compounds can be altered or modified by derivatizing them (Figure 11) [5]. Figure 11 shows a simple cyclodextrine.

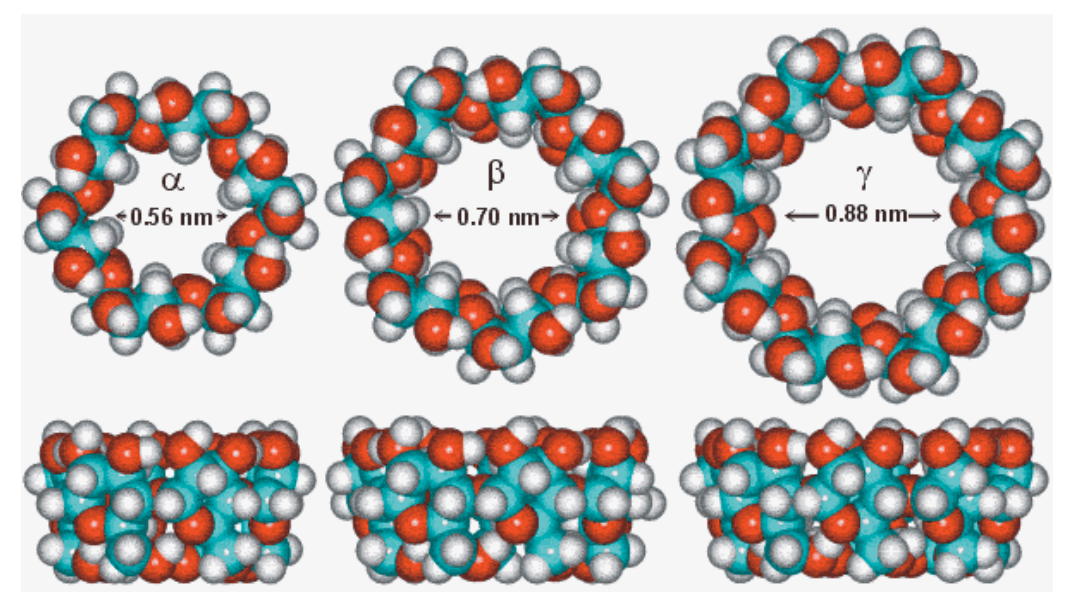

Figure 10. Cyclodextrin and their cavities ( $\alpha=6, \beta=7$ and $\gamma=8$ D-glucopyranoside units).

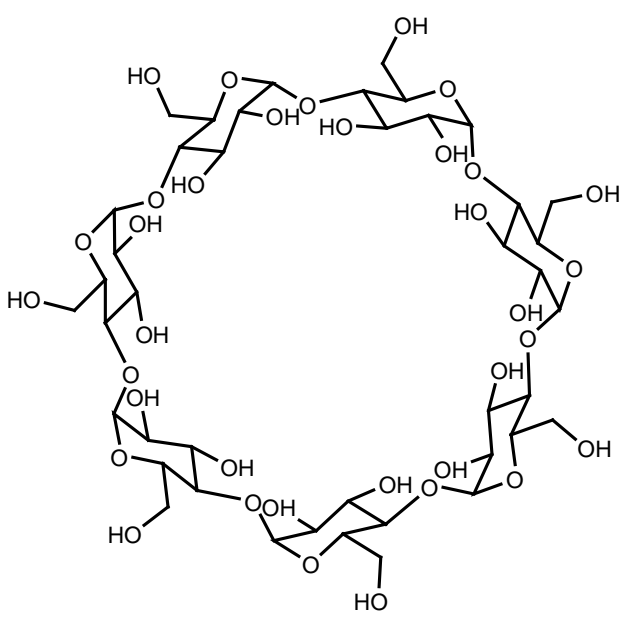

Figure 11. $\beta$-Cyclodextrine.

\subsection{Molecular Baskets and Cages}

Calixarenes (Figure 12) and their different derivatives like rim-functionalized calixarenes, homoazacalix[n]arenas, oxacalixarene derivatives (Figure 13) (e.g. substituted oxacalixarenes, 4-t- 
butyloxacalix[3]arene-tris(N,N-dimethylacetamide), azacalixarenes (e.g. 4-methyl-(N-benzyl) azacalix [3]arene, Figure 13) fit into this family. Other compounds that fit into this group are cycloveratrylenes, and cyclophanes [5].

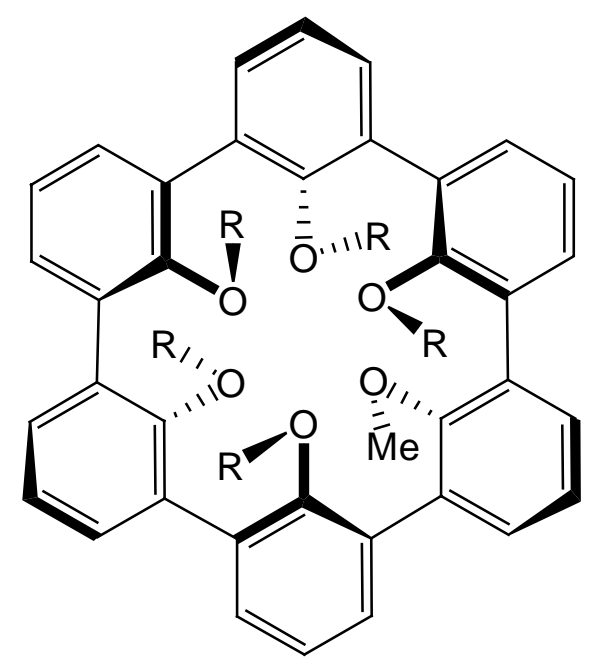

Figure 12. Calix [5]arene.

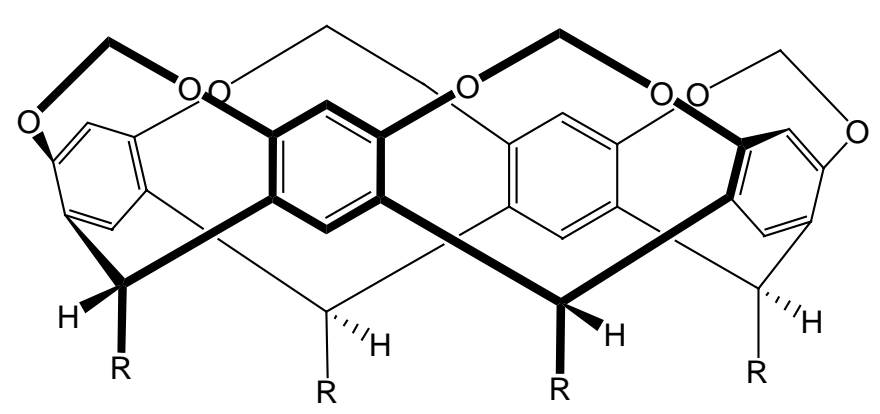

Figure 13. Oxacalix[4]arene.

\section{Construction of Supramolecule Based Ion Sensors}

A very good example of the supramolecular studies is the design, and synthesis of molecules, or metal complexes that can be used for the construction of sensing membranes that selectively response to a particular analyte, because of the incorporation of the designed species.

In such a case, it is necessary to match the size and binding properties of the species to make it or its derivative as selective towards the desired analyte as possible. The requirements for a potassium sensor, will as a result, be very different from one for a transition metal such as cobalt or even another 
alkali metal like sodium which is not very far from potassium both in the periodic table and from the aspect of chemical properties.

Likewise, a receptor molecule for tyrosine has different requirements, as compared to one for arginine, even though they are both amino acids. Matching of a receptor to an analyte may be considered an exercise in supramolecular chemistry.

Supramolecular chemistry is now a quite mature field and, hence the amount of information on molecular hosts and their affinities towards different guests in the scientific literature is considerable.

As a result, after searching the literature a scientist will be able to choose the best hosts for a specific analyte. [18]Crown-6 ether is a good receptor for the protonated N-terminus of an amino acid and for the potassium cation. Therefore, it can function as a receptor for both of the above species.

Adding to the functionality of a host compound can make it more specific that is the mentioned host can be altered to have more affinity towards one of the mentioned target compounds as compared to the other. In the case of a potassium host, attachment of a short polyether side chain improves the binding, and can be achieved using an aza[18]crown-6 derivative.

On the other hand, the phenolic group in tyrosine will readily engage in $\pi$ - $\pi$ interactions, so the incorporation of a substituent containing an aromatic group would give greater specificity for tyrosine.

In general, the overall selectivity of the host guest interaction depends on factors such as:

1) The size of the cavity of the host should be large enough to accommodate the guest species. As the complexation happens, the hydration shell of the target species is removed and substituted by the donor atoms of the host (ligand).

2) The number of donor atoms in the ligand should be sufficient, to match the coordination number of the target species.

3) The flexibility of holding of donor atoms by the host backbone must be limited, so that their positions are suitable to match the shape of the coordination sphere of the target species.

4) Using the macrocyclic backbone, an excess of certain ligating groups can be avoided, thus improving the selectivity. For example in the case of a divalent cationic target two ionizable groups can be introduced into the host, which could hold more of them. The remaining two binding groups fill up the coordination sphere.

5) There is a possibility to attach chelating moieties onto host molecules, thus combining the chelate and the macrocyclic effect. However, the chelating groups increase the flexibility of the ligand and may reduce the overall selectivity.

6) Branched groups can be attached to proper cites of the host for high hydrophobicity and avoiding crystallized membrane phases.

Another requirement, for the application of supramolecular chemistry in building recognition devices is that the binding of the analyte to the receptor, or in other words the host guest interaction, must trigger an observable response through a reporter molecule.

The nature of the response will depend upon the analytical method used to detect the signal but will typically be colorimetric, electrochemical or fluorescent. An appropriate signaling mechanism may be designed to incorporate, for example, changes in conformation or molecular orbital energies that in turn affect the reporter molecule's electronic or spectroscopic signature upon analyte binding.

Finally, the receptor must be linked to the reporter molecule such that the effect of binding directly affects the latter without compromising the observable response. Sensors for the two analytes above 
could both be based on aza[18]crown- 6 and contain a terminal anthracene group as a fluorescent reporter but differ in the link between them.

Not all of the supramolecular species, discussed above, have widespread applications in the construction of potentiometric ion selective electrodes. Because the aim of this review is to give an overall insight about the application of these compounds in the construction of ISEs, we will focus on the families of supramolecular compounds that are widely applied in the field of construction of sensors, in the following paragraphs. Hence, the classification in the following paragraphs will be different from that of the introduction.

\section{Application of the Concept of Supramolecular Chemistry in the Design of Liquid Membrane Sensors for the Potentiometric Detection of Ionic Species}

Ion selective electrodes, being among the most favorable and fastest growing devices for chemical analysis, are well known to any analytical chemist or anyone concerned with chemical analyses [10]. These devices are well known for their applications in the fast, easy, cheap, and above all selective determination of ionic species in rather complex matrices. The rapid increase in the research and the consecutive reports on the design and construction of these devices is a practical proof of the great interest in these devices.

Ion selective sensors, as their name implies, are based on the selective recognition of one specific ion (target ion), as compared to the other ions that may be present with it. This so-called selective recognition is then converted to a potential signal, which is a measure of the activity of the target ion.

Many mechanisms have been suggested for the selective recognition of different ions in the electrodes [10], most of which focus on the selective complexation between the target ion and a specific species (the ion carrier or ionophore) that is incorporated in the liquid membrane of the electrodes, in order to create the desired selectivity.

Regarding what mentioned above, the selective complexation of target ions and ionophores, one may logically say that host guest chemistry, and in other words, the concept of supramolecular chemistry can be exploited in the design and construction of ion selective electrodes for different ionic species.

In the following paragraphs, we will try to review the history of application of the most well known supramolecular species in the field of potentiometric liquid membrane ion-selective sensors.

\subsection{Calixarene Based Ion Selective Sensors}

The structure of calixarene ligands to interact with cations, anions, neutral species and their various combinations, is determined by the character of other functional groups bonded to the basic skeleton of calixarenes. Another fascinating aspect of calixarenes is also their conformational variability and formation of stable and separable conformers with different reactivity and binding abilities. Structural and thermodynamics aspects of these changes have been studied NMR spectroscopy and X-ray crystallography.

Quantum mechanics and molecular dynamics are also used for the design of novel water-soluble calixarene ligands with effective ability to bind biologically important compounds like sugars, peptides, etc. [11-15]. Different calixarene based potentiometric liquid membrane ion sensors have 
been reported in the literature, which can be divided into the three groups of calixarene-based main group, transition metal, and lanthanide selective ion sensors.

\subsubsection{Calixarene-Based Main Group ion Selective Electrodes}

In 1994, O'Connor et al, reported the complexing ability of 19 symmetrical, unsymmetrical and bridged calix[4]arene derivatives having ester, ketone, amide, amine and thio-ether functionalities by the picrate extraction method. They incorporated these calix[4]arene derivatives as neutral carrier ionophores in sodium-selective poly (vinyl chloride) membrane electrodes, and assessed their performance based on the sensitivity and selectivity over the alkali, alkaline earth metals and hydrogen and ammonium ions [16].

In the same year Y. Shibutani et al, studied six kinds of tetra alkylester type calix[4]arene derivatives, a diethyl-didecyl mixed ester, and three kinds of lower rim bridged which were characterized by electrochemical measurement to elucidate the effect of the length of the alkyl group of alkoxycarbonyl substituents on $\mathrm{Na}^{+}$selectivity [17]. They found that to obtain excellent $\mathrm{Na}^{+}$ selective ionophores, introduction of short chain alkyl groups rather than long chain ones, such as a decyl group, and maintenance of sufficient solubility of the calix[4]arene derivatives in the membrane solvent are required concurrently. Among the calix[4]arenes tested, 25,26,27,28tetrakis[(ethoxycarbonyl) methoxy]-p-tert-butylcalix[4]arene 2, and the diethyl-didecyl mixed ester type derivative 7 were the best ionophores for a $\mathrm{Na}^{+}$selective electrode. On the other hand, sodium selectivity of the bridged type derivative 9 is comparable or even superior to that of the known bis(12crown-4).

K. Kimura, Y. Tsujimura, and M. Yokoyama, reported the application of Silicone-rubber membrane sodium-ion sensors based on Calix[4]arene neutral carriers incorporating unsymmetrical structures and/or oligosiloxane moieties (Figure 14), which were highly dispersible in silicone rubber, and the application of these sensing membranes in ISFETs, in 1995 [18]. They increased the dispersibility of the ionophore by means of unsymmetrization. They claimed that these ion carriers realized high performance of silicon rubber-based sodium-ion sensors, i.e., high sensitivity, selectivity, and durability. They optimized the PVC/membranes to have a high $\mathrm{Na}^{+}$selectivity against (especially with regard to $\mathrm{K}^{+}$i.e. $\mathrm{Ksel}=3.8 \times 10^{-3}$.

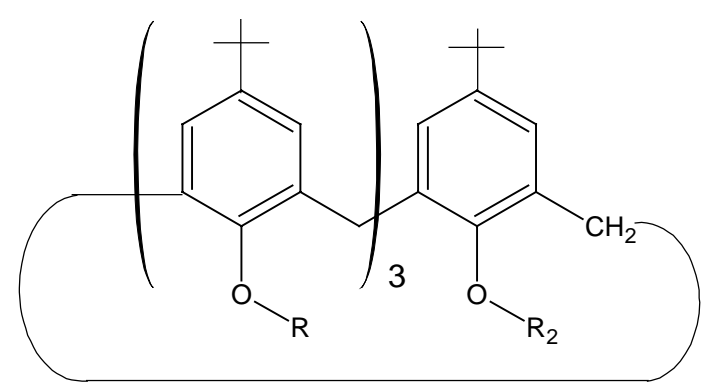

Figure 14. Calix[4]arene as a sutiable neutral carrier for $\mathrm{Na}^{+}$selective electrode.

1. $\mathrm{R}_{1}=\mathrm{R}_{2}=\mathrm{CH}_{2} \mathrm{CO}_{2} \mathrm{CH}_{2} \mathrm{CH}_{3}, 2 \mathrm{R}_{1}=\mathrm{R}_{2}=\mathrm{CH}_{2} \mathrm{CO}_{2} \mathrm{C}_{10} \mathrm{H}_{2}$,

$3 \mathrm{R}_{1}=\mathrm{CH}_{2} \mathrm{CO}_{2} \mathrm{CH}_{2} \mathrm{CH}_{3}, \mathrm{R}_{2}=\mathrm{CH}_{2} \mathrm{CON}\left(\mathrm{C}_{10} \mathrm{H}_{21}\right)_{2}$

$4 \mathrm{R}_{1}=\mathrm{CH}_{2} \mathrm{CO}_{2} \mathrm{CH}_{2} \mathrm{CH}_{3}, \mathrm{R}_{2}=\mathrm{CH}_{2} \mathrm{CO}_{2}\left(\mathrm{CH}_{2}\right)_{11}(\mathrm{SiO})_{2}\left(\mathrm{CH}_{3}\right)_{2} \mathrm{Si}\left(\mathrm{CH}_{3}\right)_{3}$

$5 \mathrm{R}_{1}=\mathrm{R}_{2}=\mathrm{CH}_{2} \mathrm{CO}_{2}\left(\mathrm{CH}_{2}\right)_{11}(\mathrm{SiO})_{2}\left(\mathrm{CH}_{3}\right)_{2} \mathrm{Si}\left(\mathrm{CH}_{3}\right)_{3}$ 
Neutral carriers, such as 16-crown-5 and calix[4]arene tetraester, immobilized on silicone-rubber membranes by covalent bonding were used to construct sodium ISFETs by Y. Tsujimura in 1996 [19]. The application of the calixarene ionophore together with an anion excluder exhibited high performance in terms of sensitivity, selectivity and response time.

T. Gardy et al, reported sodium-selective electrodes based on triester monoacid derivatives of ptert-butylcalix[4]arene and compared them with tetraester calix[4]arene. All electrodes showed slopes in excess of $50 \mathrm{mV} \mathrm{dec}^{-1}$ (53.5-56.0 $\mathrm{mV} \mathrm{dec}^{-1}$ ) and lifetimes of at least 35 days. Virtually no difference in selectivity between the monoacid derivatives and the tetraesters was found. $\mathrm{pH}$ stability studies showed that the monoacid derivatives gave best performance at neutral $\mathrm{pH}$, but at alkaline $\mathrm{pH}$ values ( $>8$ ) there was a reduction in response, which did not occur with the tetraesters [20].

H. J. Lee et al reported All-solid-state sodium-selective electrodes based on room temperature vulcanizing-type silicone rubber matrix, and $1.0 \mathrm{wt}$ percentage of tert-butyl calix[4]arene-tetraacetic acid tetraethyl ester [21]. In their work, they studied the effect of the used ionic additives, which were several phenyls; berate derivative-based additives, on the lifetime of the sensor. They found that membranes prepared with 0.5 wt \% tetrakis[3,5-bis(trifluoromethyl)phenyl] berate salt (TFPB) exhibited low impedance, resulting in electrochemical performance comparable to that of the PVCbased membranes mounted in conventional electrodes. The lifetime of all-solid-state electrodes with tert-butyl calix[4]arene tetraethyl ester was longer than 230 days.

In 1998, Kimura et al reported the synthesis of an oligo(dimethylsiloxane) carrying ionophorous calixarene (Figure 15) and applied it in the construction of sodium selective sensors, with a silicon rubber polymeric matrix [22]. The membrane contained $10 \mathrm{wt} \%$ of the ion carrier, which is equivalent to $4-6 \mathrm{wt} \%$ of the calix[4]arene unit.

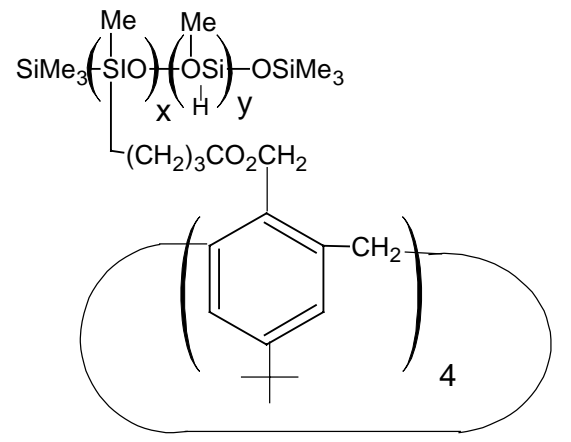

Figure 15. Oligo(dimethylsiloxane) carrying ionophorous calixarene.

L. A. Muslinkina reported Calix[4]resorcinarene to be applied as an ionophore in the ion-selective electrodes with plasticized poly(vinylchloride) membranes, in 1999 [23]. In their work, they studied the effects of choline and $\mathrm{Na}^{+}$cations present in the working solution on the ionophore, which was incorporated into a membrane phase. Due to the $\mathrm{pH}$ sensitivity of the ionophore, a study was undertaken in a wide range of $\mathrm{pH}$ values. The different characteristics of calix[4]resorcinarene interactions with these cations were discovered by the ISE with the PVC plasticized membrane containing this ionophore, which respond to both the choline and $\mathrm{Na}^{+}$cations due to the variation of working solution $\mathrm{pH}$. 
In 2001, Y. D. Kim et al, reported new lipophilic triesters of calix[4]arene and calix[4]quinone as sodium ion-selective ionophores in poly(vinyl chloride) membrane electrodes. For the ion selective

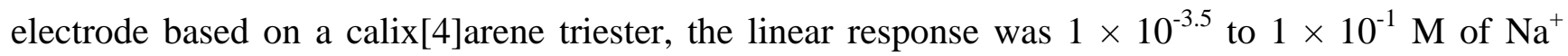
concentrations. The detection limit $\left(\log \mathrm{a}\left(\mathrm{Na}^{+}\right)=-4.50\right)$ and the selectivity coefficient (log $\mathrm{K}\left(\mathrm{Na}^{+}\right)$,(pot) $\left.\left(\mathrm{K}^{+}\right)=-1.86\right)$ were obtained for polymeric membrane electrode containing a calix[4]arene triester and calix[4]quinone ( Figure 16) [24].
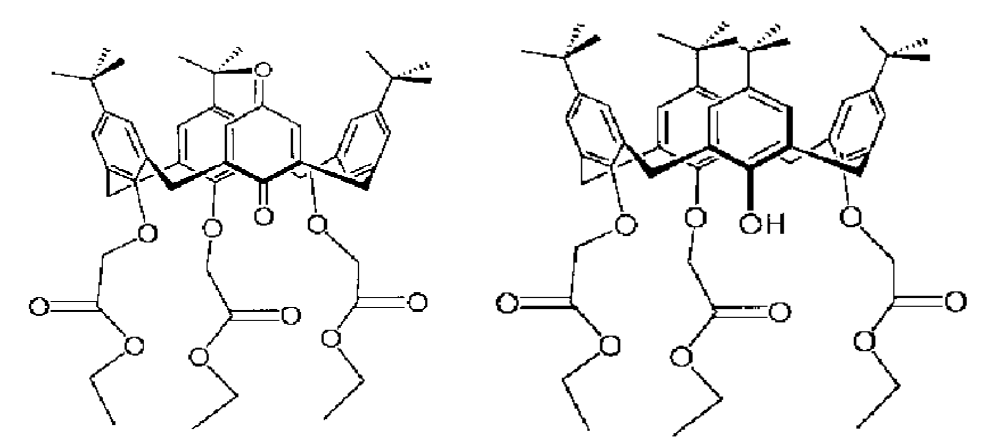

Figure 16. Triester of calix[4]arene and calix[4]quinone.

R. J. W. Lugtenberg et al, 1995, used calix[4]arene-crown-6 derivatives 1,3-alternate conformation, in poly(vinylchloride) membranes of CHEMFETs. The membranes exhibited good $\mathrm{Cs}^{+}$-selectivity and Nernstian behavior. The $\mathrm{Cs}^{+}$-selectivity over $\mathrm{Na}^{+}$, i.e., log K-Cs, $\mathrm{Na}$ (pot) was -3.3 , which is slightly better than what was observed for bis(18-crown-6) derivatives (log $\mathrm{K}-\mathrm{Cs}, \mathrm{Na}(\mathrm{pot})=-3.0$ ). The resulting CHEMFETs responded to sub-Nernstian concentrations of $\mathrm{Na}^{+}$in the presence of $\mathrm{NH}_{4}^{+}$: and $\mathrm{K}^{+}$[25].

In the same year A. Casanti et al, published a paper on the synthesis and complexation and membrane transport studies of 11'3-alternate calix[4]arene-crown-6 conformers, and suggested them as a new group of ionophores foe the construction of cesium selective electrodes [26].

One year later, $\mathrm{H}$. Oh et al, reported poly(vinyl chloride) membrane cesium ion-selective electrodes based on lipophilic calix[6]arene tetraester derivatives [27]. The linear response of the electrodes was $1 \times 10^{-6}-1 \times 10^{-1} \mathrm{M}$ of $\mathrm{Cs}^{+}$concentrations. The detection limit $\left(\log \mathrm{a}\left(\mathrm{Cs}^{+}\right)=-6.31\right)$ and the selectivity coefficient $\left(\operatorname{logK}\left(\mathrm{Cs}^{+}, \mathrm{Rb}^{+}\right)(\mathrm{pot})=-1.88\right)$ were obtained for polymeric membrane electrode containing the calix[6]arene tetraester.

Several works were reported on the $\mathrm{Cs}^{+}$-selective ionophores of this type in the year 2001. S. H. Lee et al, reported phenylene bridged calix[6]arenas for cesium selective ionophores [28]. K. C. Nam et al, studied the Synthesis and ion-binding properties of cesium selective quadruply bridged calix[6]arenas [29]. They prepared several quadruply bridged calix[6]arenes in high yields, by the reaction of various 1,4-di-O-alkylated calix[6]arenes with 1,2,4,5-tetrakis-(bromomethyl)benzene in the presence of $\mathrm{Cs}_{2} \mathrm{CO}_{3}$. The alkali metal extraction study showed that these compounds show high selectivities toward $\mathrm{Cs}^{+}$among alkali metal cations. The cesium binding characteristics were investigated with H-1 NMR and UV spectroscopy. L. X. Chen et al, [30] reported two novel double flexible spacers bridged biscalix[4]arenes 25,25',27.,27'-bis(1,3-dioxypropane)-bis(5,11,17,23-p-terttetrabutylcalix[4]arene-26,28-diol) and 25,25',27 ,27'-bis(1,4-dioxybutane)-bis(5,11,17,23-p-tert- 
tetrabutylcalix[4]arene-26,28-diol) and evaluated as cesium ion-selective ionophore in polymeric membrane electrodes. The electrodes all gave a good Nernstian response of $51 \mathrm{mV}$ per decade for $\mathrm{Cs}^{+}$ in the concentration range from $1 \times 10^{-1}$ to $1 \times 10^{-5} \mathrm{M}$ and good selectivity. The potentiometric selectivity of $\mathrm{Cs}^{+}$-ISEs based on the two compounds was selective toward cesium ion over other alkali metal ions, alkaline-earth metal ions and $\mathrm{NH}_{4}{ }^{+}$. E. M. Chio et al, reported new quadruply-bridged calix[6]arenes as cesium selective ionophores in poly(vinyl chloride) (PVC) membrane electrodes. PVC membranes were prepared with dioctyl sebacate (DOS) or 2-nitrophenyl octyl ether (o-NPOE) as the solvent mediator and potassium tetrakis(p-chlorophenyl)borate as the lipophilic salt additive. These ionophores produced electrodes with near-Nernstian slopes. The selectivity coefficients for cesium ion with respect to alkali, alkaline earth and ammonium ions have been determined. The lowest detection limit $\left(\log \mathrm{a}\left(\mathrm{Cs}^{+}\right)=-6.3\right)$ and the higher selectivity coefficient $\left(\log \mathrm{K}\left(\mathrm{Cs}^{+}, \mathrm{Rb}^{+}\right)(\mathrm{pot})=-2.1\right.$ by SSM, -2.3 by FIM for calix[6]arene for $\mathrm{Cs}^{+}$have been obtained for membranes containing quadruplybridged calix[6]arenes (Figure 17), which have no para t-butyl substituents on the bridging benzene ring [31].

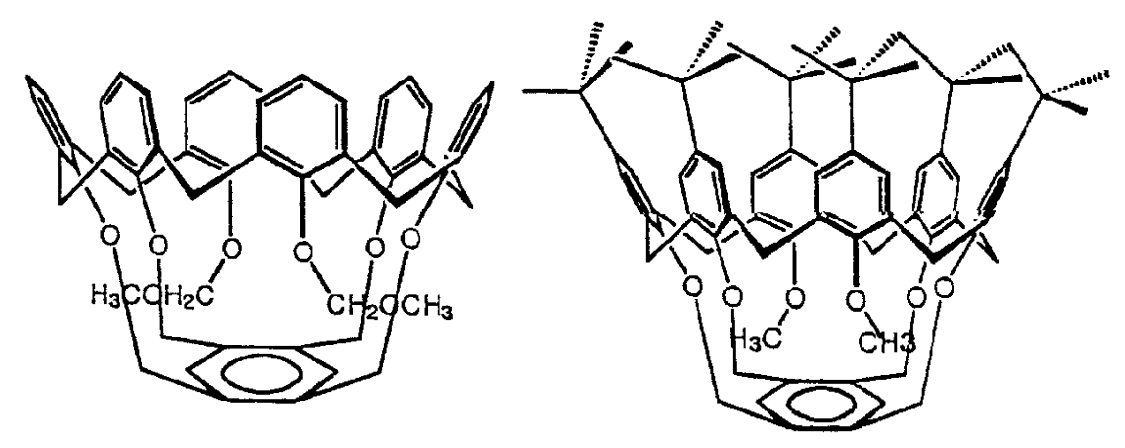

Figure 17. Quadruply-bridged calix[6]arenes.

In 2002, S. W. Ko et al, reported Synthesis, structure and cesium binding properties of calix[6]arene biscrown, and its application as a cesium selective ionophore [32]. R. K. Mahajan reported a cesium ion selective electrode based on calix[4]crown ether-ester, in the same year [33]. The electrode was found to have selectivity for cesium ion over alkali, alkaline and transition metals. The electrode exhibited a good response for cesium ion over wide concentration range of $5.0 \times 10^{-6}$ $1.0 \times 10^{-1} \mathrm{M}$ with a Nernstian slope of $59 \mathrm{mV}$ per decade. The detection limit of electrode is $5.0 \times 10^{-6}$ $\mathrm{M}$. The response time of the electrode is less than $20 \mathrm{~s}$ and can be used for more than 4 months without observing any divergence in potentiometric response.

In 2003, V. Arora et al, reported the ynthesis of a new cesium selective calix[4]arene based chromoionophore [34]. They reported a novel azo-pyridyl calix[4]arene, (5,11,17,23-tetrakis(4'azopyridyl)-25,26,27,28-tetrahydroxycalix[4]arene), in the 1,3-alternate conformations by coupling debutylated calix[4]arene with a diazotized solution of 4-aminopyridine. The selectivity coefficients for $\mathrm{Cr}^{3+}$ and $\mathrm{Ni}^{2+}$ was determined to be $\mathrm{pK}-\mathrm{Cr}^{3+}, \mathrm{Cs}^{+}=6.6$ and $\mathrm{pK}^{2} \mathrm{Ni}^{2+}, \mathrm{Cs}^{+}=66$, while other alkali and alkaline earth metal ions do not interfere. S. W. Jeon et al, reported novel cesium-selective electrodes based on lipophilic 1,3-bisbridged cofacial-calix[6]crowns in 2004 [35]. They investigated five bis-bridged calix[6]crowns as $\mathrm{Cs}^{+}$ionophore in PVC membrane electrodes. Three 1,3-bisbridged 
calix[6]crown-4-ethers(I-III), 1,3-bisbridged calix[6]crown-5-ether(IV), and 1,3-bisbridged calix[6]crown-6-ether(V) were evaluated as ionophores. The membranes all gave good Nernstian response in the concentration range from $1 \times 10^{-7}$ to $1 \times 10^{-1} \mathrm{M}$ of cesium ion. The best detection limits (-log $\left.\mathrm{a}\left(\mathrm{Cs}^{+}\right)=7.08-7.36\right)$ were obtained for electrode membranes containing 1,3-bisbridged cofacial-calix[6]crown-4-ethers, and the values are the lowest compared with those reported previously. The highest selectivity coefficients $\left[\mathrm{pKCs}^{+}=5.53(\mathrm{Cs} / \mathrm{Na}), 3.74(\mathrm{Cs} / \mathrm{K}), 2.63(\mathrm{Cs} / \mathrm{Rb})\right]$ were obtained for the membrane of 1,3-bisbridged calix[6]crown-4-ether, and these values are also the highest compared with previous reports for $\mathrm{Cs}^{+}$-ISEs. The highest selectivity towards cesium ion was attributed to the geometrically co-facial positions of two crown-ethers in calix[6]crowns in order to provide the complex of cesium ion and eight oxygen atoms of cofacial crowns.

In 2003, Setsuko Yajima et al reported that calix[4]arene derivatives incorporating $\boldsymbol{\omega}$-unsaturated alkenyl groups or saturated alkyl groups and their monomeric analogues could be used as $\pi$-coordinate neutral carriers for ion-selective electrodes (ISEs) of soft metals [silver and thallium(I)] ions [36]. This can be considered as the continuation of their work in 1999. They reported A remarkable thallium(I) selectivity for ion sensors based on $\pi$-coordination of calix[4]arene neutral carriers, where calix[4]arene derivatives without any t-butyl group at the upper rim, such as calix[4]arene tetra(propyl ether) and tetra(allyl ether), were observed to provide the thallium(I)-selective electrodes with high sensitivity and ion selectivity. t-butylcalix[4]arene derivatives employed did not afford very good results as for the thallium(I) neutral carrier [37]. Of course the work of Kyeong Soon Park et al, on thallium(I) selective electrodes based on meso-alkyl substituted calix[4]pyrroles such as, mesooctamethyl-calix[4]pyrrole, meso-octaethylcalix[4]pyrrole and meso-tetraspirocyclohexylcalix[4]pyrrole (Figure 18) as sensor molecules in 2003, can also be regarded in this respect. The conditioned electrode incorporating meso-tetraspirocyclohexylcalix[4]pyrrole gave the best results with a wide working concentration range of $10^{-5} \cdot 5 \sim 10^{-1} \mathrm{M}$ with near-Nernstian slope of 56.0 $\mathrm{mV} /$ decade of activity and detection limit of $10^{-6} \mathrm{M}$. This electrode exhibited a fast response time of $30 \mathrm{~s}$ and high selectivity over $\mathrm{Na}^{+}, \mathrm{K}^{+}$and other metal ions with only $\mathrm{Ag}^{+}$interfering. The electrode worked well in a pH range of 2.0-11.0, and it could be successfully used in the determination of $\mathrm{Tl}^{+}$ [38].

Elzbieta Malinowska et al, published a paper on Lead selective electrodes based on thioamide functionalized calix[4]arenes as ionophores, in 1994. In their work lead selective electrodes based on a di- and tetrathioamide functionalized calix[4] arene as ionophores were investigated. The $\mathrm{Pb}(\mathrm{II})$ response functions exhibited almost theoretical Nernstian slopes in the activity range $10^{-6}-10^{-2} \mathrm{M}$ of lead ions. For both ionophores, a preference for lead over other cations was observed. The best results were obtained for membranes containing the tetrathioamide derivative, potassium tetrakis(4chlorophenyl) borate and o-nitrophenyl octyl ether as a plasticizer [39]. 


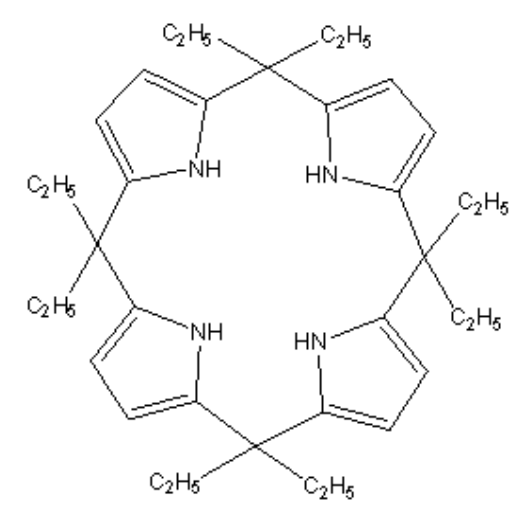

B
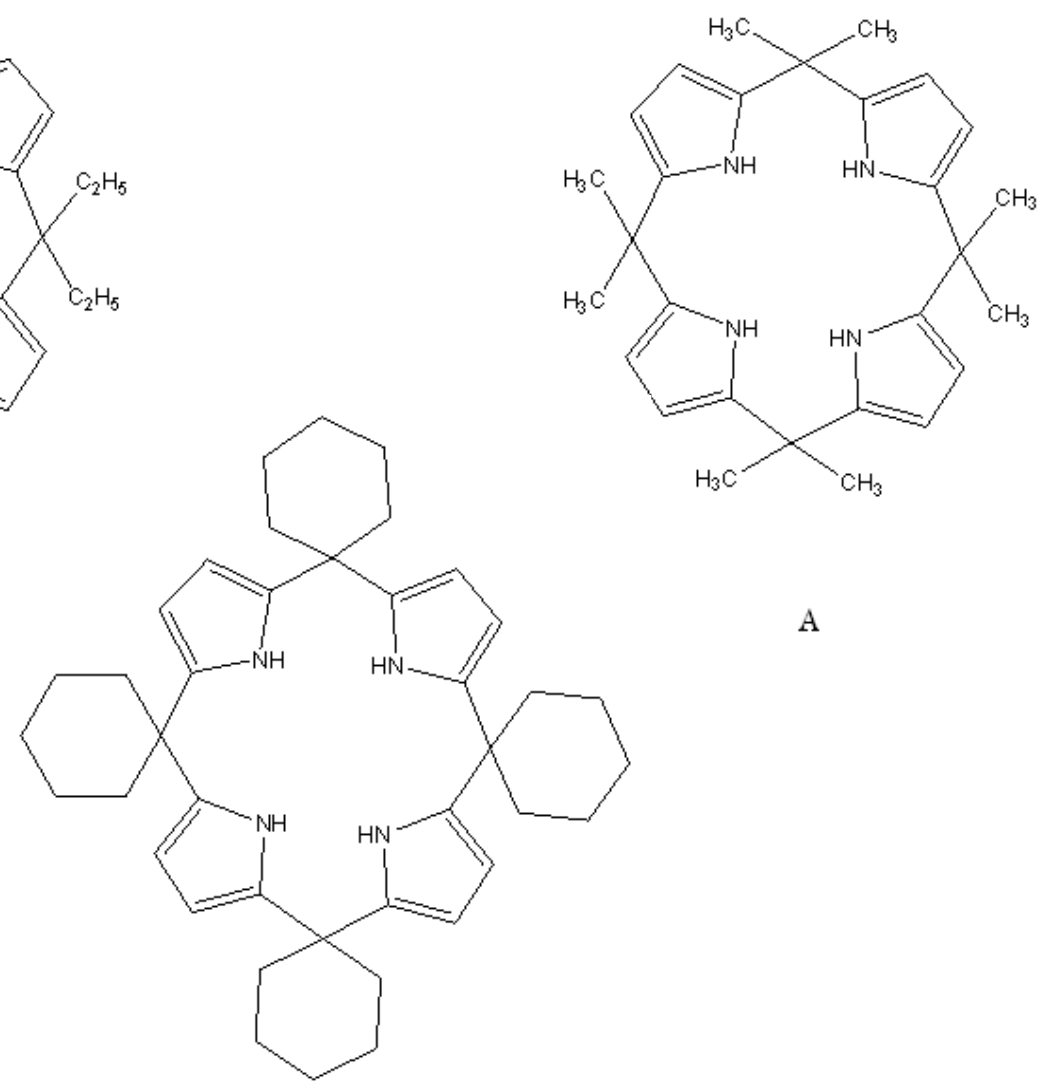

A

Figure 18. meso-octamethylcalix[4]pyrrole (A), meso-octaethylcalix[4] pyrrole (B), and tetraspirocyclohexylcalix[4]pyrrole (C).

In 2001, J. W. Ronny et al, reported the synthesis of novel calix[4]arenes fixed in the 1,3-alternate conformation and functionalized with thioamide groups. His group also evaluated the selectivities of the mentioned compounds for $\mathrm{Pb}^{2+}$ and $\mathrm{Cd}^{2+}$ ions in chemically modified field effect transistors (CHEMFETs). The 25,27-bis(dimethylaminothiocarbonylmethoxy)-26,28-dipropoxycalix[4]arene 3 in the 1,3-alternate conformation was reported to be more selective for $\mathrm{Pb}^{2+}$ than the analogous cone conformer. The 1,3-alternate calix[4]arene 8 having, in the 25- and 27-positions, two pairs of vicinal thioamide moieties at the same face of the molecule, had the highest selectivities for $\mathrm{Cd}^{2+}[40]$. In the same year, A. Ceresa, E. Bakker et al, used optimized ion-selective membranes based on the leadselective ionophore 4-tert-butylcalix[4]arenetetrakis(thioacetic acid dimethylamide) [41]. In 2002, Shahabuddin Memon and Mustafa Yilmaz used a new Schiff-base type oligocalix[4]arene containing two nitrile ligating sites at narrow rim. The extraction ability of the oligomer with selected alkali and transition metals was compared with its monomeric analogous. They observed that the oligomer was not selective as compared to its analogue, but showed a remarkable high affinity towards toxic metal cations such as $\mathrm{Cu}^{2+}, \mathrm{Hg}^{2+}$ and $\mathrm{Pb}^{2+}$ [42]. Y. Liu, and his team reported a series of novel double-armed p-(tert-butyl)calix[4]arenes, carrying benzoylamido, 4-nitrobenzoylamido, isonicotinamido, $\alpha$ naphthamido, acetamido, propionamido, or butyramido groups and ion-selective electrodes (ISEs) for $\mathrm{Pb}^{2+}$, carrying some of the mentioned ion carriers in a PVC membrane. The results obtained indicated 
that the electrodes based on the calix[4]arene-derived amides as the neutral ionophores were all $\mathrm{Pb}^{2+}$ selective and exhibited almost theoretical Nernstian slopes, except for some [43]. V. K. Gupta and his team also reported a $\mathrm{Pb}(\mathrm{II})$ selective potentiometric sensor based on 4-tert-butylcalix[4]arene in PVC matrix [44]. The sensor was reported to work well in the concentration range $1.1 \times 10^{-5}-1.0 \times 10^{-1} \mathrm{M}$ with a Nernstian slope (30.0 $\pm 1.0 \mathrm{mV} /$ decade of activity). The working $\mathrm{pH}$ range of the sensor was 2.1-4.0 and it demonstrated a good selectivity for $\mathrm{Pb}(\mathrm{II})$ over other mono-, bi- and trivalent cations that are reported to cause interference in the working of other sensors. It worked well in partially non-aqueous medium up to $30 \%(\mathrm{v} / \mathrm{v})$ (methanol, ethanol and acetone) and exhibited a fast response time (11 s). Jianquan Lu, et al, also reported A lead ion-selective electrode based on a calixarene carboxyphenyl azo derivative, in 2002 [45]. In the same year, H. F. Ju et al, reported a lead ion selective electrode based on a novel calix[4]arene derivative. They synthesized 5,11,17,23-Tetrakis (1,1-dimethylethyl)25,27-dihydroxy-26,28-bis [(2-propionamide) ethoxy] calix [4]arene by the reaction of lower rim 1,3amioethyl-substituted calix[4]arene with propionyl chloride. Calix [4] arene derivative was tested as a neutral ionophore for lead ion-selective electrode based on polyvinyl chloride matrix membrane. The influence of relative polarity of plasticizer and lipophilic anion sites such as tetrakis(pchlorophenyl)borate on the response of lead ion-selective electrode was investigated. The electrode exhibited an excellent Nemstian response to lead ion and a good selectivity for lead ion over other cations. The electrode could be used in solution $\mathrm{pH}$ from 4.0 to 6.5 [46]. In 2004, V. S. Bhat et al, reported a Coated wire lead(II) selective potentiometric sensor based on 5,11,17,23,29,35-hexa-tertbutyl-37,38,39,40,41,42-hexahydroxycalix [6]arene as neutral carrier in a poly(vinyl chloride) matrix [47].

Due to the similarities between the ammonium ion and those of the main groups, we classified the ammonium ion as a main group ion. In 1998, T. Katsu et al, developed a method for determining pH differences across cell membranes using a methylammonium-selective membrane electrode, based on monitoring of the $\mathrm{pH}$ gradient-induced uptake of methylammonium in situ. The methylammonium electrode was constructed using calix[6]arene-hexaacetic acid hexaethyl ester as a neutral carrier and bis(2-ethylhexyl) sebacate as a membrane solvent in a poly(vinyl chloride) membrane matrix. This electrode exhibited a near-Nernstian response to methylammonium in the concentration range $2 \times 10^{-5}$ - $1 \times 10^{-2} \mathrm{M}$ with a slope of $58 \mathrm{mV}$ per concentration decade in a buffer solution of $150 \mathrm{mM}$ choline chloride-10 mM TRIS-HCl (pH 7.5). The limit of detection was $5 \times 10^{-6} \mathrm{M}$ [48]. T. Katsu and M. Matsumoto reported discrimination of methylammonium from organic ammonium ions using ionselective electrodes based on calix[4]arene-crown-6 conjugates, in 2001. In their work, they reported that calix[4]-bis-2,3-naphtho-crown-6 can be used to discriminate between methylammonium and other organic ammonium ions. They observed that an electrode based on this ionophore, potassium tetrakis(p-chlorophenyl)borate (20 mol\% relative to the ionophore) as an ionic additive and bis(2ethylhexyl) sebacate as a solvent mediator in a poly(vinyl chloride) membrane matrix, displayed higher selectivity for methylammonium than for various other organic ammonium ions. However, there was considerable interference by inorganic cations, especially $\mathrm{Cs}^{+}$. They reported that similar calix[4]arene-crown-6 conjugates, such as calix[4]-bis-1,2-benzo-crown-6, calix[4]-bis-crown-6, 1,3dioctyloxy-calix[4]arene-crown-6, 13-diisopropoxy-calix[4]arene-crown-6 and 1,3-dimethoxycalix[4]arene-crown-6 were less effective in discriminating methylammonium [49]. In 2002, T. Katsu and $\mathrm{K}$. Ido reported the construction of ethylammonium-selective membrane electrodes using p-tert- 
butylcalix[6]arene derivatives [50]. In 2003, T. Katsu et al, performed a comparative study of the response of membrane electrodes based on calix[6]arene and calix[8]arene derivatives to organic ammonium ions. The results showed that p-tert-butylcalix[8]arene-octaacetic acid octaethyl ester and calix[8]arene-octaacetic acid octaethyl ester well recognized 2-phenylethylamine and phenylalanine methyl ester compared with the corresponding calix[6]arene derivatives. Moreover, the calix[8]arene derivatives, especially one having tert-butyl groups, gave better selectivity against biologically active amines having a complicated structure, such as norephedrine [51].

\subsubsection{Calixarene-Based Transition Metal Ion Selective Electrodes}

In 2001, J. S. Park et al, synthesized five novel 1,3-alternate calix[4]azacrown ethers having 2picolyl, 3-picolyl, and benzyl unit on the nitrogen atom and used them as ionophores for transition metal-selective polymeric membrane electrodes. The electrode based on 2-picolyl armed 1,3-alternate calix [4] azacrown ether exhibited Nernstian response toward copper(II) ion over a concentration range $\left(10^{-4.5} \mathrm{M}-10^{-2.5} \mathrm{M}\right)$. The detection limit was determined as $10^{-5} \mathrm{M}$ in a $\mathrm{pH}$ of 7.0 and the selectivity coefficients for possible interfering cations were evaluated [52].

In 1994 E. Malinowska et al, reported silver selective electrodes based on thioether functionalized calix[4]arenes as ionophores. For the two ionophores the selectivity coefficients ( $\log \mathrm{K}_{\mathrm{Ag}, \mathrm{M}}$ ) were lower than -2.2 for $\mathrm{Hg}(\mathrm{II})$ and lower than -4.6 for other cations tested [39].

In the year 2000, several $\mathrm{Ag}^{+}$sensors based on calixarenes were reported and this continued in the years after that. L. Chen et al, investigated the performances of calixarene derivative containing nitrogen atom used as a neutral carrier for silver polymeric membrane electrode and in metal ions transport by bulk liquid membrane and observed faster transport rates by the soft heavy metal ions such as $\mathrm{Ag}^{+}, \mathrm{Hg}^{2+}$ in the bulk liquid membrane system. They, hence, reported calixarene derivative as the neutral carrier in silver ion-selective electrode and liquid membrane transport [53]. In the same year, L. Chen et al, published a paper entitled Calixarene derivatives as the sensory molecules for silver ion-selective electrode [54]. In their study, they reported the construction of silver ion-selective electrodes with polymeric membranes based on nitrogen containing calixarene derivatives. The electrodes gave a good Nernstian response of $49-53 \mathrm{mV}$ decade $^{-1}$ for silver in the activity range $5 \times 10^{-6}-5 \times 10^{-2} \mathrm{M}$, the limit of detection reached $10^{-5.6} \mathrm{M}$ and exhibited high selectivity towards alkali, alkaline earth and transition metal ions. K. M. O'Connor et al, reported calix[4]Arenes in the partial cone conformation as ionophores in silver ion-selective electrodes [55]. They tested two calix[4]arene derivatives, in the partial cone conformation, with sulfur-containing functionalities, as neutral carrier ionophores in potentiometric silver-selective electrodes of conventional membrane and membranecoated glassy carbon electrode types. Comparison with a calix[4]arene in the cone conformation was made. The membranes were prepared using either 2-nitrophenyl octylether or bis(ethylhexyl)sebacate as plasticizers and potassium tetrakis(p-chlorophenyl)borate as the lipophilic salt in a poly(vinyl chloride) matrix. Both calix[4]arenes yielded electrodes of good sensitivity (approx. $47 \mathrm{mV} \mathrm{dec}^{-1}$ ) in the range $10^{-4}-10^{-1} \mathrm{M}$ and excellent selectivity [ $\log \mathrm{K}_{\mathrm{Ag}, \mathrm{MH}^{+}}<-1.5$ ] of transition, alkali and heavy metal cations, including sodium, mercury(II) and lead(II) cations. In the year 2000, Y. Liu et al, had a report on liquid membrane transport and silver selective electrode based on novel bis(3pyridinecarboxylate) calix[4]arene as ionophore [56]. They synthesized a novel calix[4]arene 
derivative

(5,11,17,23-tetra-tert-butyl-25,27-bis(3-pyridine

carboxylate)-26,28-dihydroxycalix[4]arene), bearing two nicotinic moieties. The liquid membrane transport and the silver selective electrode based on the calix[4]arene derivative showed excellent cation selectivities for $\mathrm{Ag}^{+} \mathrm{and}^{\mathrm{Hg}^{2+}}$ over other alkali and alkaline earth, transition metal ions, and ammonium ion. The higher cation selectivity was mainly attributed to that the host-guest interaction which occurred between the cations and the derivative calix[4]arene.

In the same year X. S. Zeng et al, hade a report on improved silver ion-selective electrodes using novel 1,3-bis(2-benzothiazolyl)thioalkoxy-p-tert-butylcalix[4]arenas [57]. L. X. Chen et al, published a paper on selective electrodes for silver based on polymeric membranes containing calix[4]arene derivatives, in the same year [58]. They reported the preparation of silver ion-selective electrodes with polymeric membranes based on two calix[4]arene derivatives functionalized by two hydroxy and two benzothiazolylthioethoxy groups. The electrodes all gave a good Nernstian response of $58 \mathrm{mV}$ decade${ }^{1}$ for silver in the activity range $5 \times 10^{-6}-10^{-1} \mathrm{M}$, the limits of detection reached $10^{-5.8} \mathrm{M}$ and exhibited high selectivity towards alkali, alkaline earth and some transition metal ions.

K. Kimura et al, reported silver ion-selective electrodes using pi-coordinate calix[4]arene derivatives as soft neutral carriers, in the year 2000 [59]. They reported, tert-butylcalix[4]arene tetra(allyl ether) as an excellent neutral carrier for plasticized poly(vinyl chloride)membrane for silver ion-selective electrodes.

In 2001, L. Chen et al reported silver ion-selective electrodes based on a novel containing benzothiazolyl calix[4]arene. The prepared the sensor by incorporating four novel calix[4]arene derivatives substituted by benzothiazolyl units, as the neutral carrier into the plasticized polymeric membranes [60]. In the same year, there were some other reports on silver selective electrodes. R. K. Mahajan et al, proposed a silver(I) ion-selective membrane based on Schiff's base-p-tertbutylcalix[4]arene (Figure 19) [61].

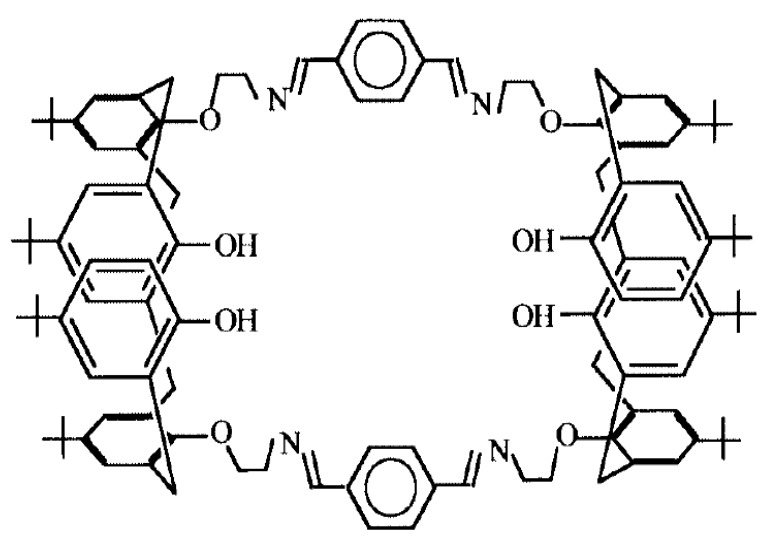

Figure 19. Schiff's base-p-tert-butylcalix[4]arene.

T. Shinohara et al, reported silver ion selective electrode based on calix[4]arene methyl ketonic derivative [62]. Seon Mook Lim et al, reported calix[2]furano[2]pyrrole and related compounds as the neutral carrier in silver ion-selective electrode [63]. They investigated the performance of calix[2]furano[2]pyrrole and related compounds used as neutral carriers for silver selective polymeric membrane electrode. The silver ion-selective electrode based on calix[2]furano[2]pyrroles gave a good 
Nernstian response of $57.1 \mathrm{mV}$ per decade for silver ion in the activity range $1 \times 10^{-6}$ to $1 \times 10^{-2} \mathrm{M}$. The present silver ion-selective electrode displayed very good selectivity for $\mathrm{Ag}^{+}$ion against alkali and alkaline earth metal ions, $\mathrm{NH}_{4}^{+}$, and $\mathrm{H}^{+}$.

K. S. Park et al, had a paper on structural selectivity of calix[m]pyrroles[n] furans $(m+n=4)$ as ionophores in $\operatorname{Ag}(\mathrm{I})$ ion-selective electrodes [64]. They studied a series of octamethylcalix[m] pyrroles[n]furans $(\mathrm{m}+\mathrm{n}=4)$, such as trans-octamethylcalix[2] pyrroles[2]furans (L1), cisoctamethylcalix[2]pyrroles[2]furans (L2) and octamethylcalix [1] pyrrole[3]furans (L3) as sensors in liquid membrane ion-selective electrodes for $\mathrm{Ag}(\mathrm{I})$ ion. The electrode based on $\mathrm{L} 1, \operatorname{trans}-\mathrm{N}_{2} \mathrm{O}_{2}$ porphyrinogen, gave the best results with a wide working concentration range of $1.0 \times 10^{-1}-1.0 \times 10^{-5.6}$ $\mathrm{M}$ and a Nernstian slope of $57.0 \mathrm{mV} /$ decade. This electrode exhibited a fast response time of $30 \mathrm{~s}$ and high selectivity over a number of mono-, di- and tri-valent cations, with only $\mathrm{Tl}(\mathrm{I})$ and $\mathrm{Hg}(\mathrm{II})$ ion interferences. The effect of anion excluders on the performance of the membrane electrodes has been also studied. L. X. Chen et al, reported a selective electrode for silver based on polymer membranes containing exocyclic chalcogen atoms calix[4]arene and crown ether [65]. M. Kumar et al, reported synthesis of new bis-calix[4]arenes with imine linkages. In their work, they made a search for new silver-selective sensors [66]. They synthesized new bis-calix[4]arenes with imine units in high yields by using a simple condensation procedure, and two of these bis-calix[4]arenes were tested as sensors in solid-state electrodes. High selectivities for $\mathrm{Ag}^{+}$, even over that of $\mathrm{Hg}^{2+}$, and excellent electrode properties were found. In the same year X. S. Zeng et al, synthesized 25,27-Bis(6-hydroxymethyl-2pyridylmethoxy)-26,28-dipropoxycalix[4]arene, one of its derivative and 25,27-bis-(6-diphenyl phosphinomethylpyridylmethoxy)-26,28-dipropoxy-5,11,17,23-tetra-tert-butylcalix[4]arene. Ion-selective electrodes (ISE) for $\mathrm{Ag}^{+}$containing the mentioned compounds as neutral ionophores in a PVC membrane were prepared and their selectivity coefficients for $\mathrm{Ag}^{+}$(log $\mathrm{K}-\mathrm{Ag}, \mathrm{M}(\mathrm{pot})$ ) were investigated against other alkali metal, alkaline-earth metal, lead, ammonium ions and some transition metal ions using the mixed-solution method. These ISEs showed excellent $\mathrm{Ag}^{+}$selectivity towards most of the interfering cations examined, except for $\mathrm{Hg}^{2+}$, which has a relatively low interference (log K-Ag, M(pot) less than or equal to -1.5) [67].

In 2003, E. Pretsch et al published a paper entitled "rational design of potentiometric trace level ion sensors $\mathrm{Ag}^{+}$-selective electrode with a $100 \mathrm{ppt}$ detection limit". In their work a silver-selective electrode was developed because of the ionophore O,O'-bis[2-(methylthio)ethyl]-tertbutylcalix[4]arene. With the predicted optimal composition of the inner electrolyte, its lower detection limit was found to be $10^{-9} \mathrm{M}$ or $100 \mathrm{ppt} \mathrm{Ag}^{+}$with an ionic background of $10^{-5} \mathrm{M} \mathrm{LiNO}_{3}$ [68]. H. Sun, et al, reported the synthesis of a tweezer-like bis(phenylthiapropoxy)calix[4]arene as a cation/pi enhanced sensor for ion-selective electrodes. They synthesized two novel 25,27-dihydroxy-26,28bis(3-phenylthia propoxy)-calix[4]arene (3) and 25,27-dihydroxy-26,28-bis(3-phen 34ddapropoxy)5,11,17,23-tetra-tert-butylcalix[4]arene for the evaluation of their ion-selectivity in ion-selective electrodes (ISEs). ISEs based on these neutral ionophores were prepared, and their selectivity coefficients for $\mathrm{Ag}^{+}(\log \mathrm{K}-\mathrm{Ag}, \mathrm{M}(\mathrm{pot}))$ were investigated against other alkali metal, alkaline-earth metal, aluminum, thallium (I), lead and some transition metal ions using the wpm-ate solution method (SSM). These ISEs showed excellent $\mathrm{Ag}^{+}$selectivity over most of the interfering cations examined, except for $\mathrm{Hg}^{2+}$ and $\mathrm{Fe}^{2+}$ having relative smaller interference (log $\mathrm{K}$-Ag, $\mathrm{M}$ (pot) less than or equal to - 
2.1) [69]. The syntheses and $\mathrm{Ag}^{+}$-selective electrode properties of benzothiazolylthiaalkoxy functionalized calix[4]arenas were reported by X. S. Zeng in the same year [70].

In 2003 M. Mazloum et al, reported the performance of octahydroxycalix[4]arene derivative (Figure 20) used as a neutral carrier for silver polymeric membrane electrode. The sensor gave a good Nernstian response of $58 \pm 1 \mathrm{mV}$ per decade for silver ion in the activity range $3.3 \times 10^{-6}$ to $3.3 \times 10^{-2}$ $\mathrm{M} \mathrm{Ag}^{+}$. The limit of detection reached $2.1 \times 10^{-6} \mathrm{M} \mathrm{Ag}^{+}$and exhibited high selectivity for silver ion against the alkali, alkaline earth and transition metal ions [71].

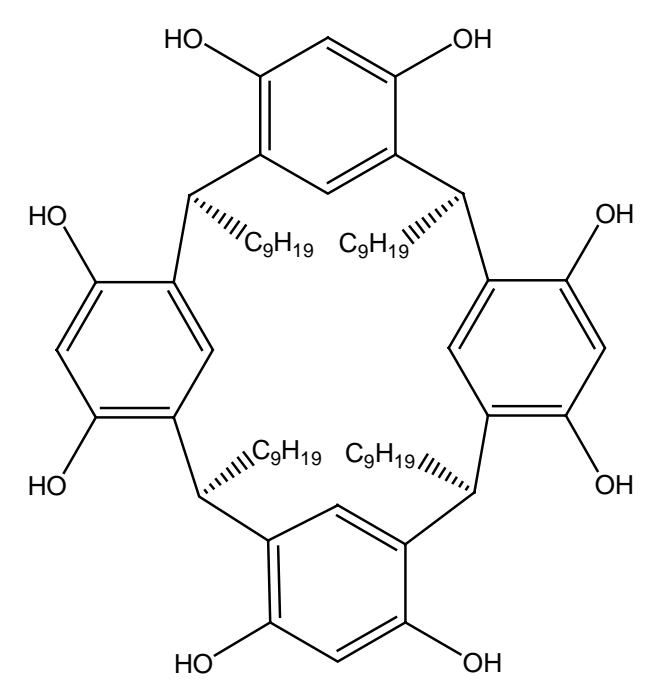

Figure 20. 2,8,14,20-tetranonyl-4,6,10,12,16,18,22,24-octahydroxycalix[4]arene.

R. K. Mahajan et al, reported silver ion-selective electrodes employing Schiff base p-tert-butyl calix[4]arene derivatives as neutral carriers [72]. X. S. Zeng published a paper on the synthesis of a tweezer-like bis(arylthiaalkoxy)calix[4]arene as a cation sensor for ion-selective electrodes: an investigation of the influence of neighboring halogen atoms on cation selectivity in the same year [73].

In 2004, M. R. Ganjali et al, prepared a PVC membrane electrode for silver ion based on a new cone shaped calix[4]arene (CASCA) as membrane carrier. The electrode exhibited a Nernstian response for $\mathrm{Ag}^{+}$over a wide concentration range with a slope of $58.2 \mathrm{mV}$ per decade. The sensor had a very fast response time ( $\sim \mathrm{s}$ ) [74]. J. Q. Lu et al. proposed a new solid-state silver ion-selective electrode based on a novel tweezer-type calixarene derivative. In this work a new silver solid-state ion-selective electrode was prepared by directly coating the surface of a glassy carbon electrode with tetrahydrofuran solution containing PVC, 25,27-dihydroxy-26,28-bis[5-(4-methyl-6-hydroxy purimidine)thiaamyloxy] calix[4]arene (Figure 21), dioctyl phthalate and sodium tetraphenyl borate [75].

In 2003, J. Q. Lu, X. Q. Tong, and X. W. He prepared a mercury ion-selective electrode (ISE) with a polymeric membrane based on a calixarene derivative containing a thiazole azo group as the ionophore. Several ISEs were conditioned and tested for the selection of common metal ions. The ISE gave two kinds of response slope for $\mathrm{Hg}^{2+}$. One, which had twice the Nernstian response for $\mathrm{Hg}^{2+}$, is obtained at $\mathrm{pH} 6.5$ with a slope of $61.1 \mathrm{mV}$ per decade in the concentration range of $7.5 \times 10^{-6}-10^{-2}$ M. Another, which had a typical Nernstian response for $\mathrm{Hg}^{2+}$, is obtained at $\mathrm{pH} 4.0$ with a slope of $28.7 \mathrm{mV}$ per decade in the concentration range of $5 \times 10^{-6}-10^{-2} \mathrm{M}$. The ISEs exhibit stable detection 
reproducibility and high selectivity towards alkali, alkaline earth and transition metal ions except $\mathrm{Ag}^{+}$ [76]. In 2004, R. K. Mahajan et al, had a report on mercury(II) ion-selective electrodes based on p-tertbutyl calix[4]crowns with imine units. They prepared PVC membranes incorporating p-tert-butyl calix[4]crown with imine units as an ionophore was prepared and used it an ion-selective electrode for the determination of mercury(II) ions. An electrode based on this ionophore showed a good potentiometric response for mercury(II) ions over a wide concentration range of $5.0 \times 10^{-5}-1.0 \times 10^{-1}$ $\mathrm{M}$ with a near-Nernstian slope of $27.3 \mathrm{mV}$ per decade. The detection limit of the electrode was $2.24 \times$ $10^{-5} \mathrm{M}$ and the electrode worked well in the $\mathrm{pH}$ range of 1.3-4.0. The electrode showed a short response time of less than $20 \mathrm{~s}$. The electrode also showed better selectivity for mercury(II) ions over many of the alkali $\left(\mathrm{Na}^{+},-1.69 ; \mathrm{K}^{+},-1.54\right)$, alkaline-earth $\left(\mathrm{Ca}^{2+},-3.30 ; \mathrm{Ba}^{2+},-3.32\right)$, and heavy metal ions $\left(\mathrm{Co}^{2+},-3.67 ; \mathrm{Ni}^{2+},-3.43 ; \mathrm{Ph}^{2+},-3.31 ; \mathrm{Fe}^{3+},-1.82\right) . \mathrm{Ag}^{+}$ion was found to be the strongest interfering ion. Furthermore, sharp end-points were obtained when the sensor was used as an indicator electrode for the potentiometric titration of mercury(II) ions with iodide and dichromate ions [77].

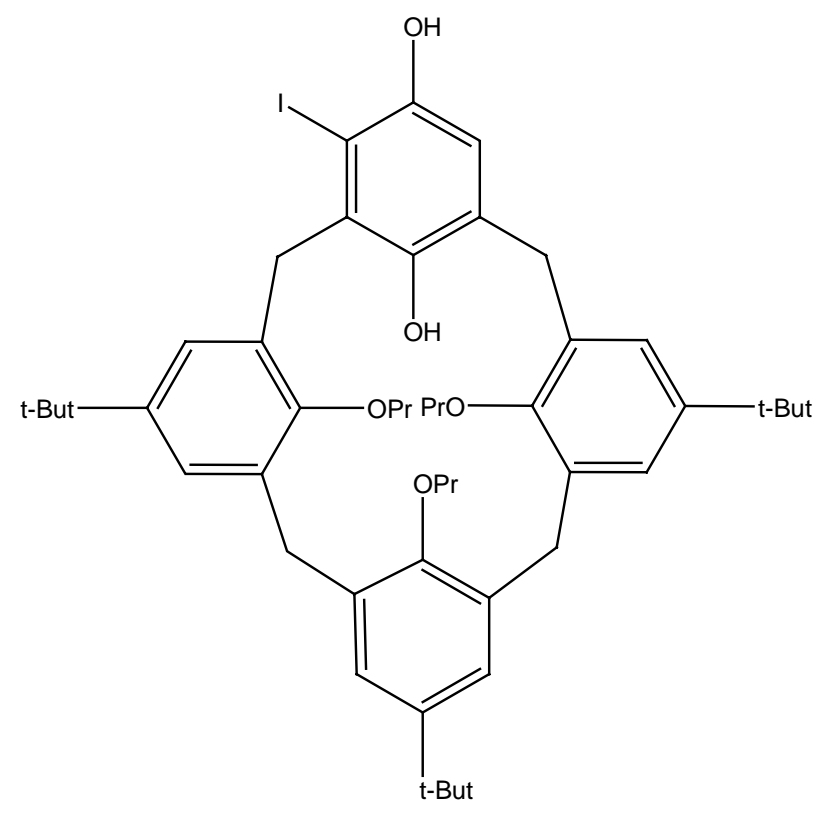

Figure 21. 25,27-dihydroxy-26,28-bis[5-(4-methyl-6-hydroxypurimidine)thiaamyloxy] calix[4]arene.

\subsubsection{Calixarene-Based Lanthanide and Actinide Ion Selective Electrodes}

In 1995 there was a report by T. Grady et al, the Characteristics of a Eu selective electrode based on a calix[4]arene tetraphophine oxide. They constructed a poly(vinyl chloride) (PVC) electrode containing a calix[4]arene phosphine oxide [calix- $\left(\mathrm{OCH}_{2} \mathrm{CH}_{2} \mathrm{POPh}_{2}\right)_{4}$ ] as the ionophore, which is selective for $\mathrm{Eu}(\mathrm{III})$ in the presence of a high background of $\mathrm{Na}^{+}$and other common ions is described. The selectivity and response of this electrode is compared with that of an electrode incorporating the tetramethyl ester calix[4]arene by injection experiments [78].

In 1999, there was a report by V. K. Gupta et al, on the determination of uranyl ions using poly(vinyl chloride) based 4-tert-butylcalix[6]arene membrane sensor, where membranes of 4-tertbutylcalix[6]arene as an ion active material in poly(vinyl chloride) (PVC) based matrix were tried for uranyl-selective sensors. The effect of anion excluder, sodium tetraphenylborate (NaTPB) and 
plasticizers, tris(2-ethylhexyl)phosphate (TEP), tributyl phosphate (TBP), dibutyl phthalate (DBP), 1chloronaphthalene (CN) and diphenyl ether (DPE) on the performance of the membrane electrodes has also been studied. It was observed that the membrane having the composition I: PVC:NaTPB:TBP in the ratio 7:52:6:35 gave the best resulted with a wide working concentration range of $3.9 \times 10^{-5}-1.0 \times$ $10^{-1} \mathrm{M}$, Nernstian slope of $29.1 \mathrm{mV}$ per decade of activity, fast response time of $10 \mathrm{~s}$ and moderate selectivity over a number of mono-, bi- and trivalent cations. The sensor worked well in the $\mathrm{pH}$ range 2.2-3.2 and could be successfully employed for the estimation of $\mathrm{UO}_{2}{ }^{2+}$ in partially non-aqueous medium having up to $20 \%(\mathrm{v} / \mathrm{v})$ non-aqueous content [79].

\subsection{Porphyrin Based Ion Selective Sensors}

\subsubsection{Porphyrin Based Main Group Anion Selective Electrodes}

The application of metal complexes of ligands that fit into the family of the supramolecular chemistry, may not suit the reader, because what happens in a metal complex-carrying anion selective electrode is not really related to supramolecular chemistry. However, it is not a bad idea to have a very general overview of the groups of supramolecular ligands that are used in the field of anion selective electrodes.

Y. Umezawa et al reported an ion-selective electrode for acetate based on a urea-functionalized porphyrin (Figure 22) as a hydrogen-bonding ionophore [80], in 1999.

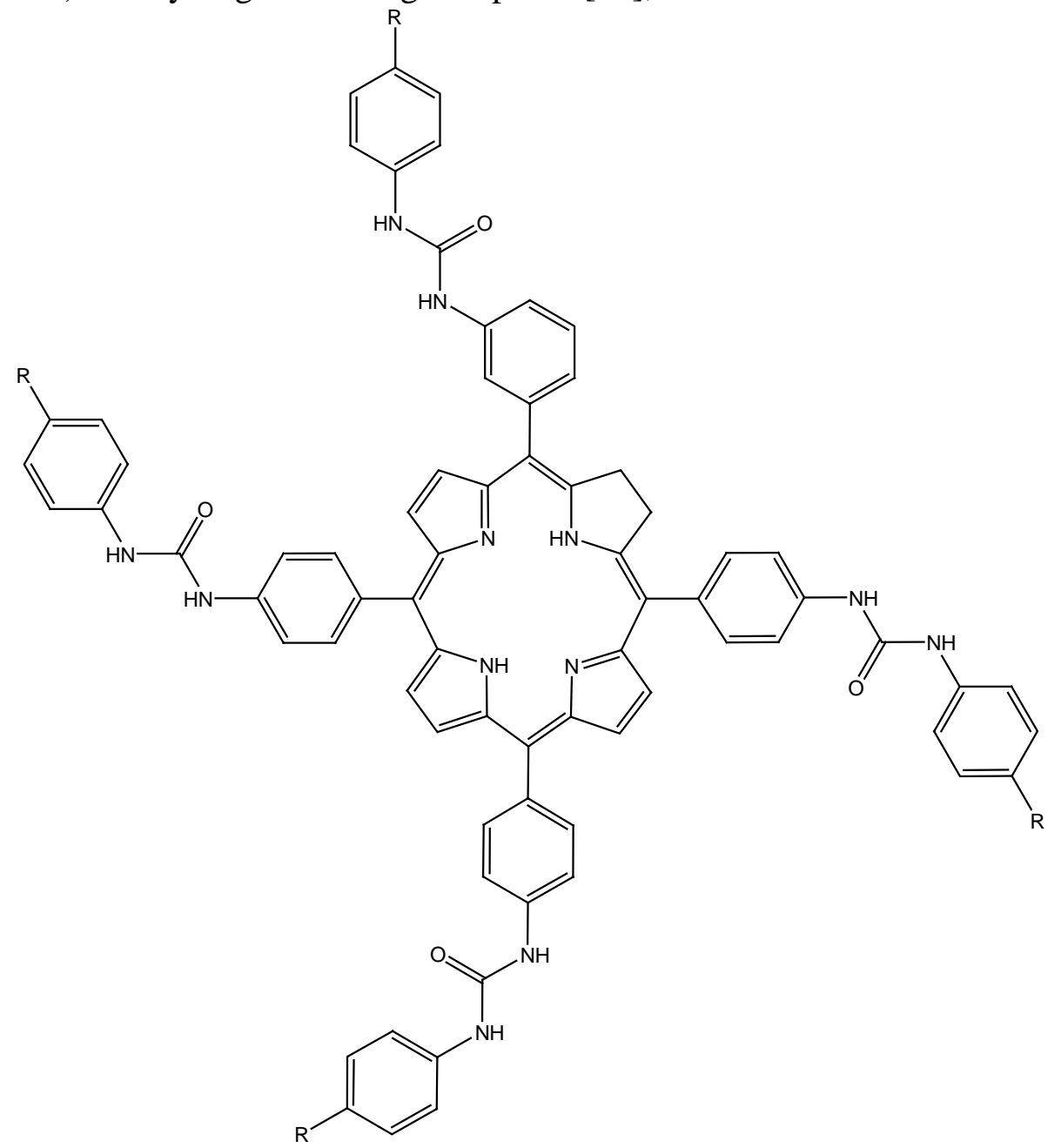

Figure 22. Urea-functionalized porphyrin $(\mathrm{R}=\mathrm{F}$ or $\mathrm{H})$. 
G. Bachas et al reported the application of Cobalt(II) tetrakis(o-amino phenyl)porphyry, as a thiocyanat selective ionophore in 1991 [81].

In 2002 M., K. Amini et al reported manganese porphyrin derivatives (Figure 23) as ionophores for thiocyanate-selective electrodes and studied the influence of porphyrin substituents and additives on the response properties [82].

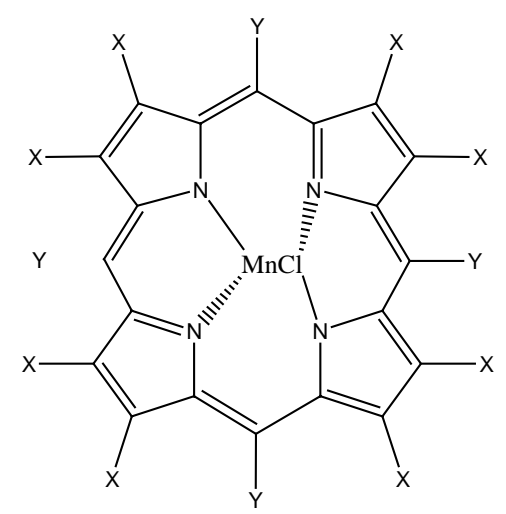

Figure 23. Manganese porphyrin derivatives

$1 \mathrm{X}=\mathrm{H}, \mathrm{Y}=\mathrm{p}$-aminophenyl, $\mathrm{Mn}\left(\mathrm{TNH}_{2} \mathrm{PP}\right) \mathrm{Cl}$

$2 \quad \mathrm{X}=\mathrm{H}, \mathrm{Y}=\mathrm{p}$-tolyl, Mn(TTP)Cl

$3 \mathrm{X}=\mathrm{H}, \mathrm{Y}=$ pentafluorophenyl, $\mathrm{Mn}\left(\mathrm{TF}_{5} \mathrm{PP}\right) \mathrm{Cl}$

$4 \mathrm{X}=\mathrm{Br}, \mathrm{Y}=$ phenyl, $\mathrm{Mn}\left(\mathrm{Br}_{8} \mathrm{TPP}\right) \mathrm{Cl}$

$5 \mathrm{X}=\mathrm{H}, \mathrm{Y}=$ phenyl, $\mathrm{Mn}(\mathrm{TPP}) \mathrm{Cl}$

In 2005, D. Vlascici et al, had a report on the characterization of the membrane material of a tiocyanate-selective electrode based on rhodium (III) [5,10,15,20-tetraphenyl-21H, 23H-porphyrinatoN21,N22,N23,N24] chloride [83]. M. E. Meyerhoff et al, reported a salicylate-selective membrane electrode based on tin(IV) Tetraphenylporphyrin, in 1989 [84]. In 2001, E. Malinowska et al published a paper on Salicylate-selective membrane electrodes based on Sn(IV)- and O=Mo(V)- porphyrins [85]. In the year, $2002 \mathrm{~S}$. Shahrokhian et al reported chromium(III) porphyrin as a selective ionophore in a salicylate-selective membrane electrode [86]. In 2005, E. D. Steinle et al reported the development of anion selective polymer membrane electrodes based on lutetium(III) porphyrins [87].

There have been reports on the application of porphyrin metal complexes (Figures 24, 25) for the detection of other anions like $\mathrm{Cl}^{-}$[88-90] $\mathrm{Br}^{-}$[91-93], $\mathrm{I}^{-}$[93-95], $\mathrm{I}^{3-}$ [96], arsenite [97], $\mathrm{SCN}^{-}$[98, 83], dinitro benzoate [99], histidin [100], nitrite [101], $\mathrm{NO}_{3}^{-}[102]$.

\subsubsection{Porphyrin-Based Transition Metal, and Lanthanide Selective Electrodes}

The reports on cationic selective electrodes with the application of porphyrin-based liquid membrane sensors are mostly related to the transition and lanthanide ion, because of the binding properties of the ionophores.

In 2001, A. R. Fakhari et al, proposed a new PVC membrane electrode for $\mathrm{Fe}^{3+}$ ions based on 5,10,15,20-tetrakis (pentaflurophenyl)-21H, 23H-porphyrin as membrane carrier was prepared. The sensor exhibited a super-Nernstian slope of $25.0 \pm 0.5 \mathrm{mV}$ per decade over a $1.0 \times 10^{-4}-1.0 \times 10^{-6} \mathrm{M}$ concentration range. The proposed sensor revealed to be very selective for $\mathrm{Fe}^{3+}$ over a wide variety of other cations over a pH range [103]. 


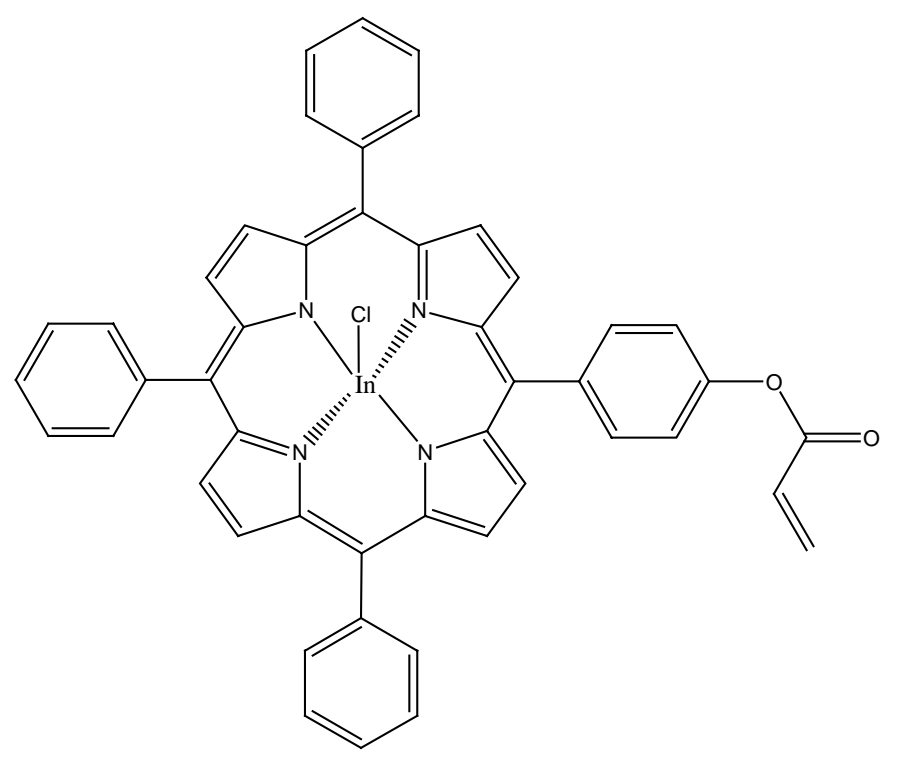

Figure 24. Indium(III) porphyrin.

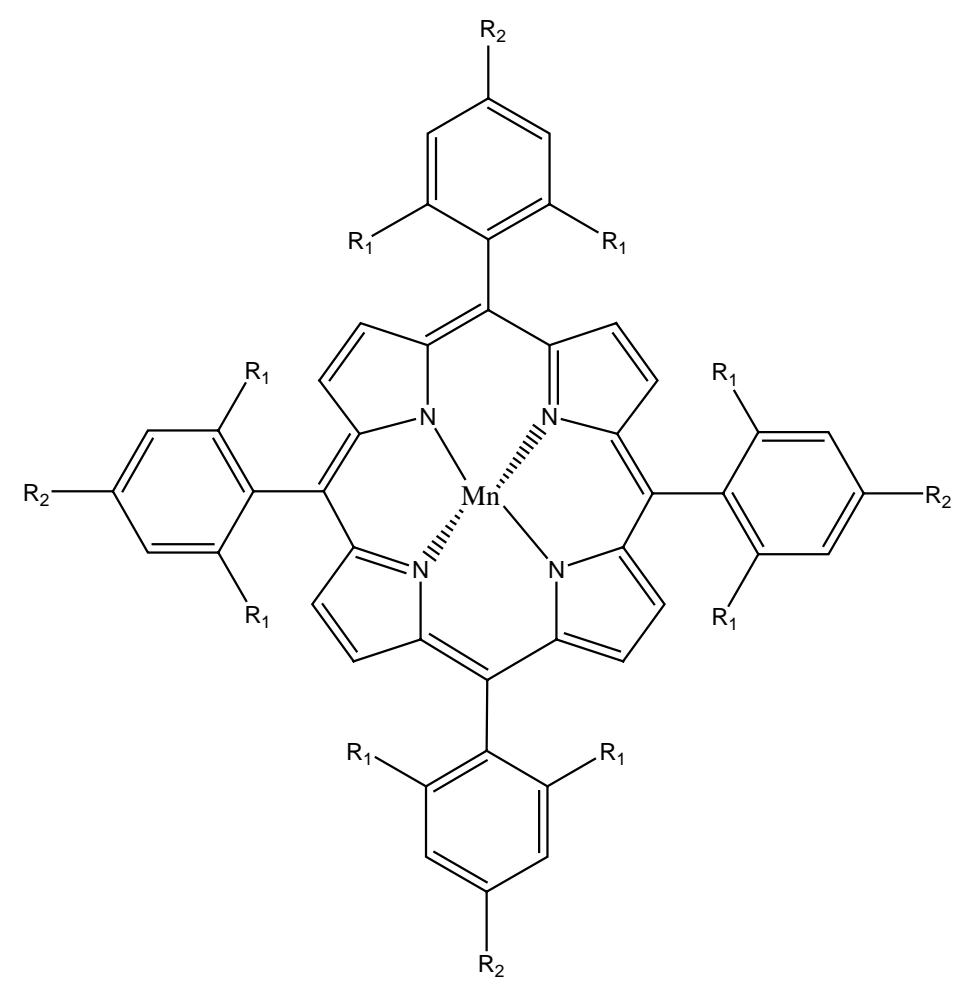

Figure 25. Tetra(trimethylphenyl)porphyrinato Manganese(III) Chloride.

$$
\begin{array}{ll}
\mathrm{R}_{1}=\mathrm{R}_{2}=\mathrm{CH}_{3} & \mathrm{Mn}(\mathrm{TMP}) \mathrm{Cl}(\mathrm{I}) \\
\mathrm{R}_{1}=\mathrm{Cl}, \mathrm{R}_{2}=\mathrm{H} & \mathrm{Mn}\left(\mathrm{Cl}_{8} \mathrm{TPP}\right) \mathrm{Cl}
\end{array}
$$

In 1990 T., Malinski et al published a paper on a tetrakis(3-methoxy-4-hydroxyphenyl) porphyrin film electrode for trace determination of nickel. They formed stable polymer film electrodes from tetrakis(3-methoxy-4-hydroxyphenyl)porphyrin with $\mathrm{Ni}$ ( II) as the central metal. The nickel-porphyrin polymer films efficiently demetaiated in acidic media at $\mathrm{pH}=1$. The resulting demetalated porphyrln polymer electrodes required no preconditioning treatment before exhibiting strong affinity for $\mathrm{Ni}(\mathrm{II})$. A detection limit of $8 \times 10^{-8} \mathrm{M}$ was obtained for a $60 \mathrm{~s}$ exposure to the sample solution. In interference studies, a 10-fold excess of Co resulted in partial suppression of the Ni(II) signal, but no new signals 
were observed. Similar concentrations of cations of $\mathrm{Zn}, \mathrm{Cd}, \mathrm{Pb}, \mathrm{Cu}$ and $\mathrm{Fe}$ did not appreciably influence the $\mathrm{Ni}(\mathrm{II})$ response [104].

In 1997, V. K. Gupta et al reported 5,10,15,20-tetraphenylporphyrin (TPP) and 5,10,15,20-tetra(4methylphenyl) porphyrin (TMPP) to be explored as electroactive materials for preparing poly(vinyl chloride) (PVC) based membrane sensors selective to $\mathrm{Ni}^{2+}$. The membrane incorporating TMPP, sodium tetraphenylborate and a solvent mediator (dibutylphthalate) in PVC in the ratio (7: 35: 4: 54) gave the best results, exhibiting Nernstian response in the concentration range $5.6 \times 10-6-1.0 \times 10-1$ $\mathrm{mol} / \mathrm{l}$ between $\mathrm{pH}$ 2.5-7.4 and a fast response time of $20 \mathrm{~s}$. The electrode showed moderate selectivity and was used for the quantitative determination of $\mathrm{Ni}^{2+}$ in chocolates and as an indicator electrode for the end detection in the potentiometric titration of $\mathrm{Ni}^{2+}$ against EDTA [105].

V. K. Gupta et al reported a $\mathrm{Cu}^{2+}$ selective sensors fabricated from polyvinyl chloride (PVC) matrix membranes containing neutral carrier porphyrin ionophores. The membranes of various compositions of two porphyrins were investigated [106].

In 2004, M. M. Ardakani et al, had a report on potentiometric determination of silver(I) by selective membrane electrode based on derivative of porphyrin. They used meso-tetraphenylporphyrin $\left(\left[\mathrm{H}_{2} \mathrm{~T}(4-\right.\right.$ $\mathrm{CH}_{3}$ )]PP) (Figure 26) as the ionophores. The electrode exhibited linear response with Nernstian slope of $59.2 \pm 1.0 \mathrm{mV}$ per decade within the concentration range of $1.0 \times 10^{-7}-1.0 \times 10^{-1} \mathrm{M}$ silver ions. The limit of detection as determined from the intersection of the extrapolated linear segments of the calibration plot was $1.0 \times 10^{-7} \mathrm{M}$. The response time of the electrode was $<10 \mathrm{~s}$ over the entire concentration range. The silver-selective electrode exhibited good selectivity for $\mathrm{Ag}(\mathrm{I})$ with respect to alkali, alkaline earth and heavy metal ions [107].

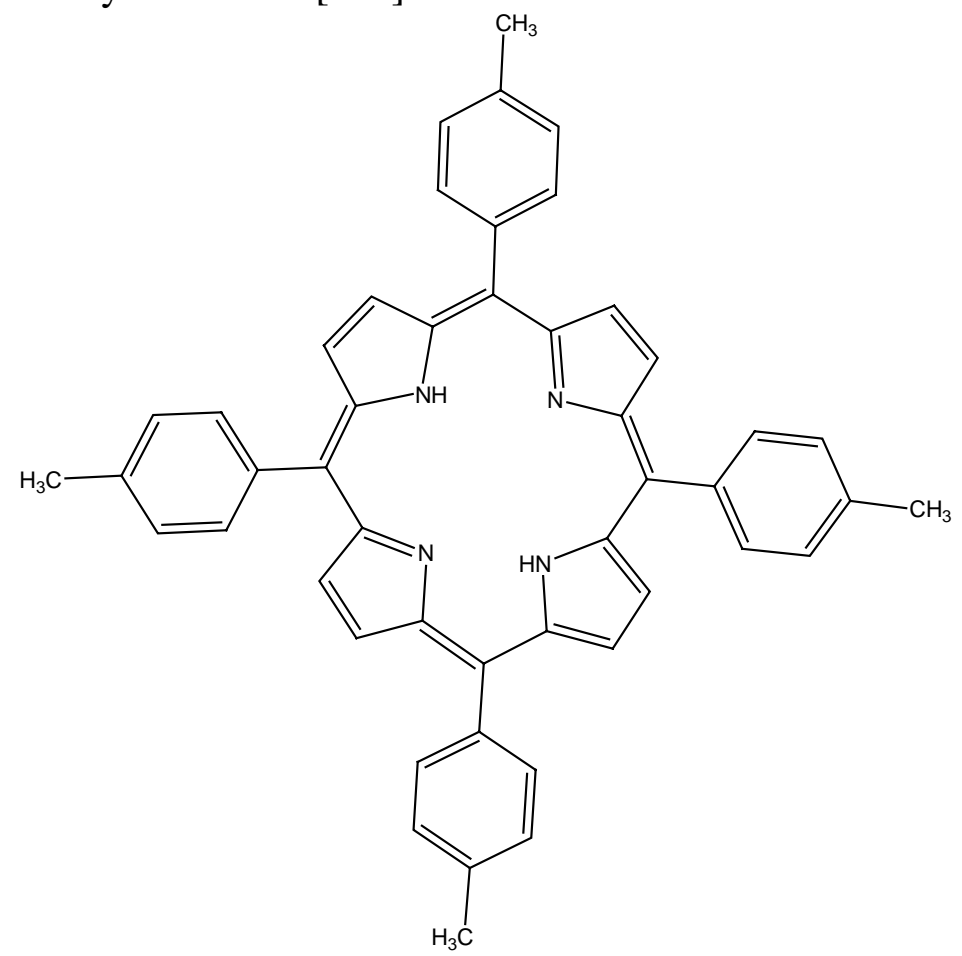

Figure 26. Meso-tetraphenylporphyrin.

In 2002, A. R. Fakhari et al, reported a new PVC membrane electrode for $\mathrm{Zn}^{2+}$ ions based on tetra(2-aminophenyl) porphyrin (TAPP). The sensor showed a linear stable response over a wide concentration range $\left(5.0 \times 10^{-5}\right.$ to $\left.1.0 \times 10^{-1} \mathrm{M}\right)$ with a slope of $26.5 \mathrm{mV} /$ decade and a limit of detection 
3.0×10-5 M (1.96 ppm) [108]. The same group had a second report on a $\mathrm{Zn}^{2+}$ selective electrode in the same year [108]. They reported a new PVC membrane electrode for $\mathrm{Zn}^{2+}$ ions based on tetra(2aminophenyl) porphyrin (TAPP). The sensor exhibited a linear stable response over a-wide concentration range $\left(5.0 \times 10^{-5}\right.$ to $\left.1.0 \times 10^{-1} \mathrm{M}\right)$ with a slope of $26.5 \mathrm{mV} /$ decade and a limit of detection $3.0 \times 10^{-5} \mathrm{M}(1.96 \mathrm{ppm})$.

\subsection{Cryptand Based Ion Selective Sensors}

\subsubsection{Cryptand Based Main Group Ion Selective Electrodes}

In 1981, J. Gajowski et al published a paper entitled potassium-selective membrane electrode electrodes based on the cryptand [2b2b2] [109]. In 1994 G. G. Cross et al, incorporated polymers containing covalently attached 18-crown-6 or 2.2.2 cryptand units into plasticized PVC membranes and the composite membranes, and examined them as potassium ion sensor elements. Ionosphores were linked to carboxy-PVC and to poly(acrylic acid) via amide linkages to an alkyl spacer unit. Coated-wire electrodes (CWEs) that used the immobilized ionophores gave acceptable responses, but conventional ion-selective membrane electrodes (ISEs) prepared by solvent casting were reported to be inactive. Dip-cast membranes gave active ISEs. Potassium electrode performance was independent of the loading of the ionophore within the acrylate support polymer, but depended upon the spacer length. Ion selectivity varied with the ionophore loading within the support polymer. They concluded that selectivity is a combination of the ionophore selectivity and ion-exchange interactions with the acrylate backbone, giving selectivities akin to carboxylate substituted crown ethers, notably enhanced mono-valent/di-valent ion discrimination relative to the ionophore in solution. Polymer immobilization extended the lifetime of active electrodes [110].

The work of N. G. Lukyanenko in 1992 resulted in the construction of an $\mathrm{Rb}^{+}$sensor. They reported the selectivity coefficients for poly(vinyl chloride) membranes containing cryptands with thiourea fragments in one of the bridges (seven compounds). The membranes exhibited rubidium selectivity as compared to the other members of the series of group IA and IIA metal cations. The cryptand 1,3,12,14-tetraaza-6,9,17,20,25-pentaoxabicyclo[12.8.5]heptacosane-2,13-dithione revealed to be useful as the electrode-active compound in a rubidium-selective electrode. The electrode function was linear within the activity range $10^{-1}-10^{-4} \mathrm{M}$, with a slope of $48 \pm 1 \mathrm{mV}$ per decade. Selectivity coefficients were reported to be 0.005 for $\mathrm{Li}^{+}, 0.006$ for $\mathrm{Na}^{+}, 0.015$ for $\mathrm{K}^{+}, 0.012$ for $\mathrm{Cs}^{+}, 0.006$ for $\mathrm{NH}_{4}{ }^{+}, 0.0027$ for $\mathrm{Mg}^{2+}, 0.0032$ for $\mathrm{Ca}^{2+}, 0.0040$ for $\mathrm{Sr}^{2+}$ and 0.0081 for $\mathrm{Ba}^{2+}$ [111].

As another example of a main group cation sensor, we can refer to the work of M. K. Amini et al, on a lead selective membrane electrode using a cryptand(222) neutral carrier in 1999 [112]. They investigated the construction, performance characteristics and applications of a polymeric membrane electrode for lead(II) ion. The electrode was prepared by incorporating cryptand(222) as the neutral carrier into a plasticized poly(vinyl chloride) membrane. The influence of membrane composition, $\mathrm{pH}$ and concentration of internal reference solution were also investigated. The electrode was reported to exhibit a potentiometric response for $\mathrm{Pb}^{2+}$ ion over the concentration range $10^{-1}-10^{-5} \mathrm{M}$ with a detection limit of $5 \times 10^{-6} \mathrm{M} \mathrm{Pb}^{2+}$. It showed a relatively fast response time of about $30 \mathrm{~s}$ and could be used for about two months without any considerable divergence in potential. 


\subsubsection{Cryptand Based Transition Metal Selective Electrodes}

The reports on the application of cryptands to construct ion-selective membrane sensors focus on zinc selective electrodes. In 1996 S. K. Srivastava et al, reported PVC-based 2,2,2-cryptand (Figure 27) sensor for zinc ions [113].

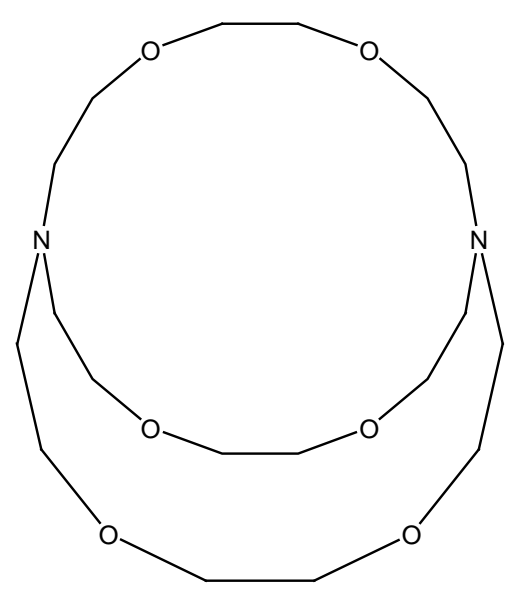

Figure 27. 4,7,13,16,21,24-hexaoxa-1,10-diazabicyclo[8.8.8]hexacosane.

They reported that a PVC-based membrane of 2,2,2-cryptand exhibits a very good response for $\mathrm{Zn}^{2+}$ in a wide concentration range (from $2.06 \mathrm{ppm}$ to $6.54 \times 10^{3} \mathrm{ppm}$ ) with a slope of $22.0 \mathrm{mV} /$ decade of $\mathrm{Zn}^{2+}$ concentration. The response time of the sensor was less than $10 \mathrm{~s}$, and the membrane could be used for more than 3 months without any observed divergence in potentials. The proposed sensor exhibited very good selectivity for $\mathrm{Zn}^{2+}$ over other cations and could be used in a wide $\mathrm{pH}$ range (2.87.0). Two years later, H. R. Pouretedal, reported a PVC membrane electrode for zinc ions based on cryptand $\mathrm{C}_{2}\left(\mathrm{~B}_{22}\right.$ as membrane carrier. The electrode exhibited a linear stable response over a wide concentration range $\left(5.0 \times 10^{-2}-5.0 \times 10^{-5} \mathrm{M}\right)$ with a slope of $24 \mathrm{mV} /$ decade and a limit of detection of $3.98 \times 10^{-5} \mathrm{~mol} / \mathrm{L}(2.6 \mathrm{ml} \mathrm{g} / \mathrm{g})$. It was reported to have a fast response time of about $30 \mathrm{~s}$ and to have the ability be used for at least 4 months without any divergence in potential. The proposed sensor revealed good selectivities for $\mathrm{Zn}^{2+}$ over a wide variety of other metal ions and could be used in a $\mathrm{pH}$ range of 4-7 [114].

\subsection{Crown Ethers Based Ion Selective Sensors}

Crown ethers are a unique class of ionic complexing agents whose recognition properties derive from both the atoms within the molecule and the overall structure. Immobilization of the crown ethers onto polymers lets the ease of handling, recyclability and adaptation to continuous processes for this important set of ligands [115].

The stability of the crown ether-metal ion complexes is dependent on the number of ether donor atoms, and the cavity size of these compounds. Of particular importance is the mentioned size and shape of the cavity relative to the size of the cation to be recognized [116]. Though a given crown ether tends to form its most stable complexes with ions having diameters comparable to that of its opened cavity, it can also form complexes with ions of larger size [117]. When the ion is able to fit 
within the cavity, the crown ether-metal ion complexes are formed in a 1:1 ratio. If the ion is larger than that of the crown cavity, there is a tendency for the crown ether moieties to "sandwich" the metal ions between adjacent crown units [118].

While the first crown ethers that were characterized contained only oxygen donor atoms, sulfur and nitrogen-containing crown ethers were subsequently prepared. Due to differences in polarizability, nitrogen-containing crown ethers (azacrowns) and sulfur-containing crown ethers (thiacrowns) display different ionic selectivities than oxygen-containing crown ethers. These differences in behavior as a function of donor atoms can be explained by hard-soft acid-base theory [119, 120]. Soft ligands, such as those containing sulfur, provide polarizable sites that have increased affinities for soft metal ions, including precious metals. In contrast, hard ligands that have sites of low polarizability have increased affinities for hard metal ions such as the alkali and alkaline earth metals [121, 122].

\subsubsection{Crown Ethers Based Main Group Ion Selective Electrodes}

The first lithium selective electrode, based on a crown ether dates back to the work of A. S. Attiyatat et al in 1988, which was published in a paper entitled Comparative-Evaluation of neutral and proton ionizable crown ether compounds (Figure 28) as lithium ionophores in ion-selective electrodes and in solvent extraction [123].

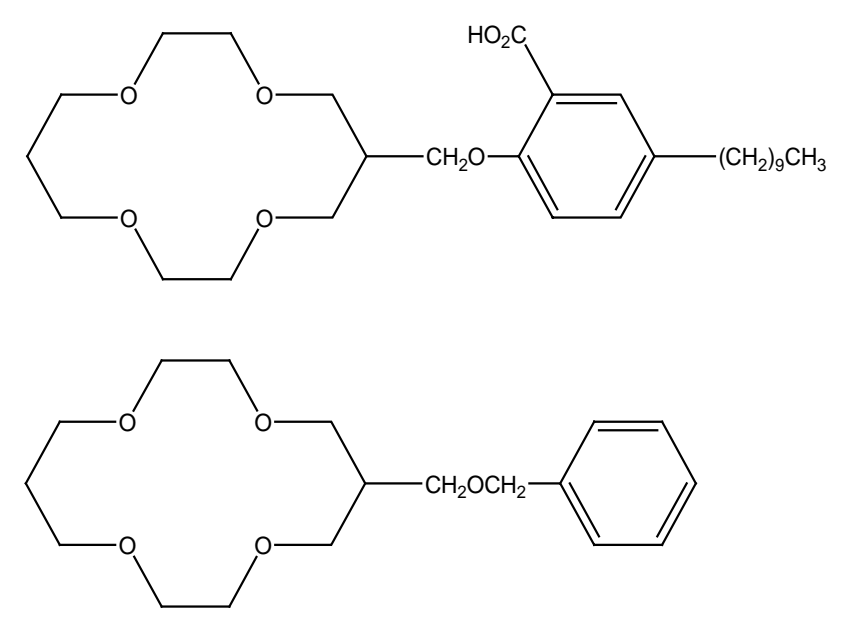

Figure 28. Proton-ionizable and neutral crown ethers.

The next report was in 1991, by R. Kataky et al, when they prepared a series of neutral ionophorebased lithium-selective liquid-membrane electrodes and compared the electrode performance compared with similar electrodes based on the lithium ionophores ETH 1810-ortho-nitrophenyl octyl ether (o-NPOE) and ETH 2137-bis(1-butylpentyl) adipate (BBPA). By using a diamide substituted 14crown-4 macrocycle, selectivities for $\mathrm{Li}^{+}$in the presence of $\mathrm{Na}^{+}$of $\log \mathrm{K}(\mathrm{Li}, \mathrm{Na})$ pot $=-3.25$ and -2.92 were obtained for diisobutylamide-o-NPOE and di-n-butylamide-o-NPOE derivatives. The di-nbutylamide-o-NPOE based electrode functioned satisfactorily in serum, exhibiting a fast response time (10-15 s), an acceptable lifetime of 50 days and minimal protein interference [124]. 
In $1993 \mathrm{~K}$. Suzuki et al, reported the design and synthesis of highly $\mathrm{Li}^{+}$-selective ionophores based on 14-crown-4 derivatives. They investigated the relationship of their molecular structures and ion selectivities, in order to obtain a highly $\mathrm{Li}^{+}$-selective electrode. The ion selectivities were examined with 11 kinds of 14-crown-4 derivatives Figure 29), which were prepared according to the proposed two types of $\mathrm{Li}^{+}$ionophore models.

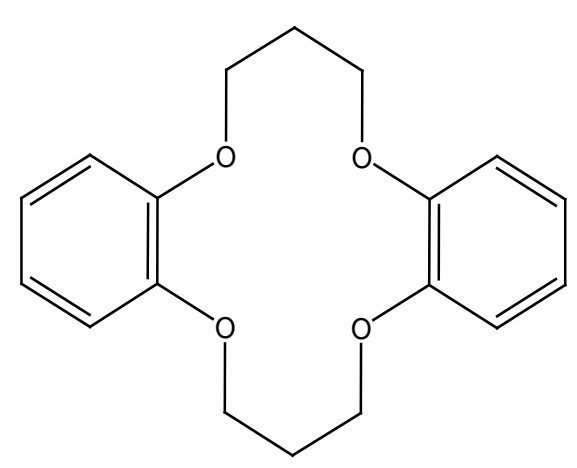

A

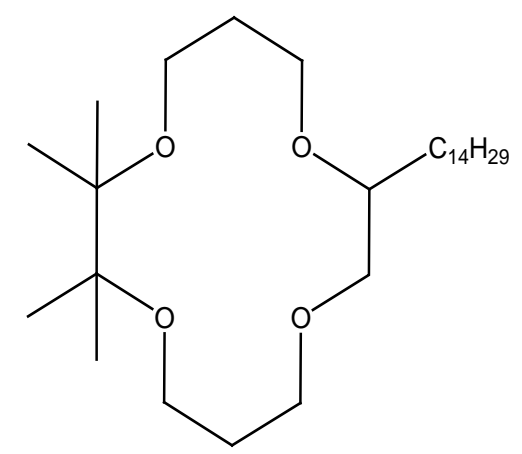

B

Figure 29. 2,3,9,10-dibenzo-14-crown-4 (A),

2,2,3,3-tetramethyl-9-tetradecyl-1,4,8,11-tetraoxatricyclo tetradecane (B).

Excellent $\mathrm{Li}^{+}$-selective ionophores were obtained by introducing a bulky "block" subunit into the ethano-bridge section of the base crown ring, which effectively prevented the formation of a 2:1 or 3:1 sandwich-type complex consisting of the crown ether and cations larger than $\mathrm{Li}^{+}$. The best $\mathrm{Li}^{+} / \mathrm{Na}^{+}$ selectivity (more than 1000) was obtained for the electrode using the 14-crown-4 derivatives with a bulky decalin subunit. They suggested that the results offered the general ion selectivity features of 14crown-4-based compounds [125].

In 1996, K. Kobiro introduced a new class of lithium ion selective crown ethers with bulky decalin subunits. He reported that didecalino-14-crown-4 and decalino-14-crown-4 respectively show excellent extractability and high transport selectivity toward lithium ion. Decalino-14-crown-4 was reported to exhibit 1:1 stoichiometry on complexation with lithium and sodium ions, while benzo-14crown-4 gave 1:1 complex with lithium ion and 2.1 complexes with sodium ion. An electrode based on decalino-14-crown-4 was reported to show the highest $\mathrm{Li}^{+} / \mathrm{Na}^{+}$selectivity. All in all tetradecyldecalino-14-crown-4 was found to be the most practically valuable ionophore for lithium ion-selective electrode [126]. In 1988 X. Y. Zhou et al, reported crown ether as a selective ionophore for the construction of sodium selective electrodes [127].

K. Suzuki et al reported the synthesis of six kinds of lipopholic 16-crown-5 derivatives possessing double side-chains. The $\mathrm{Na}^{+}$-selectivities were examined with poly(vinyl chloride) (PVC) matrixmembrane electrodes using these crown compounds. It was reported to be an effective way for obtaining high Na-selectivity by introducing a bulky side-chain such as a benzyloxymethyl group into the 16-crown-5. The electrodes based on 16-crown-5 derivatives having both a methyl or ethyl group and a benzyloxymethyl group at the pivot carbon (C-15) exhibited excellent $\mathrm{Na}^{+}$-selectivity over $\mathrm{K}^{+}$ $(\log \mathrm{K}(\mathrm{Na}, \mathrm{K})=-2.65$ and -2.75 for 3 and 4 , respectively) [128]. 
One year later Y. Shibata and H. Miagi studied anion interference in response of sodium ionselective electrodes (Na-ISEs) based on a bis (crown ether) compound, by measurements of electromotive force (cmf) of the Na-ISEs and ATR/FT-IR spectra of the membrane surface. Sodium ion-selective membranes consisted of bis[(12-crown-4)methyl] 2-methyl-2-dodecylmalonate [bis(12crown-4)] as a ligand, plasticizer with a variety of dielectric constants and poly(vinyl chloride). It was found that higher dielectric constant of the plasticizer led to smaller Nernstian slopes and a narrower linear range for the Na-ISEs. Lipophilic anions such as SCN affected the emf-response of Na-ISEs based on bis(12-crown-4). In order to eliminate the anion interference, they found it effective to use a platicizer with low dielectric constant and an additive like sodium tetraphenylborate or its derivatives, simultaneously. They reported that the optimum plasticizer and additive were dioetyl adipate (DOA) and sodium tetrakis[3,5 bis(trifluoromethyl)phenyl] horate (NaTFPB), respectively. The optimum concentration of NaTFPB was 5 approximately 20 mol\% for bis(12 crown-4) from the point of high electivity and exclusion of anion interference [129].

In the same year N. G. Lukyanenko et al, investigated the cationic selectivity and electrode characteristics of poly(vinyl chloride) (PVC) membranes based on bis[( $3 n+1)$-crown- $n]$ ethers. The electrodes were reported to exhibit Nernstian responses over the sodium ion activity range of $1 \times 10^{-5}$ $1 \times 10^{-1} \mathrm{M}$ and could be applied over the $\mathrm{pH}$ range $2-10$. The sodium selectivity of the PVC membranes increased with decrease in the biscrown ether ring size. The membrane based on bis(10crown-3)-hexamethylenebis (3,6,10-trioxacycloundecane) had $\mathrm{K}(\mathrm{Na}, \mathrm{K})$ pot $=6.15 \times 10^{-3}$ and the detection limit for sodium cations is $(6 \pm 0.5) \times 10^{-6} \mathrm{M}[130]$.

In 1996, K. Kimura studied the effects of alpha-substituents on sodium-ion selectivities of bis(12crown-4-methyl) malonates, which were highly selective for sodium ions. They did this by incorporating various substituents with high lipophilicities, bulkinesses, polarities and back strains. The incorporation of geminal substituents such as long alkyl chains and benzyl groups into the alphaposition of the malonate was found to generally enhance the $\mathrm{Na}^{+}$selectivity, especially against $\mathrm{K}^{+}$, of the bis(12-crown-4) derivatives. The alpha, alpha-dibenzylmalonate derivative gave the best $\mathrm{Na}^{+}$ selectivity of all the bis(crown ether)s designed here [131].

In $2001 \mathrm{~K}$. Kimura et al, modified pH electrode glass membranes by a sol-gel method using a quaternary ammonium salt and a bis(crown ether) (Figure 30), to obtain glass membrane electrodes selective for anions and metal ions.

A chloride ion sensing glass membrane was designed, in which a $\mathrm{pH}$ electrode glass membrane was modified chemically by an alkoxysilyl quaternary ammonium chloride. X-ray photoelectron spectroscopy confirmed the chemical bonding of the quaternary ammonium moiety to the starting glass surface, which afforded the first example of glass-based "anion"-sensing membranes. A neutral carrier-type sodium ion-selective glass membrane was also fabricated which encapsulates a bis(12crown-4) derivative in its sol-gel-derived surface. Both sol-gel-modified anion and metal ion-selective glass electrodes exhibited high sensitivity to their ion activity changes [132]. 

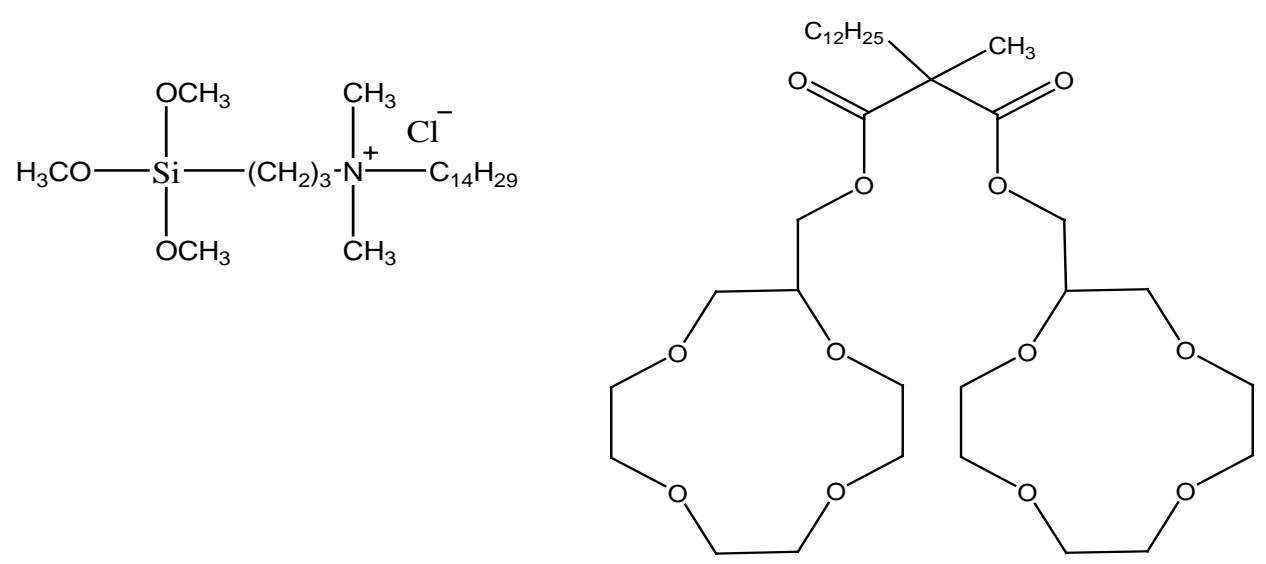

Figure 30. Quaternary ammonium salt and bis(crown ether) used to modify glass membranes for $\mathrm{pH}$ electrodes.

Moriuchi-Kawakami et al performed a conformational analysis on two crown ethers (12-crown-3 and 12-crown-4) using a combination of semi-empirical and ab initio methods. The lowest conformations of 12-crown-3 and 12-crown-4 were found to have exodentate C-3 upsilon and C-2 structure, respectively. In the case of the sandwich-type complexation, the nucleophilic cavity of 12crown-3 rather than that of 12-crown-4 seemed to be optimal for complexation with the $\mathrm{Na}^{+}$ion. Four new bis(12-crown-3) derivatives were examined as potential sodium ion-selective ionophores in poly(vinylchloride) (PVC) membrane electrodes. The ion-selective electrode (ISE) based on di(1,5,9trioxacyclododecanylmethyl) 2-dodecyl-2-methylmalonate had the highest selectivity for the sodium ion among the alkali and alkaline earths studied. The sodium ion selectivity of the ISE based on bis(12-crown-3) derivative was superior to that of the ISE based on the bis(12-crown-4) analogue [133].

N. Tavakkoli prepared a sodium ion-selective electrode based on dibenzopyridino-18-crown-6 (Figure 31) as membrane carrier in 2004.

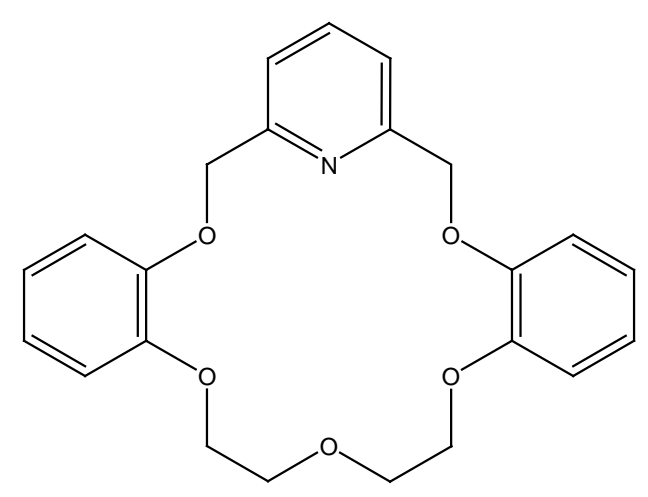

Figure 31. Dibenzopyridino-18-crown-6.

The electrode exhibited a Nernstian response for $\mathrm{Na}^{+}$ions within the concentration range of $1.0 \times$ $10^{-4}-1.0 \times 10^{-1} \mathrm{M}$. The response time of the sensor was $20 \mathrm{~s}$. The sodium ion-selective electrode 
exhibited comparatively good selectivities with respect to alkali, alkaline earth and some transition metal ions [134].

J. P. Willis reported the clinical evaluation of bis crown ether based potassium ion-selective electrodes in 1983 [135]. T. Ogata et al reported the determination of sodium and potassium in biological fluids by ion selective electrodes based on crownether compounds in 1988 [136].

H. Y. An et al, synthesized five bis(benzo-15-crown-5) derivatives connected with different bridge chains, as neutral carriers in $\mathrm{K}^{+}$-selective electrodes. Potassium ion-selective PVC membrane electrodes based on these bis(crown ether)s were prepared using dibutyl phthalate (DBP) and dioctyl phthalate (DOP) as plasticizers of the PVC membrane. The selectivity coefficients $\left(\mathrm{K}\left(\mathrm{Mn}^{+}\right) / \mathrm{K}\left(\mathrm{K}^{+}\right)\right.$) for various alkali and alkaline-earth metal ions were measured. The electrodes based on the bis(crown ether)s were reported to be more selective for $\mathrm{K}^{+}$than those based on monomeric crown ethers. The selectivity of one of the prepared potassium selective electrodes was higher than that of the electrode based on valinomycin and three of them were stable over a wide $\mathrm{pH}$ range [137].

In 1991, methods for introducing lipophilic substituents into benzocrown compounds were described by E. Luboch et al. The synthesized compounds were applied in ion-selective electrodes and exhibited high selectivities for potassium, rubidium and cesium ions [138].

N. R. Allen prepared 1,8-anthraquinono-18-crown-6 and 10-[(2,4-dinitrophenyl)azo]-9-hydroxy1,8-anthraceno-18-crown-6 from 1,8-dichloroanthraquinone and used them in the development of ionselective electrodes. The electrodes based on 10-[(2,4-dinitrophenyl)azo]-9-hydroxy-1,8-anthraceno18-crown-6 displayed better selectivity for potassium over sodium and had fewer interferences, in 1992. The differences and similarities between the ionophores, as well as the optimum conditions for the preparation of the electrodes were studied [139].

In 1993, A. G. Li synthesized five new bis(benzo-15-crown-5) derivatives with different connecting groups were synthesized. Potassium ion-selective PVC membrane electrodes based on these bis(crown ether)s were prepared and their selective properties were measured. The results showed that most of the electrodes were stable over a wide $\mathrm{pH}$ range and their selectivity coefficients were better than those of an electrode based on natural valinomycin [140].

In the same year Z. Brzozka et al, used three different conformers of 1,3-diethoxy-p-tertbutylcalix[4]arene crown ethers to study the effect of the ionophore pre-organization on the potentiometric $\mathrm{K}^{+}$-selectivity. Selectivities were measured for chemically modified field effect transistors (CHEMFETs) and membrane ion-selective electrodes (ISEs) by two different methods. The ionophores showed decreasing $\mathrm{K}^{+} / \mathrm{Na}^{+}$selectivities in the order: partial cone $>1$,3-alternate $>$ cone. As a function of time the cone conformer maintained a constant selectivity whereas a continuous decrease of the selectivity values was observed for the other two conformers [141].

Five years later, in 1998 R. E. Gyurcsanyi et al, fabricated potassium-selective potentiometric microelectrodes with a polypyrrole solid internal contact by the application of a potassium-selective bis-crown ether ligand based, plasticized poly(vinyl chloride) (PVC) membrane to the surface of conducting polymer modified $\mathrm{Pt}$, Au or $\mathrm{C}$ micro disk electrodes. The selectivity and sensitivity of the new type of potentiometric potassium microelectrode were found to be comparable with those of the conventional macro ion-selective electrodes and of the micropipet type microelectrodes based on the same ionophore. The ease of preparation and robustness are the main advantages of this new electrode design, which can replace the classical micropipet type microelectrodes in many applications. The 
microelectrodes showed good dynamic characteristics and were used successfully in a wall-jet cell incorporated flow injection analysis system and as a measuring tip in scanning electrochemical microscopy [142].

M. R. Ganjali et al, reported synthetic procedure for the preparation of styrene/4'-vinyl-benzo-24crown-8 copolymer (SPV-B24C8). The resulting copolymer was used as a membrane carrier to construct a $\mathrm{K}^{+}$ion-selective electrode. The electrode exhibited a Nernstian response for $\mathrm{K}^{+}$ions over a wide concentration range. The nature of the plasticizer, the additive, the concentration of internal solutions in the electrodes and the composition of the membrane were investigated. The performance of the electrode in terms of electrode reproducibility, response stability and regeneration was also studied. The selectivity coefficients of the electrode for potential interferents including alkali, alkaline earth, some transition and heavy metal ions were found to be in the order of $10^{-3}$ or less [143].

Z. R. Xia et al reported the design and synthesis of a new bis(crown ether) ionophore containing two benzo-15-crown-5 moieties connected with each other via a conformationally constrained bridge attached to a C-18-lipophilic side chain (Figure 32). The bridge consisted of an isophthalic acid derivative, which was selected in order to enhance potassium over sodium binding.

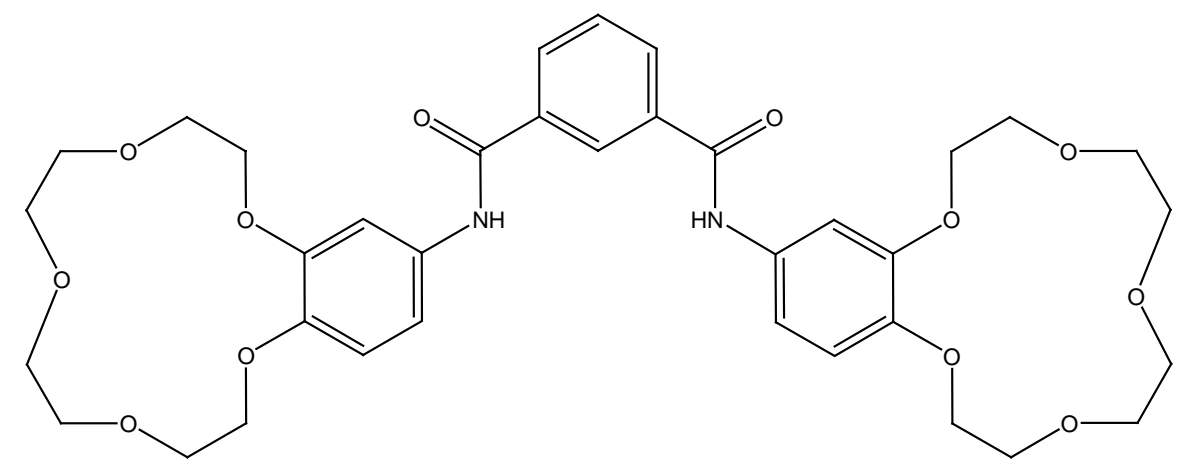

Figure 32. Bis(crown ether) ionophore, $\mathrm{R}=\mathrm{CO}\left(\mathrm{CH}_{2}\right)_{16} \mathrm{CH}_{3}$.

Liquid-polymeric membrane ion-selective electrodes (ISEs) based on this ionophore were prepared using different plasticizers and mole ratios of lipophilic ionic additives. Membrane electrodes with optimum composition (using o-nitrophenyloctyl ether or bis(1-butylpentyl)adipate as plasticizer and 60 mol\% lipophilic berate additive) showed Nernstian responses toward potassium (57 and 58 $\mathrm{mV} /$ decade, respectively) over a wide concentration range with a micro-molar detection limit. These ISEs exhibited enhanced potassium over sodium selectivity $\left(\mathrm{K} \mathrm{K} \mathrm{K}^{+}, \mathrm{Na}^{+}(\mathrm{pot})=6 \times 10^{-4}\right)$. In addition, the electrodes showed selectivities for potassium over $\mathrm{Cs}^{+}$and $\mathrm{NH}_{4}{ }^{+}$that were better than those of valinomycin-based ISEs [144].

Y. H. Cho et al, had a report on a series of bis(crown ether)s based-upon a xanthene-4,5dicarboxylic acid skeleton. The ionophoric properties of the compounds toward alkali metal cations were investigated. Bis(crown ether)s bearing 15-crown-5 and 18-crown-6 moieties exhibited pronounced extraction efficiencies toward $\mathrm{K}^{+}$and $\mathrm{Cs}^{+}$ions, respectively, and the extraction constant estimated by solvent extraction studies was as high as 109 for the $\mathrm{K}^{+}$and $\mathrm{Cs}^{+}$systems. Using UV titration of potassium picrate with 2 in THF, the complex was found to have a structure of a completely encapsulated guest in the host. In transport experiments, the bis(crown ether)s showed no significant selectivity pattern compared with extraction results, again implying the strong 
complexation of bis(crown ether)s. Ion-selective electrode studies also demonstrated that the selective ionophoric properties toward $\mathrm{K}^{+}$were reminiscent of the natural antibiotic valinomycin except for a somewhat slow response [145].

In 1999 Y. Yanagi et al, reported high-performance $\mathrm{Na}^{+}, \mathrm{K}^{+}$and $\mathrm{Cl}^{-}$ion selective electrodes (ISEs). The sensors were based on a new concept, which was an ion recognition site formed by molecular interaction. In the case of $\mathrm{Na}^{+}$and $\mathrm{K}^{+}$ISEs, crown ether compounds connecting with planar substituents were used as the ionophores. The selectivities depended on the structure of substituents. It was found that the intermolecular interact-ion of the planar substituent plays an important role on the improvement of selectivity. The selectivities of interactive mono(crown ether) were equal to that of bis(crown ether). It meant that ion recognition site like a bis (crown ether) was formed by the interaction of mono(crown ehter)s. In the case of $\mathrm{Cl}^{-}$ISE, immobilized synthetic bilayer membrane with quaternary ammonium salts was used as the ion sensitive membrane. In the immobilized synthetic bilayer membrane, ordered molecular aggregates was formed. It was found that the molecular orientation improved the $\mathrm{Cl}^{-}$selectivity; the insufficient selectivity over lipophilic anions could be controlled by addition of aliphatic alcohol. These resulting ISEs exhibited high-speed response and long lifetime, and they were applicable to clinical use, which demands both accurate measurement and high speed processing [146].

In 2000, methacrylic-acrylic copolymers that could be externally or internally plasticized were used to fabricate potassium ion-selective electrodes (ISE) with crown ethers as the potassium selective ionophores, by L. Y. Heng and E. A. H. Hall. Copolymers, which require external plasticizer have higher methacrylate content and glass transition temperatures (T-g) of approximately +30 degrees $\mathrm{C}$ whereas the internally plasticized (self-plasticized) copolymer is high in acrylate with T-g approximate to 27 degrees C. Nonlipophilic crown ethers such as benzo-15-crown-5 and benzo-18-crown-6 could be included in the plasticized copolymers and yielded functional ISEs. However as with the plasticized PVC membranes these crown ethers tend to show some leaching which reduced the ISE lifetime; they were also incompatible with the self-plasticized copolymer, forming opaque membranes and electrodes of no potassium selectivity. In contrast, lipophilic crown ethers such as bis- or mononitrobenzo-15-crown-5 were found to be compatible with the self-plasticized copolymers yielding ISEs with good potassium ion selectivity, closely resembling plasticized PVC membrane based electrodes even though these new membranes contained two added plasticizer [147]. The same group reported one-step synthesis of $\mathrm{K}^{+}$-selective methacrylic-acrylic copolymers (Figure 33) containing grafted ionophore and requiring no plasticizer in the same year [148]. 

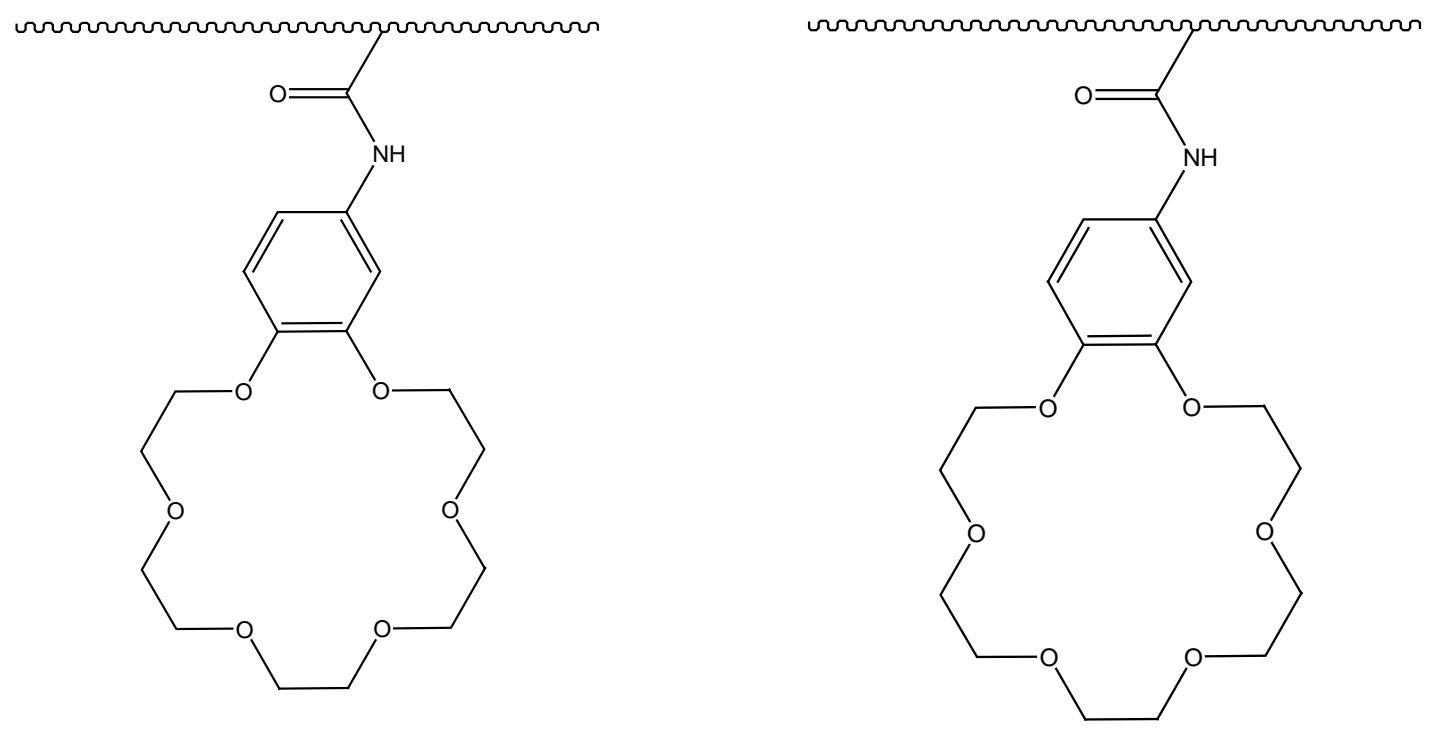

Figure 33. Methacrylic-acrylic copolymers.

They mentioned that a main drawback in the application of ion sensors that are based on plasticized polymeric membranes was the problem of leaching of plasticizer and ionophore. They also mentioned that leaching problems could be critical in solid-state mini-devices e.g. ion-selective electrodes or optodes, where a thin ion sensing polymer film is often employed. To resolve such problems, they claimed to have designed simple methacrylic-acrylic copolymers that required no plasticizer and which include immobilized polymerizable but hydrophylic ionophores such as 4-acryloylamidobenzo15-crown-5 (AAB15C5) and 4-acryloylamidobenzo-18-crown-6 (AAB18C6) that would normally be susceptible to leaching from plasticized PVC membranes, were used as model ionophores for the immobilization studies. The crown compounds were attractive since they could be employed as a monomeric unit in the copolymer recipe and thus no additional synthesis or polymer modification is required. In their work, copolymers suitable for ion-selective membrane application were synthesized by introducing more than $80 \mathrm{wt} \%$ of n-butyl acrylate to yield copolymers of T-g's between -20 to -30 degrees $\mathrm{C}$. The molecular weight distributions of the copolymers were $\mathrm{M}-\mathrm{w}<50000 \mathrm{Da}$ and they contained 2 to $6 \mathrm{wt} \%$ of immobilized crown ether ionophores. The "self-plasticising" methacrylicacrylic membranes formed with these acryloyl crown ethers demonstrated good potentiometric responses to potassium ion. In contrast, AAB15C5 and AAB18C6 entrapped in membranes in a more classical ion selective membrane recipe, even when a plasticizer was included were still inferior in their response to those with membranes containing immobilized ionophores. The restricted mobility of the immobilized ionophores in these self-plasticizing polymer matrices did not appear to hinder the normal complexation behavior of these ionophores. This was inferred from the possible formation of the usual 2:1 and 1:1 ionophore-cation complexes of AAB15C5 and AAB18C6, respectively, in these new copolymer matrices.

K. Kimura et al, reported the design of sol-gel-derived membranes were designed which encapsulate valinomycin and bis(crown ether) derivatives as the neutral carriers, for neutral carriertype ion-selective electrodes. Relatively large size ion-sensing membranes based on sol-gel-derived glass were successfully fabricated by using membrane filters and sintered glass filters as the membrane supports. Potassium and sodium ion-selective electrodes, at the tip of which sol-gel-derived 
membranes containing a neutral carrier and a poly(tetrafluoroethylene) membrane filter were incorporated, exhibited high electrode performance in their sensitivity, selectivity, and response time. The supported sol-gel-derived membranes were also modified chemically by alkoxysilylated bis(crown ether) derivatives and were tested for their usefulness as sensing membranes of ion-selective electrodes [149].

In 2005, R. Bereczki et al had a paper on the synthesis of a novel covalently immobilized crown ether based potassium ionophore (Figure 34).

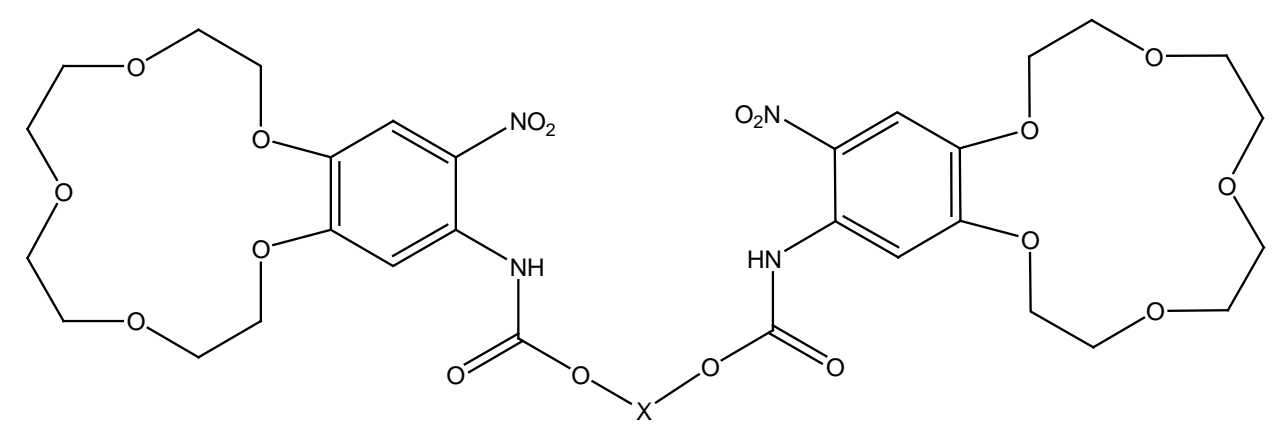

Figure 34. Covalently immobilized crown ether.

They claimed that apart from previously proposed methods for the preparation of PVC linked ionophores based on the chemical modification of functionalized PVC polymers. The proposed procedure involved the direct copolymerization of a suitable derivative of the bis-crown ether type potassium ionophore (BME 44) and vinyl chloride monomer. The analytical performance of the potentiometric ion selective electrodes incorporating the PVC bound ionophore were optimized and determined. Compared with electrodes based on other bis-crown ether type immobilized potassium selective ionophores a slightly improved $\log \mathrm{K}\left(\mathrm{K}^{+}, \mathrm{Na}^{+}\right)$(pot) and a longer lifetime was found. Spectral imaging and chronoamperometry were used to study the mobility of different bis-crown ether derivatives in plasticized PVC membranes [150].

H. Sugihara and K Hiratani (1996) reported the synthesis of a number of 1,10-phenanthroline derivatives such as 2,9-dialkyl phenanthroline derivatives, biscrown derivatives which include crown ether moieties via amide groups at different positions [151], and oligomethylene bridged phenanthrolines which worked as ionophores. Their properties not only as sensing agents for ionselective electrodes (ISEs) and fluorometry, but also as agents for selective ion transport were investigated. It was found that 2,9-dibutyl-1,10-phenanthroline is an excellent $\mathrm{Li}^{+}$-sensing agent for both ISEs and fluorometry. 1,6-Bis(9-butyl-1,10-phenanthrolin-2-yl) which is one of the bridged bisphenanthrolines, exhibited high selectivity toward $\mathrm{Li}^{+}$among alkali and alkaline earth metal ions in a liquid membrane system. The phenanthroline derivative with bis(benzo-15-crown-5) moieties functions as a highly selective $\mathrm{K}^{+}$carrier. The relationship between their structure and functions is also discussed.

In 2004 M. H. Hyun et al, reported the synthesis of binaphthyl-based crown ethers incorporating anthraquinone, benzoquinone, and 1,4-dimethoxybezene (Figure 35). 


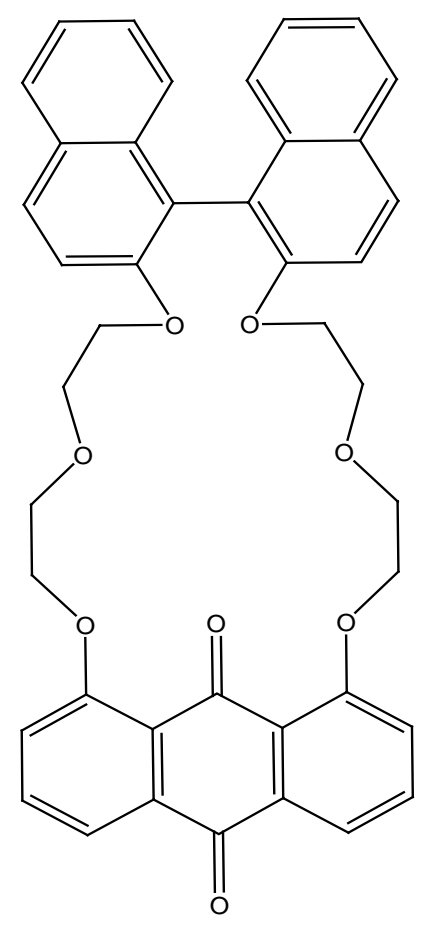

A

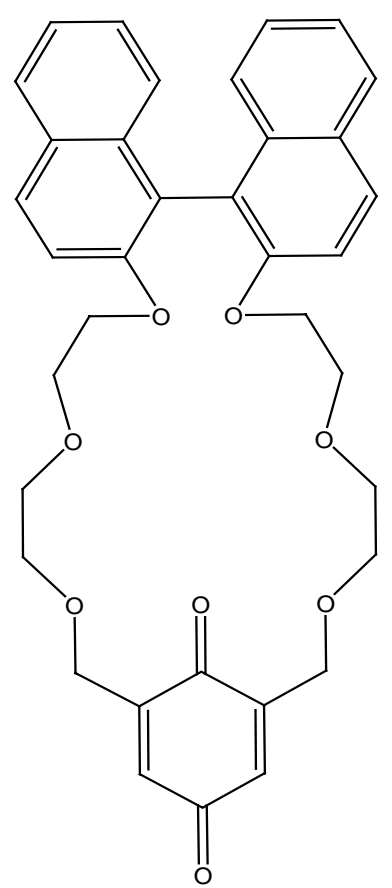

B

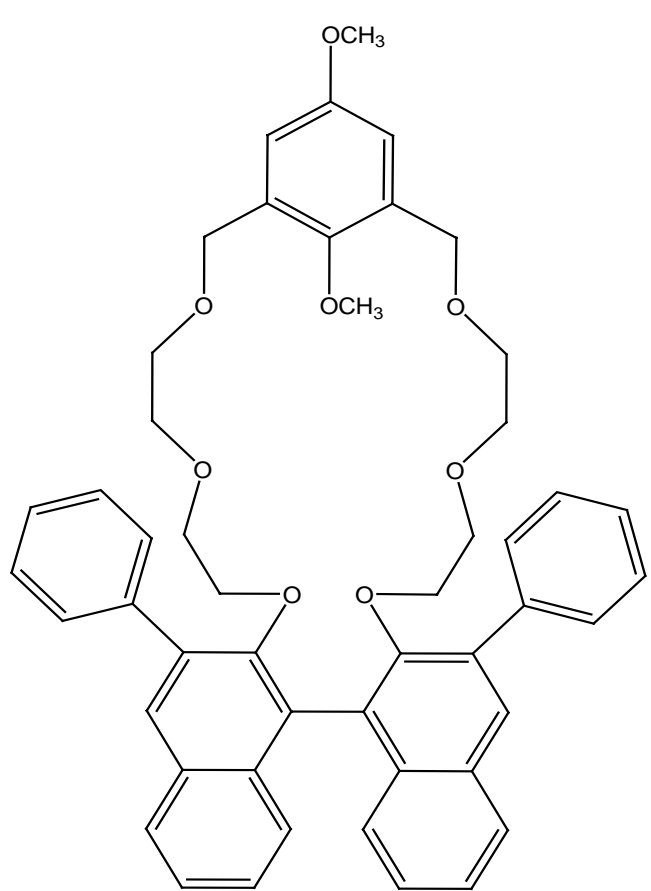

C

Figure 35. (1,1'-binaphtyl)-23-crown-6 incorporating 9,10-anthraquinon (A), (1,1'-binaphtyl)-23crown-6 incorporating 1,4-benzoquinon (B), (3,3'-diphenyl-1,1'-binaphtyl)-23-crown-6 incorporating 1,4-dimethoxybenzen (C).

The mentioned compounds were tested as $\mathrm{Rb}^{+}$selective ionophores in a poly(vinyl chloride) (PVC) membrane. The membrane containing NPOE gave a better $\mathrm{Rb}^{+}$selectivity than those containing either DOA or BPPA as a plasticizer. The response was linear within the concentration range of $1.0 \times 10^{-5}$ $1.0 \times 10^{-1} \mathrm{M}$ and the slope was $54.7 \pm 0.5 \mathrm{mV} /$ dec. The detection limit was determined to be $9.0 \times 10^{-6}$ $\mathrm{M}$ and the optimum $\mathrm{pH}$ range of the membrane was 6.0-9.0. The ISE membrane exhibited good selectivity for $\mathrm{Rb}^{+}$over ammonium, alkali metal, and alkaline earth metal ions. Selectivity coefficients for the other metal ions, $\log \mathrm{K}(\mathrm{Pot})$ were -2.5 for $\mathrm{Li}^{+}$, - 2.4 for $\mathrm{Na}^{+}$, - 2.0 for $\mathrm{H}^{+}$, - 1.0 for $\mathrm{K}^{+}$, - 1.2 for $\mathrm{Cs}^{+}$, - 1.6 for $\mathrm{NH}_{4}^{+},-4.5$ for $\mathrm{Mg}^{2+}-5.0$ for $\mathrm{Ca}^{2+},-4.9$ for $\mathrm{Ba}^{2+}$. The lifetime of the membrane was reported to be about one month [152].

In 1999, J. S. Kim reported the preparation of four calix[4]arene dibenzocrown ether compounds and their evaluation as $\mathrm{Cs}^{+}$-selective ligands in solvent polymeric membrane electrodes. The ionophores include 25,27-bis(1-propyloxy)calix[4]arene dibenzocrown-6, 25,27-bis(1alkyloxy)calix[4]arene dibenzocrown-7s and, and 25,27-bis(1-propyloxy)calix[4]arene dibenzocrown8 . For an ion-selective electrode (ISE) based on 25,27-bis(1-propyloxy)calix[4]arene dibenzocrown-6,

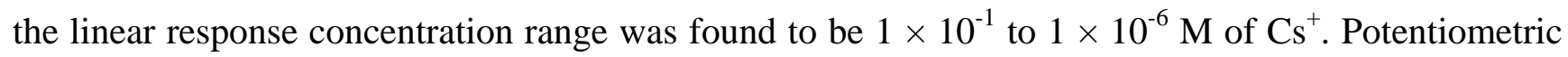
selectivities of ISEs based on the ionophores for $\mathrm{Cs}^{+}$over other alkali metal cations, alkaline earth metal cations, and $\mathrm{NH}_{4}{ }^{+}$were assessed. For 25,27-bis(1-propyloxy)calix[4]arene dibenzocrown-6-ISE, a remarkably high $\mathrm{Cs}^{+} / \mathrm{Na}^{+}$selectivity was observed, the selectivity coefficient (K-Cs,Na(Pot)) being ca. $10^{-5}$. As the size of crown ether ring was enlarged from crown-6 to crown-7, to crown-8 (4), the $\mathrm{Cs}^{+}$selectivity over other alkali metal cations, such as $\mathrm{Na}^{+}$and $\mathrm{K}^{+}$, was reduced successively [153] 
In 2002, R. K. Mahjan et al, studied the potentiometric response characteristics of cesium ion selective PVC membrane electrode employing calix[4]crown ether-ester as an ionophore. The electrode exhibited a good response for cesium ion over wide concentration range of $5.0 \times 10^{-6}-1.0 \times$ $10^{-1} \mathrm{M}$ with a Nernstian slope of $59 \mathrm{mV}$ per decade. The detection limit of electrode was reported to be $5.0 \times 10^{-6} \mathrm{M}$. The electrode was found to have selectivity for cesium ion over alkali, alkaline and transition metals. The response time of the electrode was less than $20 \mathrm{~s}$ and it could be used for more than 4 months without observing any divergence in potentiometric response [154].

H. C. Sheu and J. S. Shih reported an organic ammonium(I) ion selective PVC membrane electrodes based on crown ether-phosphotungstic acid (PW) precipitates, e.g. 18-crown-6-PW, dibenzo-18-crown-6-PW, 15-crown-5-PW, monobenzo-15-crown-5-PW and 12-crown-4-PW, as neutral carriers, in 1996. Among the crown ether electrodes, the electrodes based on 18-crown-6-PW gave the best performance and exhibited good linear responses with near-Nernstian slopes (ca. 55-63 $\mathrm{mV}$ decade ${ }^{-1}$ ) for organic ammonium ions, e.g. $\mathrm{BuNH}_{3}{ }^{+}, \mathrm{C}_{6} \mathrm{H}_{5} \mathrm{CH}_{2} \mathrm{NH}_{3}{ }^{+}, \mathrm{Et}_{2} \mathrm{NH}^{2+}$ and $\mathrm{Et}_{3} \mathrm{NH}^{+}$, within the concentration range $10^{-1}-10^{-5} \mathrm{M}$. The electrodes based on 18-crown-6-PW exhibited good selectivity for organic ammonium ions relative to ammonium ion $\left(\mathrm{NH}_{4}{ }^{+}\right)$; alkali, alkaline earth and some transition metal ions. The electrode performance also depends on the $\mathrm{pH}$ of the test solution and the optimum pH range was about ca. 2-6 [155].

Two years later N. V. Shvedene et al, studied open chain polyethers with phosphoryl-containing terminal groups as carriers in plasticized membrane electrodes that were selective towards cationic surfactants. Host-guest complexation was also studied by means of batch extraction and bulk membrane transport experiments. For the various guests, the bulk membrane (chloroform) transport rate decreased in the series tetraalkyl ammonium > alkyl pyridinium > alkyl ammonium, while the series of solvent extraction efficiency was exactly opposite; an explanation for this behaviour was proposed. The performance of electrode membranes followed the series for bulk membrane transport. Among the ISE membranes of various compositions, one containing the longest (seven oxygen atoms) podand, o-nitrophenyl octyl ether (plasticizer), and sodium tetraphenyl berate (anionic additive) performed the best. The slope of the electrode function equaled $58.5 \mathrm{mV} /$ decade, the detection limit for dodecyltrimethylammonium was reported to be $3.2 \times 10^{-6} \mathrm{M}$. ISE response time was found to be 5$10 \mathrm{~s}$, the working $\mathrm{pH}$ range was 2-11 and lifetime was at least 6 months. The electrode selectivity was reported to be significantly better than that of conventional ion-association and crown ether based electrodes [156].

In the same year T. Moriuchi-Kawakami, reported that the pyrazole-containing 18-membered crown ether, which possesses a less-bulky substituent on the $\mathrm{sp}^{3}$ nitrogens and not only the $\mathrm{sp}^{3}$ nitrogen, but also the carbonyl groups as ligating points, exhibited excellent ability as an ionophore for a $\mathrm{NH}_{4}{ }^{+}$-selective electrode. The value of the selectivity coefficient of an ion-selective electrode (ISE) containing 1 for the $\mathrm{NH}_{4}{ }^{+}$ion with respect to an interfering $\mathrm{K}^{+}$ion was $6.3 \times 10^{-2}$. This result was claimed to be superior to that of LSE based on an antibiotic substance, nonactin $1.2 \times 10^{-1}$ [157].

In 2004 H. S. Kim et al, reported a short and efficient synthesis, solvent extraction and potentiometric measurements of new thiazole-containing naphtho-crown ethers (Figure 36). 

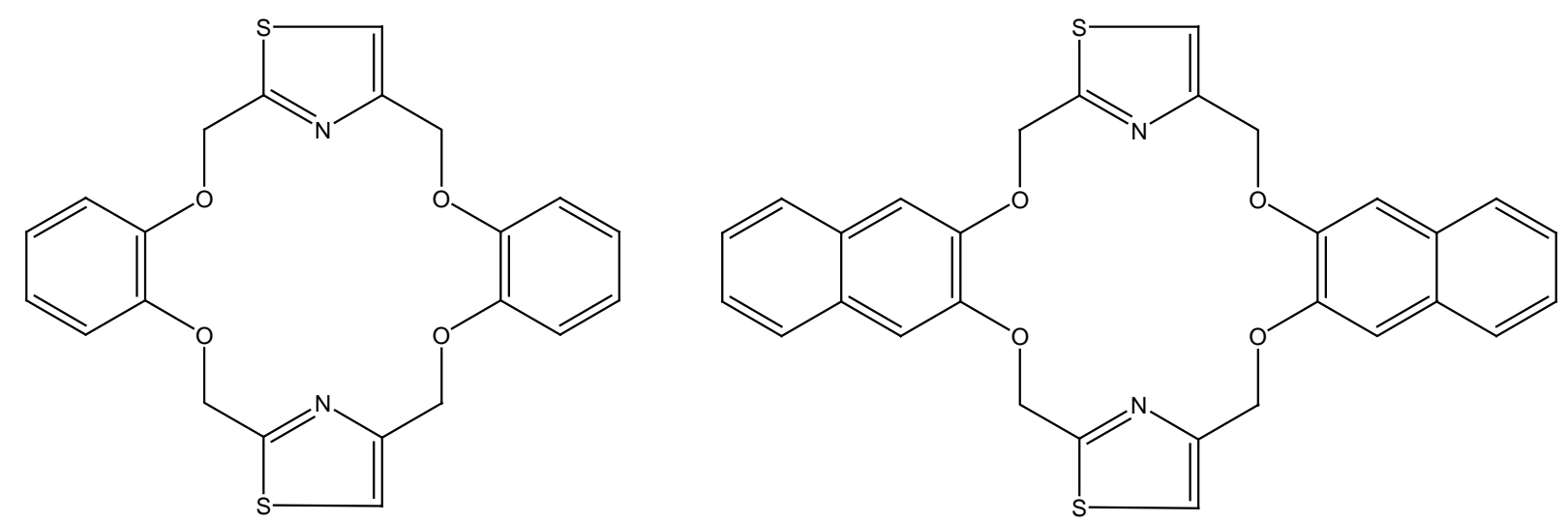

Figure 36. Thiazole-containing naphtho-crown ethers.

The naphthalene moiety enhanced the ammonium ion selectivity over potassium ion. The selectivity of $\mathrm{NH}_{4}{ }^{+} / \mathrm{K}^{+}$followed the trend 3 approximate to $2>1$, indicating that the differences in conformational changes of 2 and 3 in forming ammonium complexes affect little on the resulting ammonium/ potassium extraction selectivity ratio. The ammonium ion-selective electrodes were prepared with octylphenyl ether plasticized poly(vinyl chloride) membranes containing the ionophores. The effect of one naphthalene unit introduced on either right or left side of thiazolo-crown ether on their potentiometric properties (e.g., ammonium ion selectivity over other cations, response slopes, and detection limits) were not apparent. However, the ammonium ion selectivity of the ionophores over other alkali metal and alkaline earth metal cations was reported to be 10-100 times higher than that of nonactin [158].

In 1998 M. R. Ganjali et al reported the preparation of a PVC membrane electrode for beryllium(II) ions based on benzo-9-crown-3 as membrane carrier. The sensor exhibited a Nernstian response for $\mathrm{Be}^{2+}$ ions over a wide concentration range $\left(4.0 \times 10^{-3-2.5} \times 10^{-6} \mathrm{M}\right)$ with a limit of detection of $1.0 \times 10^{-}$ ${ }^{6} \mathrm{M}\left(9.0 \times 10^{-3} \mathrm{ppm}\right)$. It had a response time of similar to $50 \mathrm{~s}$ and can be used for at least 4 months without any divergence in potential. The proposed electrode revealed very good selectivities for $\mathrm{Be}^{2+}$ over a wide variety of other cations including alkali, alkaline earth, transition, and heavy metal ions and could be used in a pH range of 2.0-6.0 [159]. Four years later the same group reported a novel potentiometric membrane electrode based on 2,4-di-nitrophenylhydrazine-benzo-9-crown-3 (NPHCE) for selective and sensitive monitoring of beryllium ion. The best performance was obtained by incorporating of 9\%NPHCE, 58\%NPOE, 30\%PVC and 3\%NaTPB in the PVC membrane. The sensor displayed a nice Nernstian slope of $29.8 \pm 0.5 \mathrm{mV}$ per decade in a wide concentration range from $1.0 \times$ $10^{-1}$ to $1.0 \times 10^{-6} \mathrm{M}$. The detection limit of the sensor was reported to be $5.0 \times 10^{-7} \mathrm{M}$ and to operate in the $\mathrm{pH}$ range of 3.0-9.0. The sensor could be used for a long time ( $>20$ weeks) without any measurable change in slope. The selectivity of the electrode was checked and it was found that the selectivity of the sensor is high enough to permit the detection of as little as $4.5 \mathrm{mug} / \mathrm{l}$ of $\mathrm{Be}(\mathrm{II})$ without any interference from high levels of other cations [45]. The same group had a report on a novel poly(vinyl chloride) (PVC) membrane electrode based on naphto-9-crown-3 and its application for the selective detection of beryllium ions. A suitable lipophilicity of the carrier and appropriate coordination ability were found to be essential for designing an electrode with good response characteristics. A PVC membrane with 9\% naphtho-9-crown-3 carrier, 58\% o-NPOE plasticizer, 3\% tetraphenylborate anionic excluder and 30\% poly(vinyl chloride) satisfied these requirements. The proposed sensor 
displayed a linear response to beryllium over a wide concentration range of $1.0 \times 10^{-1}-8.0 \times 10^{-6} \mathrm{M}$ with a Nemstian slope of $29.5 \mathrm{mV}$ per decade. The electrode showed very short response time $(<15 \mathrm{~s})$ and could be used in the $\mathrm{pH}$ range 3.5 - 9.0. The selectivity coefficient for alkali, alkaline earth, transition and heavy metal ions was smaller than $4.0 \times 10^{-4}$ [160].

In 2003, M. R. Ganjali et al had another report on a highly sensitive and selective membrane electrode with 9-crown-3 derivative (CD) (Figure 37) as ionophore, potassium tetrakis-(pchlorophenyl) borate as anionic additive (KTB), acetophenone $(\mathrm{A}(\mathrm{P})$ ) as solvent mediator was prepared and investigated as a Be(II) sensor.

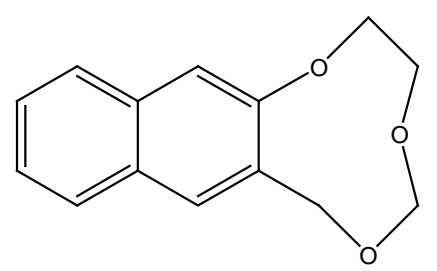

Figure 37. Naphto-9-crown-3.

The best performance was observed with the membrane having the percent ratio 30\% PVC: $8 \%$ CD: 6\% KTB: 56\% Acetophenone. The poly(vinyl chloride) PVC membrane containing 9-crown-3 derivative directly coated on a graphite electrode, showed a Nernstian response for Be(II) ions over a very wide concentration range $\left(1.0 \times 10^{-1}-1.0 \times 10^{-7} \mathrm{M}\right.$ ) with a detection limit Of $8.0 \times 10^{-8} \mathrm{M}$ (ca. $0.72 \mathrm{ng} / \mathrm{mL}$ ). It was reported to have a fast response time of ca. $20 \mathrm{~s}$ and could be used for at least 10 weeks without any major deviation in potential. The proposed sensor exhibited very good selectivity with respect to common alkali, alkaline earth, transition and heavy metal ions [161].

2,6-diphenyl-4-benzo-9-crown-3-pyridine (DPCP) was used by the same group in 2004, as an excellent ionophore in construction of a coated graphite poly(vinyl chloride) (PVC)-based membrane sensor [162]. The best performance was obtained with a membrane composition of 30\% poly(vinyl chloride), 60\% o-nitrophenyloctyl ether (NPOE), 5\% 2,6-diphenyl-4-benzo-9-crown-3-pyridine and $5 \%$ sodium tetraphenyl borate TBP). This sensor showed very good selectivity and sensitivity towards beryllium ion over a wide variety of cations, including alkali, alkaline earth, transition and heavy metal ions. The sensor revealed a great enhancement in selectivity coefficients and sensitivity for beryllium, in comparison with the previously reported beryllium electrodes. The electrode exhibited a Nernstian behavior (with slope of $29.6 \mathrm{mV}$ per decade) over a very wide concentration range $(1.0 \times$ $10^{-7}$ to $\left.1.0 \times 10^{-1}\right)$ With a detection limit of $4.0 \times 10^{-8} \mathrm{M}\left(360 \mathrm{pg} \mathrm{ml}^{-1}\right)$ [163].

In 2003, Ganjali et al, published a paper on the potential response of a strontium(II) ion selective electrode based on dibenzo-30-crown-10 (DBCE) as ion-carrier. They evaluated this by varying the amount of ionophore, plasticizer, and anionic additive. The sensitivity, working range, response time, and metal ions interference showed a significant dependence on the amount of ionophore, kind and amount of additive, and solvent mediator. The electrode prepared with 5\% ionophore, 55\% benzyl acetate, $10 \%$ oleic acid, and 30\% PVC showed a Nernstian slope of $29.20 \mathrm{mV}$ per decade to activities of $\mathrm{Sr}^{2+}$ ions with a short response time of $10 \mathrm{~s}$. The sensor revealed an appreciable selectivity for $\mathrm{Sr}^{2+}$ ions in the presence of alkali, alkaline earth, transition, and heavy metal ions and could be used in a $\mathrm{pH}$ range of 3.0-10.0. The wrap around complex of DBCE with $\mathrm{Sr}^{2+}$ contributed significantly to enhance the selectivity of the electrode [164]. 
In 2005, H. Aghaie et al, published a paper on a PVC membrane Sn(II)-ion-selective electrode that was constructed using dibenzo-18-crown-6(DB18C6) as membrane carrier. The sensor was reported to show a near Nernstian response for Sn(II) ions over a concentration range from $1.0 \times 10^{-6}$ to $1.0 \times 10^{-2}$ $\mathrm{M}$ with a slope of $27.5 \mathrm{mV}$ per concentration decade in an acidic solution $(\mathrm{pH}=1)$. The limit of detection was $8.0 \times 10^{-7} \mathrm{M}$. It had response time of $15 \mathrm{~s}$ and could used for at least 3 months without any divergence in potentials. The proposed membrane electrode revealed very good selectivity for $\mathrm{Sn}$ (II) ions over a wide variety of other cations and could be used in acidic media. The isothermal temperature coefficient of the electrode amounted to $0.0012 \mathrm{~V} / \mathrm{C}$. The stability constant $\left(\log \mathrm{K}_{\mathrm{s}}\right)$ of the $\mathrm{Sn}(\mathrm{II})-\mathrm{DB} 18 \mathrm{C} 6$ complex was determined at $25 \mathrm{C}$ by potentiometric titration in mixed aqueous solution [165].

A. S. Attiyat et al, reported the preparation of ion-selective microelectrodes prepared by coating a matrix containing the crown ether benzo-18-crown-6 or one of five polyether ring-substituted benzo18-crown-6 derivatives on a preconditioned silver wire in a flow cell, in 1992. Responses of the electrodes toward lithium, sodium, potassium, magnesium, calcium, strontium, and lead were measured. Selectivity coefficients were obtained by the matched potential, fixed interference, and separate solution methods. Compared with benzo-18-crown-6, the nature of the side arm in the lariat ether derivatives was found to influence the selectivities in different ways. For specific ionophores, high selectivities of potassium over lithium, sodium, magnesium, calcium, and strontium, of strontium over magnesium and calcium, and of lead over magnesium, calcium, and strontium were demonstrated [166].

S. R. Sheen and J. S. Shin, published a paper on the preparation of lead(II) ion-selective poly(vinyl chloride) membrane electrodes based on monobenzo-15-crown-5 (MB15C5), MB15C5phosphotungstic acid (PW) and MB15C5-phosphomolybdic acid (PMo) as neutral carriers. All the crown ether electrodes gave linear responses with Nernstian slopes of $30 \mathrm{mV}$ per decade within the concentration range $10 \times 10^{-1}-1 \times 10^{-5} \mathrm{~mol} \mathrm{dm}^{3} \mathrm{~Pb}^{2+}$. The $\mathrm{Pb}^{2+}$ electrodes based on MB15C5-PW and MB15C5-PMo showed better sensitivities, with detection limits of $1 \times 10^{-6} \mathrm{~mol} \mathrm{dm}^{-3}$, than the electrode based on MB15C5 with a detection limit of $1 \times 10^{-5} \mathrm{~mol} \mathrm{dm}^{-3}$. Selectivity coefficients of various interfering ions for these electrodes were determined and were sufficiently small for most of them. Among these electrodes, the electrode based on pure MB15C5 exhibited the best selectivity. Effects of the $\mathrm{pH}$ of test solutions, the concentrations of internal solutions in the electrodes and the composition of the membranes were also investigated [167].

In 1995, S. K. Srivastava et al, claimed that a poly(vinyl chloride) (PVC)-based membrane of 15crown-5 exhibits a good response for lead(II) ions over a wide concentration range [168]. The response time of the sensor was reported to be $30 \mathrm{~s}$ and the membrane could be used for more than four months without observing any divergence in its potential. The selectivity of the sensor was reported to be comparable with those reported for other such electrodes.

M. F. Mousavi et al reported a PVC membrane lead(II) ion-selective electrode using 1,10-dibenzyl1,10-diaza-18-crown-6 (DBzDA 18C6) as membrane carrier. The sensor showed a Nernstian response for $\mathrm{Pb}(\mathrm{II})$ ions over a wide concentration range of $5.0 \times 10^{-5}$ to $1.0 \times 10^{-2} \mathrm{M}$. The sensor was reported to have a fast response time and the ability to be used for more than 10 months without any considerable divergence in potentials. The proposed sensor exhibited comparatively good selectivities with respect to alkali, alkaline earth and some transition and heavy metal ions [169]. 
In 1998 M. R. Ganjali et al prepared a PVC membrane electrode for lead ions based on 4'vinylbenzo-15-crown-5 homo-polymer as membrane carrier. The electrode was reported to exhibit a Nernstian response for $\mathrm{Pb}^{2+}$ ions over a wide concentration range $\left(4.0 \times 10^{-3}\right.$ to $\left.1.0 \times 10^{-6} \mathrm{M}\right)$, with a limit of detection of $7.0 \times 10^{-7} \mathrm{M}$. It had a response time of $80 \mathrm{~s}$ and could be used for at least 4 months without any considerable divergence in potentials. The proposed membrane electrode revealed very good selectivities for $\mathrm{Pb}^{2+}$ over a wide variety of other cations and could be used in the $\mathrm{pH}$ range 2.0-6.0 [170]. Three years later, the same group reported a PVC-based membrane electrode for lead ions based on hexathia-18-crown-6-tetraone (Figure 38) as membrane carrier.

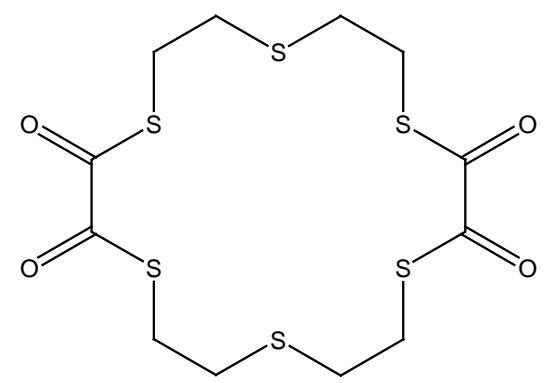

Figure 38. Hexathia-18-crown-6-tetraone.

The influence of membrane composition, $\mathrm{pH}$ of test solution and foreign ions on the electrode performance were investigated. The electrode showed a Nernstian response over a lead concentration range from $1.0 \times 10^{-6}$ to $8.0 \times 10^{-3} \mathrm{M}$ at 25 degrees $\mathrm{C}$, and was found to be very selective, precise and usable within the $\mathrm{pH}$ range 3.0 - 6.0 [171].

A novel selective membrane electrode for determination of ultra-trace amount of lead was prepared by M. R. Ganjali et al, in 2002. The PVC membrane containing N,N'-dimethylcyanodiaza-18-cown-6 $\left(\mathrm{DMCDA}_{18} \mathrm{C}_{6}\right.$ ) directly coated on a graphite electrode, exhibited a Nernstian response for $\mathrm{Pb}^{2+}$ ions over a very wide concentration range (from $1.0 \times 10^{-2}$ to $1.0 \times 10^{-7} \mathrm{M}$ ) with a limit of detection of 7.0 $\times 10^{-8} \mathrm{M}$ (equal to14.5 ppb). It had a fast response time of similar to10 $\mathrm{s}$ and could be used for at least 2 months without any major deviation in potential. The electrode revealed very good selectivity with respect to all common alkali, alkaline earth, transition and heavy metal ions. The proposed sensor was used as an indicator electrode in potentiometric titration of lead ions and in determination of lead in edible oil, human hair and water samples [172].

M. B. Saleh (1999) had a report on a cationic surfactant ion-selective sensor. The ion-selective PVC membrane electrode was based on 2,3,11,12-dibenzo-5,9-diaza-4,9(10)-cis-diimino-1, 13dioxacyclopentadecane as a novel macrocyclic diimine crown ether. O-Nitrophenyl octyl ether and potassium tetrakis(4-chlorophenyl)borate were used as the plasticizer and lipophilic salt. The electrode exhibited a Nernstian response for $1.0 \times 10^{-2}-1.0 \times 10^{-6} \mathrm{~mol} \mathrm{l}^{-1} \mathrm{DPCl}$ with a slope of $58 \mathrm{mVdecade}^{-1}$. The detection limit was $2.5 \times 10^{-7} \mathrm{~mol} \mathrm{l}^{-1}$. The electrode response was stable over a wide $\mathrm{pH}$ range (311). The lifetime of the electrode was about 2 months. The electrode showed a high selectivity towards inorganic cations. Among the organic cations tested, only hexadecyltrimethylammonium ion interfered with the electrode response significantly. The electrode was reported to be suitable for determining the 
critical micelle concentration and as an end-point detector in the potentiometric titration of the cationic surfactants [173].

J. Bobacka et al, in 2002, reported ion-selective electrodes (ISEs) based on pi-coordinating carriers. They investigated the electrodes' ability as potentiometric sensors for aromatic cations, using $\mathrm{N}$ methylpyridinium as a model aromatic cation. Derivatives of tetraphenylborate were studied as charged carriers in plasticized poly(vinyl chloride) membranes. Furthermore, neutral compounds containing pi-coordinating anthryl groups were studied as neutral carriers. Bis(2-ethylhexyl)sebacate (DOS) and 2-nitrophenyl octyl ether (o-NPOE) were used as non-polar and polar plasticizer, respectively. ISEs were constructed by using poly(3,4-ethylenedioxythiophene) (PEDOT) as solidcontact material. Conventional ISEs with internal filling solution were used for comparison. The potentiometric responses of the ISEs were investigated using $\mathrm{N}$-methylpyridinium as primary ion. The results showed that both the plasticizer influences the selectivity of the ISEs significantly and the charged carriers, while the neutral carriers studied have only a minor influence on the selectivity [174].

\subsubsection{Crown Ether Based Transition Group Ion Selective Electrodes}

In 2001 C. C. Su, C. H. Ueng, and L. K. Liu reported an ion-selective electrode using ionophore 2'picolyl sym-dibenzo-16-crown-5 ether (Figure 39) as membrane carrier, sodium tetraphenylborate (NaTPB) as an anion excluder, and 2-nitrophenyl-octyl ether (NOPE) as the plasticising solvent mediator has been successfully developed.

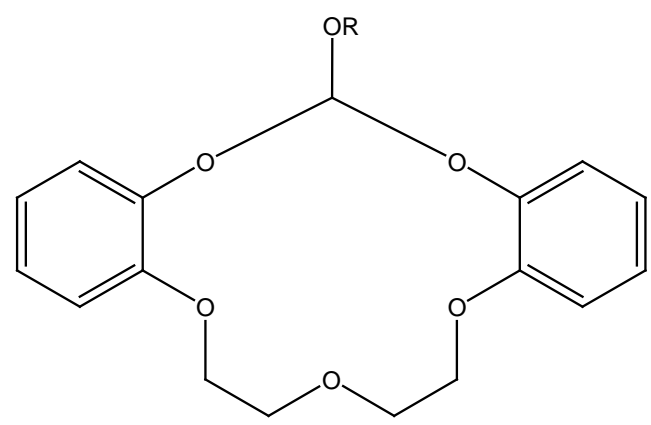

Figure 39. Sym-dibenzo-16-crown-5 ether, $\mathrm{R}=\mathrm{H} \quad$ or

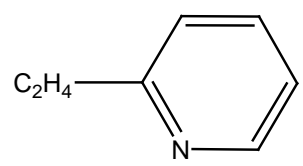

The electrode exhibited a linear response with a slope of $42 \mathrm{mV} /$ decade in concentration range from $10^{-5} \mathrm{M}$ to $10^{-1} \mathrm{M}$, slightly larger than the $30 \mathrm{mV}$ expected from the one-to-one complex. The reason for the super-Nernstian slope was suggested to be the partial dimmer formation inside the membrane of the electrode, that this dimmer $\left[\mathrm{Cu}\left(\mathrm{C}_{25} \mathrm{H}_{27} \mathrm{NO}_{6}\right)_{2}\left(\mathrm{H}_{2} \mathrm{O}\right)_{2}\right]{ }_{2} \mathrm{ClO}_{4}$, was isolated and confirmed by single crystal X-ray crystallography. The detection limit for the copper(II) ion was estimated to be $1 \times 10^{-6} \mathrm{M}$. Electrodes composed of other plasticising solvent mediators such as tris(2-ethylhexyl) phosphate (TOP), his (2-ethylhexyl) sebacate (DOS) and dibutyl phthalate (DBP) were also investigated. Stability constants $\left(\log \mathrm{K}_{\mathrm{s}}\right.$ ) of the two to one and the one to one 2-picolyl sym-dibenzo16-crown-5 ether-Cu (II) complexes were determined by potentiometric titration in methanol [175]. Kuckling D, Pareek P, had a paper on the synthesis of a functionalized cyclam by the attachment of a 
polymerizable acryloyl group to one of the four nitrogens on the cyclam molecule. The polymerization of the functionalized cyclam was performed with $\mathrm{N}$-isopropylacrylamide and $\mathrm{N}, \mathrm{N}$ '-methylene bisacrylamide, and the gels obtained were studied in the presence of different transition-metal-ion solutions. There was a drastic difference in the phase-transition temperature (T-c) of the poly $(\mathrm{N}$ isopropylacrylamide) (PNIPAAm)/cyclam gel in comparison with the pure PNIPAAm gel. For the described system, a T-c shift of $15^{\circ} \mathrm{C}$ was obtained. The presence of functionalized cyclam increased the hydrophilicity and T-c of the aforementioned polymer gels in deionized water (at pH 6) because of the presence of protonated amino moieties. The PNIPAAm/cyclam gels showed a dependence of the swelling behavior on $\mathrm{pH}$. T-c of the pure PNIPAAm gel was weakly influenced by the presence of any transition-metal ions, such as $\mathrm{Cu}^{2+}, \mathrm{Ni}^{2+}, \mathrm{Zn}^{2+}$, and $\mathrm{Mn}^{2+}[176]$.

In 1994 J. Casabo et al, reported the synthesis of four new acyclic dithia benzene derivatives namel 1,3-bis[(ethylthio)methyl]benzene; 1,3-bis[(pentylthio)methyl] benzene; 1,3bis[(octylthio)methyl]benzene, and 1,3-bis[(dodecylthio)methyl]benzene. All compounds were tested as silver(I) ion sensors in membrane-based ion-selective electrodes, exhibiting good sensitivity, detection limits, reproducibility and selectivity. The chemical recognition of silver(I) by these receptors was compared to the behaviour presented by closely related macrocyclic and acyclic polythia compounds [177].

The same group reported transport-assisted membranes that could perform specific chemical separation and chemical determination tasks. These membranes were conventional polymeric or ceramic membranes incorporating a carrier. The use of this technology in the development of ionselective electrodes using a variety of cyclic ethers and thioethers was also suggested [178].

One year later D. Siswanta et al, synthesized several 14-membered thia crown ether ionophores having a bulky block subunit, and examined their chemical structures and ion selectivities in detail when the compounds were used as an ion-sensing component of an ion-selective electrode. The ionophores of both cyclic and noncyclic thia ethers exhibited a high selectivity for silver ion $\left(\mathrm{Ag}^{+}\right)$, in which the sulfur atom in the ionophore molecule was reported to play a role as the effective coordination donor site for the silver ion. The best $\mathrm{Ag}^{+}$-selective electrode was prepared with the 14membered thia crown ether having one sulfur atom, three oxygen atoms, and a bulky pinan subunit. The ion selectivity of this electrode for $\mathrm{Ag}^{+}$was over 104 times that for other metal cations. In the case where the sulfide in the thia ether ionophore was changed to sulfoxide by oxidation, ion selectivity for mercury ion became higher; therefore, the sulfoxide was found to be an effective coordination site for the mercury ion [179].

In 2001 L. X. Chen et al, reported testing of four novel exocyclic sulfur and selenium ligands based on calix[4]arenes and crown ethers as ionophore in $\mathrm{Ag}^{+}$ion-selective PVC membrane electrodes. All electrodes exhibited good linear responses with one giving a response of $56.0 \mathrm{mV} /$ decade in the $\mathrm{Ag}^{+}$ ion activity range $10^{-5}-10^{-2} \mathrm{M}$ and show fairly good discriminating ability towards $\mathrm{Ag}^{+}$ion in comparison to some alkali, alkaline earth transition and heavy metal ions. The electrodes based on sulfur exocyclic ligands exhibited higher sensitivity than that of selenium analogs. The membrane electrodes based on chalcogen atoms calix[4]arene and crown ether were reported to be suitable for use with aqueous solutions at $\mathrm{pH}>2$ [65].

C. C. Su et al, published a paper on the synthesis of two sym-dibenzo-16-crown-5 ethers with sidearms and their fabrication as ion selective (PVC) membrane electrodes. Among these two ion 
selective electrodes (ISEs), 3-butenyl sym-dibenzo-16-crown-5 ether 1 was reported to give the best $\mathrm{Ag}^{+}$selectivity and 2'-methoxyethoxyl sym-dibenzo-16-crown-5 ether 2 the best selectivity for $\mathrm{Pb}^{2+}$. The electrodes were composed of the respective lariat crown ether (LCE) as ionophore, sodium tetraphenylborate (NaTPB) as anion excluder, and 2-nitrophenyl-octyl ether (NPOE) as plasticizer. Electrodes composed of other plasticizer including tris(2-ethylhexyl) phosphate (TOP), bis(2ethylhexyl) sebacate (DOS) and dibutyl phthalate (DBP) were also investigated. The best performance observed included the two membrane electrodes with the following composition: (1) 3-butenyl symdibenzo-16-crown-5 ether-PVC-NaTPB-NPOE, and (2) 2'-methoxyethoxyl sym-dibenzo-16-crown-5 ether-PVC-NaTPB-NPOE, at a ratio of 5:50:1.100. The two membrane electrodes showed Nernstain response toward silver and lead (55.4 and $28.9 \mathrm{mV}$ per decade, respectively) over a wide concentration range from $5 \times 10^{-5}$ to $5 \times 10^{-1} \mathrm{M}$. The detection limit for silver(I) and lead(II) ions were estimated as $1 \times 10^{-6} \mathrm{M}$. The response time was less than $30 \mathrm{~s}$ and a good reproducibility over a period of 3 months was observed. The newly designed $\mathrm{Ag}^{+}$and $\mathrm{Pb}^{2+}$ ISEs were claimed to be more reliable than the corresponding commercial $\mathrm{Ag}^{+}$and $\mathrm{Pb}^{2+}$-ISEs due to a greater resistance to the interference of $\mathrm{Hg}^{2+}$ or to $\mathrm{Cd}^{2+}$. Stability constants ( $\log \mathrm{K}_{\mathrm{s}}$ ) of 3-butenyl sym-dibenzo-16-crown-5 ether (for $\mathrm{Ag}^{+}$) and 2'methoxyethoxyl sym-dibenzo-16-crown-5 ether (for $\mathrm{Pb}^{2+}$ ) were determined as 3.11 and 3.23, respectively, by potentiometric titration in methanol [180].

Recently V. K. Gupta et al proposed membranes of dibenzo-24-crown-8 (1) as an ion active material in poly(vinylchloride) (PVC) based matrix for constructing zinc(II)selective sensors. The effect of anion excluder, sodium tetraphenylborate (NaTPB) and plasticizers, tris(2ethylhexyl)phosphate (TEP), tributylphosphate (TBP), dibutylphthalate (DBP), dibutyl(butyl)phosphonate (DBBP), 1-chloronaphthalene (CN) and dioctylphthalate, (DOP) on the performance of the membrane electrodes was studied. It was observed that the membrane having the composition (1): PVC: NaTPB: DOP in the ratio 10:200:2:100 gave the best results with a wide working concentration range of $9.2 \times 10^{-5}$ to $1.0 \times 10^{-1} \mathrm{M}$, Nemstian slope of $29.0 \pm 0.5 \mathrm{mV} /$ decade of activity, fast response time of $12 \mathrm{~s}$ and good selectivity over a number of mono-, bi-, and trivalent cations. The sensor was reported to work well in a $\mathrm{pH}$ range 4.8-6.2 and can be employed for the estimation of zinc ions in partially non-aqueous medium having up to $10 \%(\mathrm{v} / \mathrm{v})$ methanol, ethanol or acetone content [181].

V. K. Gupta et al also reported a PVC based membrane containing dicyclohexano-18-crown-6 (1) as active material along with sodium tetraphenyl borate (NaTPB) as an anion excluder and dibutyl phthalate as solvent mediator in the ratio 20:4:150:150 (w/w) (I-NaTPB-DBP-PVC) with a Nernstian response of $29.0 \pm 1.0 \mathrm{mV}$ per decade of activity and a working concentration range of $2.1 \times 10^{-5}-1.0 \times$ $10^{-1}$. The working $\mathrm{pH}$ range of the sensor is 1.9-7.0. It was reported to exhibit a fast response time as fast as $17 \mathrm{~s}$ and a lifetime of about 6 months. The proposed sensor had good selectivity for cadmium over alkali, alkaline earth, some transition and heavy metal ions [182]. Gupta's group reported a $\mathrm{Hg}^{2+}$ sensor in 1997 [183]. They reported that poly(vinyl chloride) (PVC)-based membrane of pentathia-15crown-5 (Figure 40) exhibit good potentiometric response for $\mathrm{Hg}^{2+}$ over a wide concentration range $\left(2.51 \times 10^{-5}\right.$ to $\left.1.00 \times 10^{-1} \mathrm{~mol} \mathrm{dm}^{-3}\right)$ with a slope of $32.1 \mathrm{mV}$ per decade of $\mathrm{Hg}^{2+}$ concentration. 


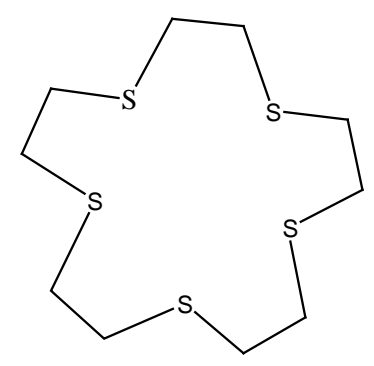

Figure 40. Pentathia-15-crown-5.

In 1997, a PVC membrane sensor for mercury(II) ions based on hexathia-18-crown-6-tetraone as membrane carrier was prepared, by Ganjali et al. The sensor exhibited a Nernstian response for $\mathrm{Hg}^{2+}$ ions over a wide concentration range $\left(1.0 \times 10^{-3}-4.0 \times 10^{-6} \mathrm{M}\right)$. It had a relatively fast response time and could be used for at least 3 months without any considerable divergence in potentials. The proposed sensor revealed very good selectivities for $\mathrm{Hg}^{2+}$ over a wide variety of other metal ions and could be used in a pH range of 0.5-2.0 [184].

In 1999, M. R. Ganjali et al reported a PVC-based membrane of dibenzodiazathia-18-crown-6dione (Figure 41) to reveal a Nernstian potentiometric response for $\mathrm{Hg}^{2+}$ over a wide concentration range $\left(8.0 \times 10^{-6}\right.$ to $\left.1.0 \times 10^{-2} \mathrm{M}\right)$.

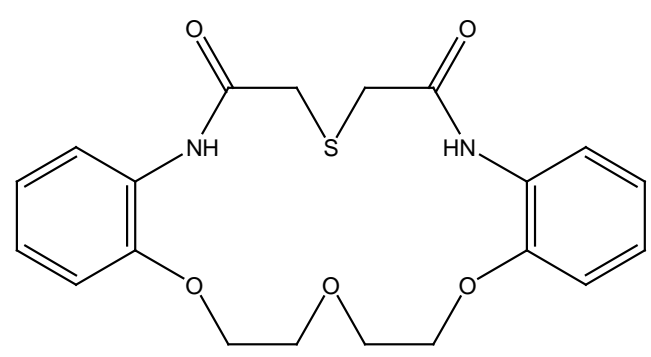

Figure 41. Dibenzodiazathia-18-crown-6-dione.

It had a response time of about $10 \mathrm{~s}$ and was reported to be applicable for at least 3 months without any divergence. The proposed electrode revealed very good selectivities for $\mathrm{Hg}^{2+}$ over a wide variety of alkali, alkaline earth, transition and heavy metal ions and could be used in a $\mathrm{pH}$ range of 0.5-2.5 [185].

\subsection{Podand Based Ion Selective Sensors}

V. Natalya et al, reported the study of open chain polyethers with phosphoryl-containing terminal groups have been studied as carriers in plasticized membrane electrodes that were selective towards cationic surfactants. For the various guests, the bulk membrane (chloroform) transport rate decreased in the series tetraalkyl ammonium > alkyl pyridinium > alkyl ammonium, while the series of solvent extraction efficiency is exactly opposite; an explanation for this behaviour is proposed. The performance of electrode membranes followed the series for bulk membrane transport. Among the ISE membranes of various compositions, one containing the longest (seven oxygen atoms) podand, onitrophenyl octyl ether (plasticizer), and sodium tetraphenyl borate (anionic additive) performed the 
best. The slope of the electrode function equals $58.5 \mathrm{mV} / \mathrm{decade}$, the detection limit for dodecyltrimethylammonium was $3: 2-10^{-6} \mathrm{M}$. ISE response time is $5-10 \mathrm{~s}$, the working $\mathrm{pH}$ range is 2-11 and lifetime was at least 6 months. The electrode selectivity was significantly better than that of conventional ion-association and crown ether based electrodes [156]. In the same year S. L. Shim et al, reported application of a series of nitrogen- and sulfur-containing podands (Figure 42) as sensing components to prepare $\mathrm{Ag}^{+}$-selective polymeric membrane electrodes.<smiles>CN(C)CCSc1ccccc1</smiles>

A

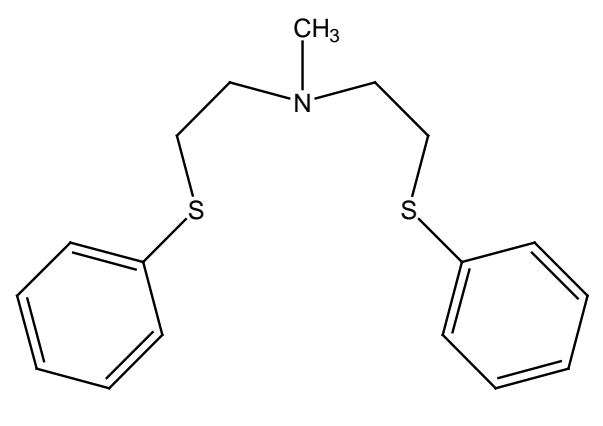

B

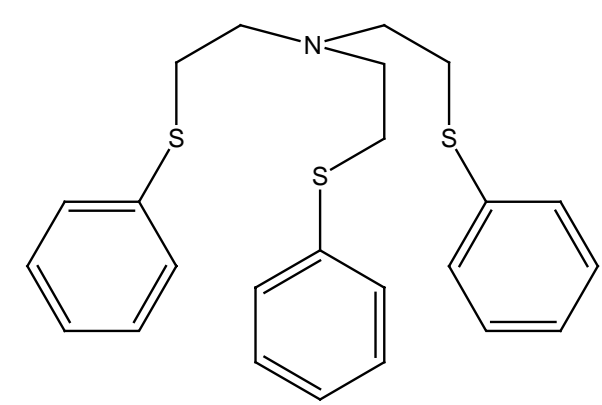

C

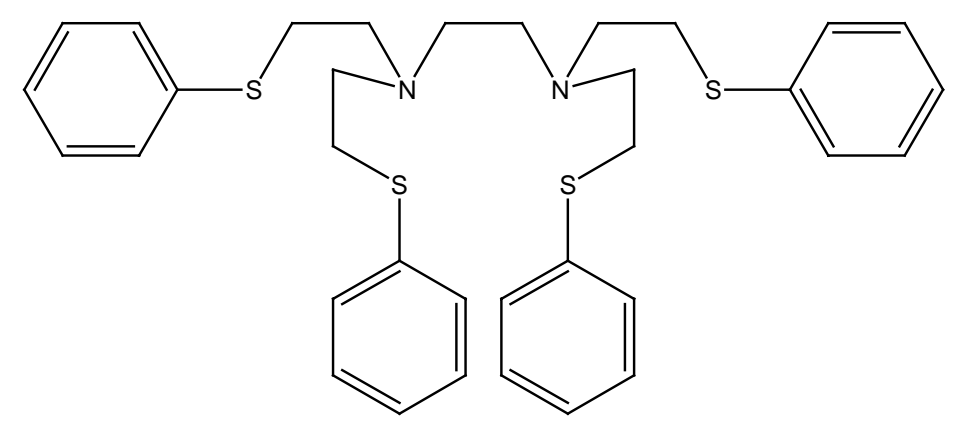

D

Figure 42. Nitrogen- and sulfur-containing podands.

They reported that when incorporated into an optimum FIA system, the podand-based membrane electrode might serve as a suitable detector for measuring $\mathrm{Ag}^{+}$levels in various samples that contain heavy metal ions, including $\mathrm{Hg}^{2+}$. In particular, the increased selectivity towards $\mathrm{Ag}^{+}$over $\mathrm{Hg}^{2+}$ suggested the possibility of tailoring podand molecules for practical membrane sensors [186].

T. Hayashita et al published a paper in 2003 in which they reported a novel podand fluoroionophore/g-cyclodextrin (g-CyD) complex (Figure 43) sensor that shows markedly high selectivity for lead $\left(\mathrm{Pb}^{2+}\right)$ ion in water [187]. 


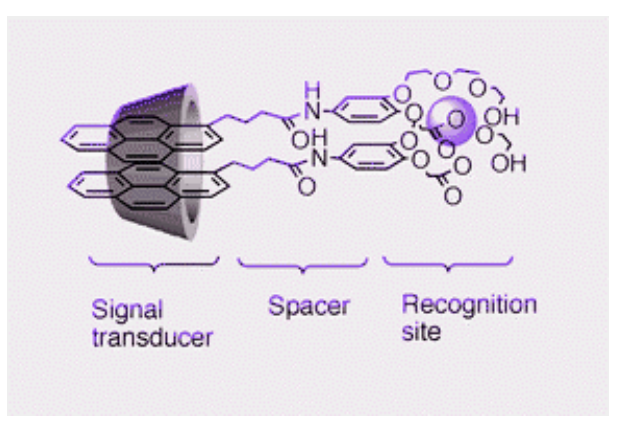

Figure 43. Podand fluoroionophore/ $\gamma$-cyclodextrin $(\gamma-C y D)$ complex.

\subsection{Tripod Based Ion Selective Sensors}

In 2002, Z. Yan et al, reported the synthesis of a new tripodal compound, 1,1,1-tris(N-ethyl-Nphenylamino-carboxylmethoxymethyl) propane, and its evaluation as an ionophore in PVC membrane electrode for the analysis of alkali and alkaline earth metal cations. The influence of the nature of the plasticizers (o-NPOE, DBP and DOP) and of the amount of incorporated ionophore on the characteristics of the electrode was discussed. Selectivity coefficients against alkali and alkaline earth metal cations were calculated. The electrodes based on the tripodal compound with o-NPOE and DBP as plasticizer gave good performance (slope, limits of detection) to lithium and sodium ions. The electrode plasticized with o-NPOE also exhibited near-Nernstian response to divalent ions: $\mathrm{Ca}^{2+}, \mathrm{Sr}^{2+}$ and $\mathrm{Ba}^{2+}$. The electrode prepared with $3.9 \mathrm{mg}$ ionophore, $185 \mathrm{mg}$ o-NPOE, $92 \mathrm{mg}$ PVC and $0.46 \mathrm{mg}$ $\mathrm{KTpClPB}$ can be used as a $\mathrm{Ca}^{2+}$ electrode. The influence of $\mathrm{pH}$ has also been studied. The electrodes exhibited better potential stability and operational lifetime of more than 3 months [188]. Y. K. Kim et al published a paper on new C-3 symmetric, tripodal trifluoroacetophenone derivatives (Figure 44) as anion ionophores.

Evaluation of their ion selectivity has been carried out through ion-selective electrode membranes. The selectivity coefficients for the carbonate electrode toward various anions are dependent on the composition of the membranes and the lipophilicity of the ionophores. The tripodal ionophore showed an improved selectivity toward salicylate when $90 \mathrm{~mol} \%$ of a lipophilic additive was used, compared to that of p-dodecyltrifluoroacetophenone [189].

M. J. Berrocal et al reported a tripodal ionophore with sulfate recognition properties for anionselective electrodes. They mentioned that ionophore topology has a profound effect on the behavior of ion-selective electrodesand that this can be demonstrated with a new class of ionophores that incorporates aminochromenone moieties linked through urea spacers to different scaffolds that preorganize the ionophore binding cleft into tripodal topologies. In their work tris(2-aminoethylamine) and cis-1,3,5tris(aminomethyl) cyclohexane (Figure 45) were employed as the scaffolds.

The two differed in their rigidity and in the size of ionophore cavity that they createed. The electrodes based on the ionophore that incorporated the tris(2-aminoethylamine) scaffold show antiHofmeister behavior with an improved selectivity for sulfate. In contrast, the ionophore with the cis1,3,5-tris(aminomethyl)cyclohexane scaffold exhibits a more Hofmeister-like response [190]. 
<smiles>[R]c1c(Cc2cccc(C(=O)C(F)(F)F)c2)c([R])c(Cc2cccc(C(=O)C(F)(F)F)c2)c([R])c1Cc1cccc(C(=O)C(F)(F)F)c1</smiles><smiles>Cc1c(Cc2ccc(C(=O)C(F)(F)F)cc2)c(C)c(Cc2ccc(C(=O)C(F)(F)F)cc2)c(C)c1Cc1ccc(C(=O)C(F)(F)F)cc1</smiles>

A

B<smiles>O=C(c1ccccc1)c1cccc(Cc2c(Br)c(Cc3cccc(C(=O)C(F)(F)F)c3)c(Br)c(Cc3cccc(C(=O)C(F)(F)F)c3)c2Br)c1</smiles>

Figure 44. Tripodal trifluoroacetophenone derivatives. 


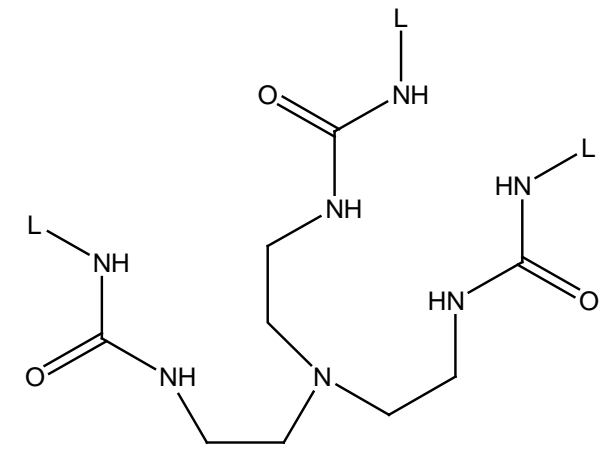

A

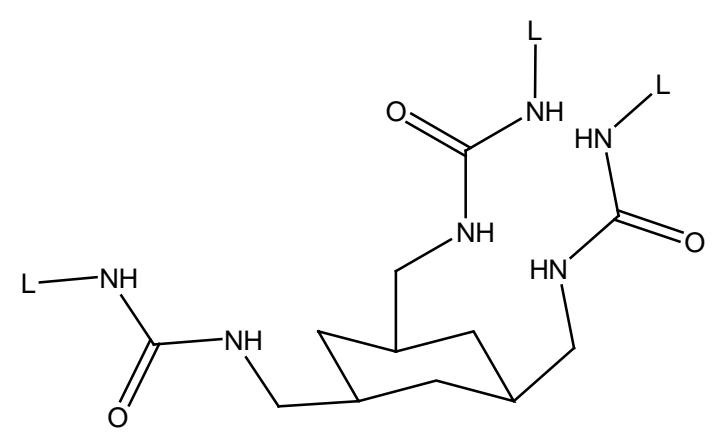

B<smiles>CCCCCNC(=O)c1cc(=O)c2cc(C(C)(C)C)cc(O)c2o1</smiles>

$\mathbf{L}$

Figure 45. Tris(2-aminoethylamine) (A) and cis-1,3,5tris(aminomethyl) cyclohexane (B).

\subsection{Rigid Schiff's Bases Based Ion Selective Sensors}

In 1999, N. Alizadeh et al, reported the construction of a PVC membrane sensor for $\mathrm{Hg}(\mathrm{II})$ ion based on a sulfur Schiff's base 1-(2-hydroxy-1,2-diphenylethylidene) thiosemicarbazide (HDPET) as ionophore. The sensor exhibited a Nernstian response for $\mathrm{Hg}^{2+}$ ions over a wide concentration range $1.0 \times 10^{-2}-2.0 \times 10^{-6} \mathrm{M}$. It revealed to have a very good selectivity for $\mathrm{Hg}^{2+}$ over a wide variety of other metal ions and could be used in a pH range of 2.0-5.0 [191].

One year later K. C. Gupta et al, reported another copper(II) ion selective electrode based on copper(II) salicylaniline Schiff's base complex in styrene-co-acrylonitrile copolymer (SAN). The SAN-based membrane electrode containing copper(II)-Schiff's base complex, dioctylphthalate as plasticizer and sodium tetraphenylborate as an anion excluder exhibited a linear response with a Nerstian slope of $30 \mathrm{mV}$ decade ${ }^{-1}$ within the concentration range of $10^{-6}-10^{-2} \mathrm{M}$ of $\mathrm{Cu}^{2+}$ ions. The prepared electrode had an average response time of $15 \mathrm{~s}$ to achieve $95 \%$ steady potential for $\mathrm{Cu}^{2+}$ concentration ranging from $10^{-4}$ to $10^{-2} \mathrm{M}$. The electrode was reported to show a detection limit of $10^{-7}$ $\mathrm{M}$ of $\mathrm{Cu}^{2+}$ ion with an average lifetime of 6 months. The selectivity of electrode for $\mathrm{Cu}^{2+}$ ion was found to be better in comparison to other various interfering ions. The electrode was suitable for use within the $\mathrm{pH}$ range of 2.0-7.0 at $1.0 \times 10^{-3} \mathrm{M}$ of $\mathrm{Cu}^{2+}$ ion [192].

M. R. Ganjali et al, in 2001, reported a highly selective and sensitive PVC-membrane electrode for $\mathrm{Cu}(\mathrm{II})$ ion by using a new thiophene-derivative Schiffs base (Figure 46). 


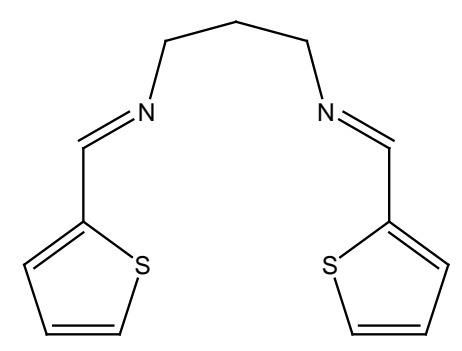

Figure 46. Bis-Thiophenalpropanediamine.

The electrode exhibited a Nernstian slope of $29.3 \pm 0.7 \mathrm{mV}$ per decade at 25 degreesC over a very wide concentration range $\left(1.0 \times 10^{-1}-6.0 \times 10^{-8} \mathrm{M}\right)$ with a detection limit of $2.0 \times 10^{-8} \mathrm{M}(1.28 \mathrm{ng} / \mathrm{mL})$. The ion selectivity of this electrode for $\mathrm{Cu}^{2+}$ was greater than $3.0 \times 10^{3}$ times over various metal ions [193].

In the same year the same group reported a PVC membrane electrode based on bis-2-thiophenal propanediamine (TPDA) coated directly on graphite. The electrode exhibited a Nernstian response for $\mathrm{Cu}^{2+}$ over a very wide concentration range $\left(1.0 \times 10^{-1}\right.$ to $\left.6.0 \times 10^{-8} \mathrm{M}\right)$ with a detection limit of $3.0 \times$ $10^{-8} \mathrm{M}(2.56 \mathrm{ng} / \mathrm{ml})$. It was reported to have a fast response time and the ability to be used for at least 2 months without any major deviation. The proposed sensor revealed very good selectivities for $\mathrm{Cu}^{2+}$ over a wide variety of other metal ions and could be used in the pH range of 3.0-7.0 [194].

M. M. H. Sheikhshoaie, et al proposed a new polyvinyl chloride (PVC) membrane electrode that was highly selective to $\mathrm{Hg}(\mathrm{II})$ ions by using bis[5-((4-nitrophenyl)azo salicylaldehyde)] (BNAS) as a suitable neutral carrier. The sensor exhibited a Nernstian response for mercury ions, over a wide concentration range $\left(5.0 \times 10^{-2}-7.0 \times 10^{-7} \mathrm{M}\right)$ with a slope of $30 \pm \mathrm{mV}$ per decade. It had a response time of $<10 \mathrm{~s}$ and could be used for at least 3 months without any measurable divergence in potential. The electrode could be used in the $\mathrm{pH}$ range from 1.0 to 3.5. The proposed sensor showed fairly good discriminating ability towards $\mathrm{Hg}^{2+}$ ion in comparison with some hard and soft metals [195].

M. R. Ganjali et al, published a paper on a novel gadolinium membrane sensor based on a new S-N Schiff $\mathrm{s}$ base (2-[\{3-[(2-sulfanylphenyl)imino)-1-methylbutylidene $\}$ amino] phenylhydrosulfide $(\mathrm{SMPH})$. The sensor displayed a linear dynamic range between $1.0 \times 10^{-1}$ and $1.0 \times 10^{-5} \mathrm{M}$, with a nice Nernstian slope of $19.8 \pm 0.3 \mathrm{mV}$ per decade and a detection limit of $3.0 \times 10^{-6} \mathrm{M}$. The best performance was obtained with a membrane composition of 33\% poly(vinyl chloride), $61 \%$ benzyl acetate, $2 \%$ sodium tetraphenyl borate and 5\% SMPH. The potentiometric response of the sensor was independent of the $\mathrm{pH}$ of the solution in the $\mathrm{pH}$ range of 4.0-8.0. The sensor possessed the advantages of short conditioning time, very fast response time, and especially, very good selectivity towards a large number of cations, such as $\mathrm{Sm}(\mathrm{III}), \mathrm{Ce}(\mathrm{III}), \mathrm{La}(\mathrm{III}), \mathrm{Cu}(\mathrm{II}), \mathrm{Pb}(\mathrm{II})$ and $\mathrm{Hg}(\mathrm{II})$. The electrode could be used for at least 9 weeks without any considerable divergence in the potentials [196].

In the same year the same group reported the construction, performance characteristics, and application of a novel chromium(III) membrane sensor based on a new tridentates S, N, O Schiff's base 4-hydroxysalicylade-2-mercaptoanil (TSNO). The sensor was prepared by incorporating of TSNO, o-nitrophenyloctyl ether (NPOE), and sodium tetraphenylborate (NaTPB), into a plasticized poly(vinyl chloride) membrane. The sensor exhibited a Nernstian response in the concentration range from $3.0 \times 10^{-6}$ to $1.0 \times 10^{-1} \mathrm{M}$ with a detection limit of $1.5 \times 10^{-6} \mathrm{M}$. It showed a very short response 
time (20 s). The electrode displayed high selectivity towards chromium ion over several cations and can be used in a pH range 3.0-5.5 [197]. They also reported the use of a new Schiff's base with sulfur and nitrogen donor atoms (2-(\{(E)1,2-diphenyl-2-[(2-2-sulfanylphenyl)imino]ethylidene $\}$ amino)-1benzenethiol, DSAB) as a membrane-active component to prepare a Y(III)-selective polymeric membrane microelectrode. The electrode was reported to exhibit a Nernstian response toward Y(III) ions over a wide concentration range $\left(1.0 \times 10^{-2}-1.0 \times 10^{-7} \mathrm{M}\right)$, with a detection limit of $7.0 \times 10^{-8} \mathrm{M}(6.2$ $\mathrm{mug} / \mathrm{mL}$ ). It had a very fast response time $<5$ s and could be used for at least one month without any considerable divergence in potentials. The proposed membrane sensor revealed very good selectivity toward yttrium over a wide variety of other metal ions including alkali, alkaline earth, transition, and heavy metal ions and could be used in the $\mathrm{pH}$ range 4.0-9.0 [198]. In 2004, Ganjali et al reported a dysprosium [Dy(III)]-selective solvent polymeric membrane sensor based on N,N-bis(pyrrolidene) benzne-1,2-diamine, poly(vinyl chloride)(PVC), the plasticizer benzylacetate (BA), and anionic site. The sensor responded to Dy(III) activity in a linear range from $1.0 \times 10^{-5}$ to $1.0 \times 10^{-1} \mathrm{M}$, with a slope of 20.6 $\pm 0.2 \mathrm{mV}$ per decade and a detection limit of $6.0 \times 10^{-6} \mathrm{M}$ at the $\mathrm{pH}$ range of 3.5-8.0. It had a fast response time of $<20 \mathrm{~s}$ in the entire concentration range, and could be used for at least 2 months without any considerable divergence in the electrode potentials. The proposed sensor revealed comparatively good selectivity with respect to common alkali, alkaline earth, transition and heavy metal ions [199].

M. Shamsipur et al 2004 reported a new PVC membrane electrode for $\mathrm{UO}_{2}{ }^{2+}$ ion based on 2,2'-[1,2ethanediyI bis (nitriloethylidene)]bis(1-naphthalene) (Figure 47) as a suitable ionophore.

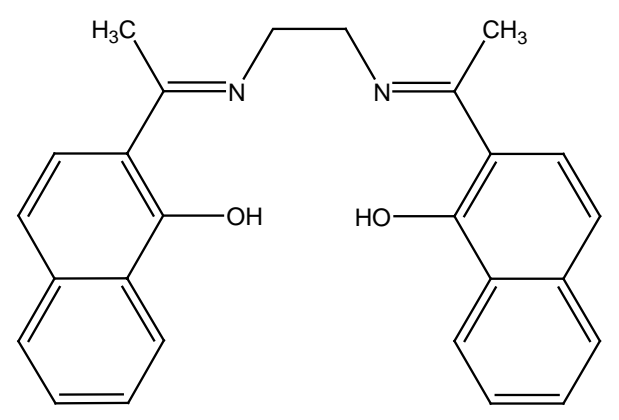

Figure 47. 2,2'-[1,2-ethanediyI bis (nitriloethylidene)]bis(1-naphthalene).

The electrode exhibited a Nernstian response for $\mathrm{UO}_{2}{ }^{2+}$ ion over a wide concentration range $\left(1.0 \times 10^{-1}-1.0 \times 10^{-7} \mathrm{M}\right)$ with a slope of $28.5 \pm 0.8 \mathrm{mV} /$ decade. The limit of detection was $7.0 \times 10^{-8} \mathrm{M}$. The electrode had a response time of $<20 \mathrm{~s}$ and a useful working $\mathrm{pH}$ range of 3-4. The proposed membrane sensor showed good discriminating abilities towards $\mathrm{UO}_{2}{ }^{2+}$, ion with regard to several alkali, alkaline earth transition and heavy metal ions [200].

Ganjali et al, published a paper on a novel lanthanum(III) sensor based on bis(thiophenal)phenylen1,3-diamine (TPD). The sensor was prepared by incorporating the TPD into plasticized PVC membrane. The sensor displayed high selectivity for lanthanum with respect to many common alkali, alkaline earth, transition and heavy metal ions. The effect of membrane composition and $\mathrm{pH}$ and influence of additive anionic on the response properties of were investigated. The sensor with 35\% PVC, 54\% solvent mediator, 8\% ionophore and 3\% anionic additive, showed the best potentiometric 
response characteristics. It displayed a Nernstian behavior (19.6 $\mathrm{mV}$ per decade) over the concentration range $1.0 \times 10^{-7}$ to $1.0 \times 10^{-1} \mathrm{M}$. The detection limit of the electrode is $2.0 \times 10^{-8} \mathrm{M}$ ( similar to3.0 $\mathrm{ng} / \mathrm{ml}$ ). The response time of the electrode was reported to be very fast $(10 \mathrm{~s})$ in whole concentration range. The sensor could be used in the $\mathrm{pH}$ range 3.5-9.5 for at least 2 months [201].

In 2005, M. Shamsipur et al used a newly synthesized azao-containing Schiff's base N,N'adipylbis(5-phenylazo salicylaldehyde hydrazone) (Figure 48) as a suitable neutral ion carrier in construction of a highly selective $\mathrm{La}^{3+}$-PVC membrane electrode.

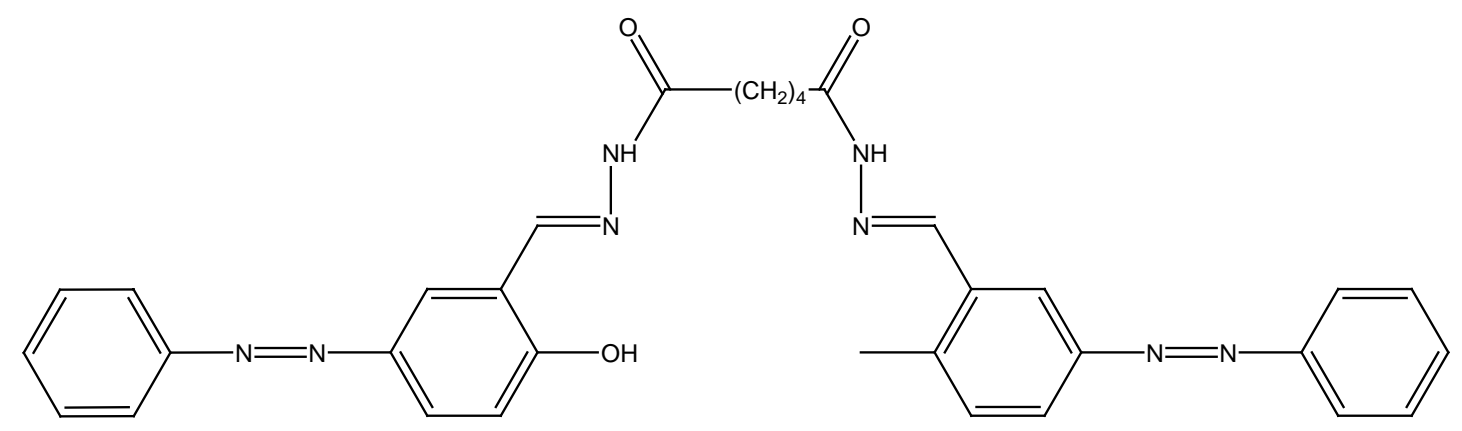

Figure 48. Schiff's base N,N'-adipylbis(5-phenylazo salicylaldehyde hydrazone).

The electrode exhibited a Nernstian response with a slope of $19.4 \mathrm{mV}$ decade $^{-1}$ over a wide concentration range $\left(1.0 \times 10^{-6}-1.0 \times 10^{-2} \mathrm{M}\right)$ and a limit of detection of $4.0 \times 10^{-1} \mathrm{M}(0.05 \mathrm{ppm})$. The electrode possessed a fast response time of ca. $10 \mathrm{~s}$ and could be used for at least 3 months without observing any deviations. The proposed electrode revealed excellent selectivity for $\mathrm{La}^{3+}$ over a wide variety of alkali, alkaline earth, transition and heavy metal ions and could be used in a $\mathrm{pH}$ range of 4.0-8.0 [202].

In the same year, Ganjali et al used bis(2-methylbenzaldehyde)butane-2,3-dihydrazone(TDSB) (Figure 49), a new N-N Schiffs base, which was reported to play the role of an excellent ion carrier in the construction of a La(III) membrane sensor.

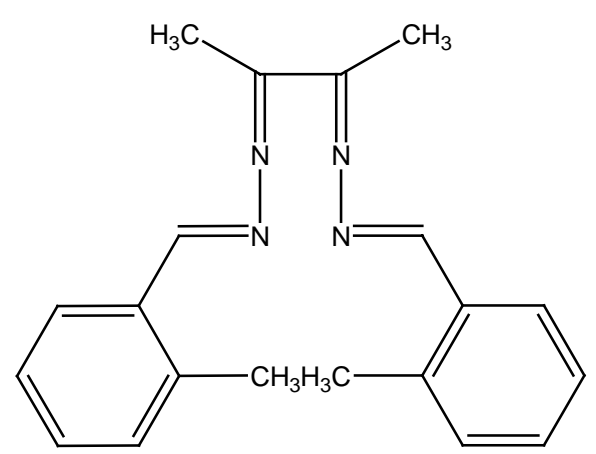

Figure 49. Bis(2-methylbenzaldehyde)butane-2,3-dihydrazone.

The best performance was obtained with a membrane containing, 30\% poly(vinyl chloride), 60\% benzyl acetate, 6\% TDSB and 4\% sodium tetraphenyl borate. This sensor showed a very good selectivity towards La(III) ions over a wide variety of cations, including alkali, alkaline earth, 
transition and heavy metal ions. The proposed electrode exhibited a Nernstian behavior (with slope of $19.8 \mathrm{mV}$ per decade) over a wide concentration range $\left(1.0 \times 10^{-5}-1.0 \times 10^{-1} \mathrm{M}\right)$. The detection limit of the sensor was $7.0 \times 10^{-6} \mathrm{M}$. It had a very short response time, in the whole concentration range (similar to5 s), and could be used for at least twelve weeks in the $\mathrm{pH}$ range of 3.0-9.4 [203]. The same group described a terbium-selective solvent polymeric membrane sensor based on N,N,bis(pyrrolidene) benzene-1,2-diamine, poly(vinyl chloride) (PVC), benzylacetate (BA) plasticizer, and an anionic additive in the same year. At a $\mathrm{pH}$ range of 3.5-7.7, the sensor responded to dysprosium concentration in a linear range from $1.0 \times 10^{-5}$ to $1.0 \times 10^{-1} \mathrm{M}$, with a slope of $19.8 \mathrm{mV}$ per decade and a detection limit of $7.0 \times 10^{-6} \mathrm{M}$. It had a fast response time of $<20 \mathrm{~s}$ in the whole concentration range, and could be used for at least 2 months without any considerable divergences in the potentials. The proposed sensor revealed comparatively good selectivity with respect to common alkali, alkaline earth, transition and heavy metal ions [204]. They also reported the fabrication of a Dy(III) ion-selective membrane sensor from polyvinyl chloride (PVC) matrix membrane containing a new asymmetrical Schiff's base [(E)-N-(2-hydroxybenzylidene)benzohydraide] or BBH as a neutral carrier, sodium tetraphenyl borate (NaTPB) as an anionic excluder and nitrobenzene (NB) as a plasticizing solvent mediator. The membrane sensor displayed linear potential response in the concentration range of $1.0 \times$ $10^{-2}-1.0 \times 10^{-6} \mathrm{M}$ of Dy(III). The electrode exhibited a nice Nernstian slope of $20.1 \pm 0.8 \mathrm{mV} /$ decade in the $\mathrm{pH}$ range of 3.0-8.0. The sensor had a relatively short response time in whole concentration ranges (<20 s). The detection limit of the proposed sensor was reported to be $8.0 \times 10^{-7} \mathrm{M}$ (similar to 128 $\mathrm{ng} / \mathrm{mL}$ ), and it could be used over a period of six weeks. The selectivity of the proposed sensor with respect to other cations, (alkali, alkaline earth, transition and heavy metal ions) and especially lanthanid ions, was excellent [205].

In the same year M. B. Saleh et al reported a mercury (II) ion-selective polyvinyl chloride (PVC) membrane sensor based on ethylenediamine bisthiophenecarboxaldehyde (EDBT) as a novel nitrogenand sulfur-containing sensing material. The ionophore was produced through Schiff's base formation between ethylenediamine and 2-thiophenecarboxaldehyde. The two reagents were claimed to have the advantages of low cost and simple chemical compounds. Ortho-nitro phenyl pentyl ether (o-NPPE) as solvent and sodium tetraphenyl borate (NaTPB) as a lipophilic salt was chosen. The sensor exhibited a good linear response of $30.0 \pm 0.4 \mathrm{mV}$ per decade within the concentration range of $10^{-7}-10^{-2}$ and a detection limit of $7.0 \times 10^{-8} \mathrm{M} \mathrm{Hg}(\mathrm{II})$. The sensor showed good selectivity and fast response for the mercury(II) ion with respect to some alkali, alkaline earth, transition, and heavy metal ions. The EDBT-based sensor was suitable for aqueous solutions of $\mathrm{pH}$ range from 2.0 to 4.5 . It could be used for about 3 months without any considerable divergence in potential. The formation constant of ionophore complex with $\mathrm{Hg}$ (II) ion was calculated by using the segmented sandwich membrane method. The structure of both the ionophore and its $\mathrm{Hg}(\mathrm{II})$ complex were examined using infrared spectra and elemental analysis [206]. M. R. Ganjali et al, have other newly published papers on shciff bases for ions like Eu(III) [207], Lu(III) [208].

\subsection{Cyclodextrin Based Ion Selective Sensors}

Most of the cyclodextrin based sensors have been either optodes for ions like potassium [209], or drug or surfactant sensors for species like propranolol [210], diclofenac [211], glutathione [212], 
sodium dodecyl sulfate (SDS) [213], dopamine [214], atropine, diclofenac [210], zolpidemhemitartrate [215], tetradecyltrimethyl ammonium ion and hexadecylpyridinium [216], levobetaxolol [217], 2phenyl ethylamine, 1-adamantanamine, benzylamine, cyclohexanamine, dopamine [218], dodecyldimethylamine oxide [219].

\section{Supra Molecule based Amperometric Sensors}

Although amperometric sensors do not fit in the family of the membrane sensors, be cause of their importance we give a very short review of this family here. Literature survey also reveals the application of some supramolecular in the construction of amperometric sensors for the detection of different species.

In 2000 Zhang Guorong et al reported a b-Cyclodextrin-ferrocene inclusion complex modified carbon paste electrode for amperometric determination of ascorbic acid [220].Three years later Ru-Qin $\mathrm{Yu}$ et al, published a paper on an amperometric metronidazole sensor that was based on the supermolecular recognition through metalloporphyrin incorporated in a carbon paste electrode [221]. In the same year Flavio Santos Damos et al reported an amperometric sensor for phenolic compound determinations based on Iron(III) tetra-(N-methyl-4-pyridyl)-porphyrin as a biomimetic catalyst of horseradish peroxidase on the electrode surface[222].

In 2004, Lu'cio Angnes et al, reported a new composite material constituted by $m-\{5,10,15,20$ tetra(4-pyridyl)porphyrinato cobalt(III)\}-tetrakis-\{chloro-bis-(2,29-bipyridine)ruthenium(II)\} complex (or CoTRP) and cobalt oxide. The composite was reported to exhibit high stability and sensitivity for the quantification of hydrogen peroxide, and was obtained by the electrochemical polymerization of the tetraruthenated cobalt porphyrin in alkaline medium. Such characteristics allied to a good stability were explored for the specific determination of hydrogen peroxide in six commercial cosmetics and pharmaceutical product samples, giving results in excellent agreement with those obtained by the spectrophotometric method [223]. The same group reported an amperometric sensor for glucose based on electrochemically polymerized tetraruthenated nickel-porphyrin [224] one year later. Fu-Chun Gong et al, reported an amperometric dimetridazole sensor using glycosylated metalloporphyrin as a recognition element one year later [225].

In the same year S^onia M.C.N. Tanaka et al reported the development of a highly sensitive amperometric sensor for nitrite using a glassy carbon electrode modified with alternated layers of iron(III) tetra-(N-methyl-4-pyridyl)-porphyrin (FeT4MPyP) and cobalt(II) tetrasulfonated phthalocyanine (CoTSPc) is described. The modified electrode was reported to show an excellent catalytic activity and stability for the nitrite oxidation decreasing the peak potentials about $200 \mathrm{mV}$ toward less positive values and presenting much higher peak currents than those obtained on the bare GC electrode [226].

\section{Acknowledgements}

The authors wish to express their heartful gratitude to the following people without whose available assistance; the preparation of this article would not be possible: Simindokht Shirvani-Arani, Zahra Pahlavan, Parandis Daneshgar and Nader Hatambeighi. 


\section{References}

1. Pedersen, C.J. Cyclic polyethers and their complexes with metal salts. J. Am. Chem. Soc. 1976, 89, 7017-7036.

2. Weber, E.; Vögel, F. Cristaline 1:1-alkalimetalkomplexe nichtcycclischer neutralligandens. Tetrahedron Lett. 1975, 16, 2415-2418.

3. Lehn, J.M. Supramolecular chemistry-scope and perspectives. Molecules, supermolecules, and molecular devices (Nobel lecture). Angew. Chem. Int. Ed. Engl. 1988, 27, 89-112.

4. Fischer, E. Einflus der Configuration auf die Wirkung der Enzyme. Ber: Dtsch., Chem. Ges. 1894, 27, 2985.

5. Cragg, P.J. A Practical Guide to Supramolecular Chemistry, John Wiley \& Sons, England, 2005.

6. Ciampolini, M.; Nardi, N. Five-coordinated high-spin complexes of bivalent cobalt, nickel and copper with tris(2-dimethylaminoethyl)amine. Inorg. Chem. 1966, 5, 41-44.

7. Perisic, O.; Fong, S.; Lynch, D.E.; Bycroft, M.; Williams, R.L. Crystal structure of a calciumphospholipid binding domain from cytosolic phospholipase. A2, J. Biol. Chem. 1998, 273, 15961604.

8. Kaim, W.; Schwederski, B. Bioorganic Chemistry: Inorganic Chemistry of Life-An Introduction and Guide. John Wiley \& Sons, Chichester, 1994.

9. Greene, R.N. 18-Crown-6: a strong complexing agent for alkali metal cations. Tetrahedron Lett. 1972, 13, 1793-1796.

10. Encyclopedia of Sensors, Vol.8, Potentiometric Ion Sensors, American Scientific Publishers, 2006, 197-288.

11. Ludwig, R.; Dzung, N.T.K. Calixarene-Based Molecules for Cation Recognition. Sensors, 2002, 2, 397-416.

12. Cajan, M.; Lhotak, P.; Lang, J.; Dvorakova, H.; Stibor, I.; Koca, J. Conformational Behavior of Calixarenes: The Pinched Cone Pinched Cone Interconversion. J. Chem. Soc., Perkin. Trans. 2 2002, 2, 1922-1929.

13. Cajan, M.; Damborsky, J.; Stibor, I.; Koca, J. Stability of Complexes of Aromatic Amides with Bromide Anion: Quantitative Structure-Property Relationships. J. Chem. Inf. Comp. Sci. 2000, 40, 1151-1157.

14. Cajan, M.; Stibor, I.; Koca, J. Computational Studies on the Stability of [Amide]Br- Complexes. J. Phys. Chem. A 1999, 103, 3778-3782.

15. Stibor, I.; Hafeed, D.S.M.; Lhotak, P.; Hodacova, J.; Koca, J.; Cajan, M. From the Amide Bond Activation to Simultaneous Recognition of Anion-Cation Couple. Gazz. Chim. Ital. 1997, 127, 673-685.

16. O'Connor, K.M.; Cherry, M.; Svehla, G.; Harris, S.J. Symmetrical, unsymmetrical and bridged calix[4]arene derivatives as neutral carrier ionophores in poly (vinyl chloride) membrane sodium selective electrodes. Talanta 1994, 41, 1207-1217.

17. Shibutani, Y.; Yoshinaga, H.; Yakabe, K.; Shono, T.; Tanaka, M. Polymeric membrane sodiumselective electrodes based on calix[4]arene ionophores. J. Inclus. Phenom. 1994, 19, 333-342.

18. Kimura, K.; Tsujimura, Y.; Yokoyama, M. Silicone-rubber membrane sodium-ion sensors based on calix[4]arene neutral carriers. Pure \& Appl. Chem. 1995, 67, 1085-1089.

19. Tsujimura, Y.; Sunagawa, T.; Yokoyama, A.; Kimura, K. Sodium ion-selective electrodes based on silicone-rubber membranes covalently incorporating neutral carriers. Analyst 1996, 121, 1705-1709.

20. Grady, T.; Cadogan, A.; McKittrick, T.; Harris, S.J.; Diamond, D.; McKervey, M.A. Sodiumselective electrodes based on triester monoacid derivatives of p-tert-butylcalix[4]arene. Comparison with tetraester calix[4]arene ionophores. Anal. Chem. Acta 1996, 336, 1-12.

21. Lee, H.J.; Oh, H.J.; Cui, G.; Cha, G.S.; Nam, H. All-solid-state sodium-selective electrodes based on room temperature vulcanizing-type silicone rubber matrix. Anal. Sci. 1997, 13, 289264. 
22. Kimura, K.; Tsujimura, Y.; Yokoham, M.; Maeda, T. Calix[4]arene Modified Oligosiloxane as a Quasi-Immobilized Neutral Carrier for Silicone-Rubber-Membrane Sodium Ion-Selective Electrodes. Bull. Chem. Soc. Jpn. 1998, 71, 657-667.

23. Muslinkina, L.A.; Evtugyn, G.A.; Kazakova, E.K.; Budnikov, H.C. Calix[4]resorcinarene ionophore in the ion-selective electrodes with plasticized poly(vinylchloride) membranes. $J$. Inclu. Phenom. 1999, 35, 361-367.

24. Kim, Y.D.; Jeong, H.; Kang, S.O.; Nam, K.C.; Jeon, S. Polymeric membrane sodium ionselective electrodes based on calix[4]arene trimesters. Bull. Korean Chem. Soc. 2001, 22, 405408.

25. Lugtenber, R.J.W.; Brzozka, Z.; Casnati, A.; Ungaro, R.; Engbersen, J.F.J.; Reinhoudt, D.N. Cesium-selective chemically-modified field-effect transistors with calix[4]arene-crown-6 derivatives. Anal. Chem. Acta 1995, 310, 263-267.

26. Casnati, A.; Pochini, A.; Ungaro, R.; Ugozzoli, F.; Arnaud, F.; Fanini, S.; Schwing, M.J.; Egberink, R.J.M.; Dejong, F.; Reinhoudt, D.N. Synthesis, Complexation, and membranetransport studies of 1,3-alternate calix[4]arene-crown-6 conformers-a new class of cesium selective ionophores. J. Am. Chem. Soc. 1995, 117, 2767-2777.

27. Oh, H.; Choi, E.M.; Jeong, H.; Nam, K.C.; Jeon, S. Poly(vinyl chloride) membrane cesium ionselective electrodes based on lipophilic calix[6]arene tetraester derivatives. Talanta 2000, 53, 535-542.

28. Lee, S.H.; Ko, S.W.; Cho, E.J.; Chun, J.C.; Nam, K.C. Phenylene bridged calix[6]arenes: Cesium selective ionophores. Bull. Korean Chem. Soc. 2001, 22, 100-102.

29. Nam, K.C.; Ko, S.W.; Kang, S.O.; Lee, S.H.; Kim, D.S. Synthesis and ion binding properties of cesium selective quadruply bridged calix[6]arenas. J. Inclus. Phenom. 2001, 40, 285-289.

30. Chen, L.X.; Ju, H.F.; Zeng, X.S.; He, X.W.; Zhang, Z.Z. Cesium selective electrodes based on novel double flexible spacers bridged biscalix[4]arenas. Anal. Chem. Acta 2001, 447, 41-46.

31. Choi, E.M.; Oh, H.; Ko, S.W.; Choi, Y.K.; Nam, K.C.; Jeon, S. Polymeric membrane cesiumselective electrodes based on quadruply-bridged calix[6]arenas. Bull. Korean Chem. Soc. 2001, 22, 1345-1349.

32. Ko, S.W.; Yang, Y.S.; Mun, J.H.; Park, K.M.; Lee, S.S.; Nam, K.C. Highly cesium selective calix[6]arene receptors: Synthesis, structure and cesium binding properties of calix[6]arene biscrown. Bull. Korean Chem. Soc. 2002, 23, 1379-1380.

33. Mahajan, R.K.; Kumar, M.; Sharma, V.; Kaur, I. Cesium ion selective electrode based on calix[4]crown ether-ester. Talanta 2002, 58, 445-450.

34. Arora, V.; Chawla, H.M.; Francis, T.; Nanda, M.; Singh, S.P. Synthesis of a new cesium selective calix[4]arene based chromoionophore. Ind. J. Chem. section a-inorganic bio-inorganic physical theoretical and analytical chemistry 2003, 42, 3041-3043.

35. Jeon, S.W.; Yeo, H.Y.; Lee, H.K.; Ko, S.W.; Nam, K.C. Novel cesium-selective electrodes based on lipophilic 1,3-bisbridged cofacial-calix[6]crowns. Electroanalysis 2004, 16, 472-477.

36. Yajima, S.; Yoshioka, N.; Tanaka, M.; Kimura, K. Soft Metal Ion-Selective Electrodes Based on $\pi$-Coordinate Calixarene Derivatives. Electroanalysis 2003, 15, 1319-1326.

37. Kimura, K.; Tatsumi, K.; Yokoyama, M.; Ouchi, M.; Mocerino, M. Remarkable thallium(I) selectivity for ion sensors based on $\pi$-coordination of calix[4]arene neutral carriers. Anal. Comm. 1999, 36, 229-230.

38. Park, K.S.; Jung, S.O.; Lee, S.S.; Kim, J.S. Thallium(l)-Selective Electrodes Based on Calix[4]pyrroles. Bull. Korean Chem. Soc. 2000, 21, 909-912.

39. Malinowska, E.; Brzózka, Z.; Kasiura, K.; Egberink, J.M.; David, N. Reinhoudt Lead selective electrodes based on thioamide functionalized calix[4]arenes as ionophores. Anal. Chim. Acta 1994, 298, 253-258.

40. Lugtenberg, R.J.W.; Egberink, R.J.M.; Engbersen, J.F.J.; Reinhoudt, D. N. $\mathrm{Pb}^{2+}$ and $\mathrm{Cd}^{2+}$ selective chemically modified field effect transistors based on thioamide functionalized 1,3alternate calix[4]arenas. J. Chem. Soc. Perkin Trans. 2 1997, 1353-1357. 
41. Ceresa, A.; Bakker, E.; Hattendorf, B.; Gunther, D.; Pretsch, E. Potentiometric polymeric membrane electrodes for measurement of environmental samples at trace levels: New requirements for selectivities and measuring protocols, and comparison with ICPMS. Anal. Chem. 2001, 73, 343-351.

42. Memon, S.; Yilmaz, M. An exchange approach towards the designing of a Schiff-base type oligocalix[4]arene, selective for the toxic metal ions. J. Macromol. Sci. Pure Appl. Chem. 2002, 39, 63-73.

43. Liu, Y.; Zhao, B.T.; Zhang, H.Y.; Ju, H.F.; Chen, L.X.; He, X.W. Molecular Design of Calixarene, Part 4, Synthesis of Novel Double-Armed $p$-(tert-Butyl)calix[4]arene-Derived Amides and Their Lead(II) $\left(\mathrm{Pb}^{2+}\right)$-Selective-Electrode Properties. Helv. Chim. Acta 2001, 84, 1969-1975.

44. Gupta, V.K.; Mangla, R.; Agarwal, S. Pb(II) Selective Potentiometric Sensor Based on 4-tertButylcalix[4]arene in PVC Matrix. Electroanalysis 2002, 14, 1127-1132.

45. Lu, J.Q.; Chen, R.; He, X. A lead ion-selective electrode based on a calixarene carboxyphenyl azo derivative. J. Electroanal. Chem. 2002, 528, 33-38.

46. Ju, H.F.; Chen, L.X.; He, X.W.; Zhao, B.T.; Liu, Y. Lead ion selective electrode based on novel calix[4]arene derivative. Chinese J. Anal. Chem. 2001, 29, 1121-1124.

47. Vaishali, S.; Ijeri, V.S.; Ashwini, K.; Srivastava, K. Coated wire lead(II) selective potentiometric sensor based on 4-tert-butylcalix[6]arene. Sens. Actuators B 2004, 99, 98-105.

48. Katsu, T.; Akagi, M.; Hiramatsu, T.; Tsuchiya, T. Determination of the $\mathrm{pH}$ difference across a cell membrane using a methylammonium-selective membrane electrode. Analyst 1998, 123, 1369-1372.

49. Katsu, T.; Matsumoto, M. Discrimination of methylammonium from organic ammonium ions using ion-selective electrodes based on calix[4]arene-crown-6 conjugates. Anal. Sci. 2001, 17, 721-725.

50. Katsu, T.; Ido, K. Ethylammonium-selective membrane electrode using p-tert-butylcalix[6]arene derivatives. Anal. Sci. 2002, 18, 473-476.

51. Katsu, T.; Okaki, N.; Watanabe, K.; Takaishi, K.; Yokosu, H. Comparative study of the response of membrane electrodes based on calix[6]arene and calix[8]arene derivatives to organic ammonium ions. Anal. Sci. 2003, 19, 771-774.

52. Park, S.J.; Shon, O.J.; Rim, J.A.; Lee, J.K.; Kim, J.S.; Nam, H.; Kim, H. Calixazacrown ethers for copper(II) ion-selective electrode. Talanta 2001, 55, 297-304.

53. Chen, L.; He, X.; Zhao, B.; Liu, Y. Calixarene derivative as the neutral carrier in silver ionselective electrode and liquid membrane transport. Anal. Chim. Acta 2000, 417, 51-56.

54. Chen, L.; Zeng, X.; Ju, H.; He, X.; Zhang, Z. Calixarene derivatives as the sensory molecules for silver ion-selective electrode. Microchem. J. 2000, 65, 129-135.

55. O'Connor, K.M.; Henderson, W.; O'Neill, E.; Arrigan, D.W.M.; Harris, S.J.; Mckervey, M.A.; Svehla, G. Calix[4]Arenes in the partial cone conformation as ionophores in silver ion-selective electrodes. Electroanalysis 1997, 9, 311-315.

56. Liu, Y.; Zhao, B.T.; Chen, L.X.; He, X.W. Liquid membrane transport and silver selective electrode based on novel bis(3-pyridinecarboxylate) calix[4]arene as ionophore. Microchem. J. 2000, 65, 75-79.

57. Zeng, X.S.; Weng, L.H.; Chen, L.X.; Leng, X.B.; Zhang, Z.Z.; He, X.W. Improved silver ionselective electrodes using novel 1,3-bis(2-benzothiazolyl)thioalkoxy-p-tert-butylcalix[4]arenas. Tetrahedron Lett. 2000, 41, 4917-4921.

58. Chen, L.X.; Zeng, X.S.; He, X.W.; Zhang, Z. Selective electrodes for silver based on polymeric membranes containing calix[4]arene derivatives. J. Anal. Chem. 2000, 367, 535-538. 
59. Kimura, K.; Yajima, S.; Tatsumi, K.; Yokoyama, M.; Oue, M. Silver ion-selective electrodes using pi-coordinate calix[4]arene derivatives as soft neutral carriers. Anal. Chem. 2000, 72, 5290-5294.

60. Chen, L.; Ju, H.; Zeng, X.; He, X.; Zhang, Z. Silver ion-selective electrodes based on novel containing benzothiazolyl calix[4]arene. Anal. Chem. Acta 2001, 437, 191-197.

61. Mahajan, R.K.; Kumar, M.; Sharma, V.; Kaur, I. Silver(I) ion-selective membrane based on Schiff base-p-tert-butylcalix[4]arene. Analyst 2001, 126, 505-507.

62. Shinohara, T.; Higuchi, H.; Senba, Y.; Ohto, K.; Yoshizuka, K.; Inoue, K. Silver Ion Selective Electrode Based on Calix[4]arene Methyl Ketonic Derivative. Anal. Sci. 2001, 17, 889-892.

63. Lim, S.M.; Chung, H.J.; Paeng, K.J.; Lee, C.H.; Choi, H.N.; Lee, W.Y. Calix[2]furano[2]pyrrole and related compounds as the neutral carrier in silver ion-selective electrode. Anal. Chim. Acta 2002, 453, 81-88.

64. Park, K.S.; Jung, S.O; Yoon, I.; Park, K.M.; Kim, J.; Lee, S.S.; Kim, J.S. Structural Selectivity of Calix[m]pyrroles[n]furans $(\mathrm{m}+\mathrm{n}=4)$ as Ionophores in Ag(I) Ion-Selective Electrodes. J. Inclus. Phenom. 2001, 39, 295-301.

65. Chen, L.X.; He, X.W.; Zhang, H.Y.; Liu, Y.; Hu, X.B.; Sheng, Y. Selective electrode for silver based on polymer membranes containing exocyclic chalcogen atoms calix[4]arene and crown ether. Anal. Lett. 2001, 34, 2237-2248.

66. Kumar, M.; Mahajan, R.K.; Sharma, V.; Singh, H.; Sharma, N.; Kaur, I. Synthesis of new biscalix[4]arenes with imine linkages. A search for new silver-selective sensors. Tetrahedron Lett. 2001, 42, 5315-5318.

67. Zeng, X.S.; Weng, L.H.; Chen, L.X.; Leng, X.B.; Ju, H.F.; He, X.W.; Zhang, Z.Z. The synthesis of some pyridyl functionalized calix[4]arenes as the sensor molecule for silver ion-selective electrodes. J. Chem. Soc. Perkin Trans. 2 2001, 2, 545-549.

68. Ceresa, A.; Radu, A.; Peper, S.; Bakker, E.; Pretsch, E. Rational Design of Potentiometric Trace Level Ion Sensors. A $\mathrm{Ag}^{+}$-Selective Electrode with a 100 ppt Detection Limit. Anal. Chem. 2002, 74, 4027-4036.

69. Sun, H.; Zeng, X.S.; Lu, J.Q.; Leng, X.B.; Chen, Q.F.; Xu, F.B.; Li, Q.S.; He, X.W.; Zhang, W.Q.; Zhang, Z.Z. Synthesis of a tweezer-like bis(phenylthiapropoxy)calix[4]arene as a cation/pi enhanced sensor for ion-selective electrodes. Chin. J. Chem. 2002, 20, 1109-1114.

70. Zeng, X.S.; Weng, L.H.; Chen, L.X.; Xu, F.B.; Li, Q.S.; Leng, X.B.; He, X.W.; Zhang, Z.Z. The syntheses and $\mathrm{Ag}^{+}$-selective electrode properties of benzothiazolylthiaalkoxy functionalized calix[4]arenes: an investigation of the structure-selectivity relationship in the ionophore-based ISEs. Tetrahedron 2002, 58, 2647-2658.

71. Mazloum Ardakani, M.; Ensafi, A.A.; Salavati Niasari, M.; Mirhoseini, H. Silver(I)-selective Coated-wire Electrode Based on an Octahydroxycalix[4]arene Derivative. Anal. Sci. 2003, 19, 1187-1190.

72. Mahajan, R.K.; Kaur, I.; Kumar, M. Silver ion-selective electrodes employing Schiff's base $p$ tert-butyl calix[4]arene derivatives as neutral carriers. Sens. Actuators B 2003, 91, 26-31.

73. Zeng, X.S.; Sun, H.; Chen, L.X.; Leng, X.B.; Xu, F.B.; Li, Q.S.; He, X.W.; Zhang, Q.W.; Zhang, Z.Z.; Zhang, Z.; Zhang, Synthesis of a tweezer-like bis(arylthiaalkoxy)calix[4]arene as a cation sensor for ion-selective electrodes: an investigation of the influence of neighboring halogen atoms on cation selectivity. Org. Bio. Chem. 2003, 1, 1073-1079.

74. Ganjali, M.R.; Hajiagha Babaei, L.; Taghvaei Ganjali, S.; Modjallal, A.; Shamsipur, M.; Hosseini, M.; Javanbakht, M. A new cone shaped asymmetrically substituted calix[4]arene as an excellentIonophore in construction of $\mathrm{Ag}(\mathrm{I})$ ion-selective membrane electrode. Bull. Korean Chem. Soc. 2004, 25, 177-181.

75. Lu, J.Q.; Pang, D.W.; Zeng, X.S.; He, X.W. A new solid-state silver ion-selective electrode based on a novel tweezer-type calixarene derivative. J. Electroanal. Chem. 2004, 568, 37-43.

76. Lu, J.Q.; Tong, X.O.; He, X.W. A mercury ion-selective electrode based on a calixarene derivative containing the thiazole azo group. J. Anal. Chem. 2003, 540, 111-117. 
77. Mahajan, R.K.; Kaur, R.; Kaur, I.; Sharma, V.; Kumar, M. Mercury(II) ion-selective electrodes based on p-tert-butyl calix[4]crowns with imine units. Anal. Sci. 2004, 20, 811-814.

78. Grady, T.; Maskula, S.; Diamond, D.; Marrs, D.J.; Mckervey, M.A.; Ohagan, P. Haracteristics of a europium-selective electrode based on a calix[4]arene tetraphosphine oxide. Anal. Proceed. 1995, 32, 471-473.

79. Gupta, V.K.; Mangla, R.; Khurana, U.; Kumar, P. Determination of Uranyl Ions Using Poly(vinyl chloride) Based 4-tert-Butylcalix[6]arene Membrane Sensor. Electroanalysis 1999, 11, 573-576.

80. Amemiya, S.; Bu1hlmann, P.; Umezawa, Y.: An ion-selective electrode for acetate based on a urea-functionalized Porphyrin as a Hydrogen-Bonding Ionophore. Anal. Chem. 1999, 71, 10491054.

81. Daunert, S.; Wallace, S.; Florido, A.; Bachas, G.L. Anion-Selective Electrodes Based on Electropolymerized Porphyrin Films. Anal. Chem. 1991, 63, 1676-1679.

82. Khorasani, J.H.; Amini, M.K.; Motaghi, H.; Tangestaninejad, S.; Moghadam, M. Manganese porphyrin derivatives as ionophores for thiocyanate-selective electrodes: the influence of porphyrin substituents and additives on the response properties. Sens. Actuators B 2002, 87, 448456.

83. Vlascici, D.; Fagadar-Cosma, E.; Spiridon-Bizerea, O.; Pascariu, A. Chiriac, The characterization of the membrane material of a tiocyanate-selective electrode based on rhodium (III) [5,10,15,20-tetraphenyl-21H, 23H-porphyrinato-N21,N22,N23,N24] chloride). Rev. Chim. 2005, 56, 224-227.

84. Chaniotakis, N.A.; Park, S.B.; Meyerhoff, M.E. Anion-Selective Electrodes Based on Electropolymerized Porphyrin Films, Anal. Chem. 1989, 61, 566-570.

85. Malinowska, E.; Niedzióka, J.; Roźniecka, E.; Meyerhoff, M.E. Salicylate-selective membrane electrodes based on $\mathrm{Sn}(\mathrm{IV})-$ and $\mathrm{O}=\mathrm{Mo}(\mathrm{V})$ - porphyrins: differences in response mechanism and analytical performance. J. Electroanal. Chem. 2001, 514, 109-117.

86. Shahrokhian, S.; Hamzehloei, A.; Bagherzadeh, M. Chromium(III) Porphyrin as a Selective Ionophore in a Salicylate-Selective Membrane Electrode. Anal. Chem. 2002, 74, 3312-3320.

87. Messick, M.S.; Krishnan, S.K.; Hulvey, M.K.; Steinle, E.D. Development of anion selective polymer membrane electrodes based on lutetium(III) porphyrins. Anal. Chim. Acta 2005, 539, 223-228.

88. Pimenta, A.M.; Araújo, A.N.; Conceição, M.; Montenegro, B.S.M.; Pasquini, C.; Rohwedder, J.J.R.; Raimundo, I.M. Chloride-selective membrane electrodes and optodes based on an indium(III) porphyrin for the determination of chloride in a sequential injection analysis system. J. Pharm. Biomed. Analysis 2004, 36, 49-55.

89. Qin, Y.; Bakker, E. Elimination of Dimer Formation in In(III) Porphyrin-Based Anion-Selective Membranes by Covalent Attachment of the Ionophore. Anal. Chem. 2004, 76, 4379-4386.

90. Jagessar, R.C.; Shang, M.; Scheidt, W.R.; Burns, D.H. Neutral Ligands for Selective Chloride Anion Complexation:(R,R,R,R)-5,10,15,20-Tetrakis(2-(arylurea)phenyl)porphyrins. $J . \quad A m$. Chem. Soc. 1998, 120, 11684-11692.

91. Malinowska, E.; Górski, L.; Meyerhoff, M.E. Zirconium(IV)-porphyrins as novel ionophores for fluoride-selective polymeric membrane electrodes. Anal. Chim. Acta 2002, 468, 133-141.

92. Gorski, L.; Meyerhoff, M.E.; Malinowska, E. Polymeric membrane electrodes with enhanced fluoride selectivity using $\mathrm{Zr}(\mathrm{IV})$-porphyrins functioning as neutral carriers. Talanta 2004, 63, 101-107.

93. Mitchell-Koch, J.T.; Pietrzak, M.; Malinowska, E.; Meyerhoff, M.E. Aluminum(III) Porphyrins as Ionophores for Fluoride Selective Polymeric Membrane Electrodes. Electroanalysis 2006, 18, 551-557.

94. Sun, C.; Zhao, J.; Xu, H.; Sun, Y.; Zhang, X.; Shen, J. Fabrication of a multilayer film electrode containing porphyrin and its application as a potentiometric sensor of iodide ion. Talanta 1998, $46,15-21$. 
95. Farhadi, K.; Maleki, R.; Hosseinzadeh Yamchi, R.; Sharghi, H.; Shamsipur, M. [Tetrakis(4- $N, N-$ dimethylaminobenzene)porphyrinato]-manganese(III) Acetate as a Novel Carrier for a Selective Iodide PVC Membrane Electrode. Anal. Sci. 2004, 20, 805-809.

96. Farhadi, K.; Shaikhlouei, H.; Maleki, R.; Sharghi, H.; Shamsipur, M. Highly Selective Triiodide Polymeric Membrane Electrode Based on Tetra(p-chlorophenyl)porphyrinato Manganese (III) Acetate. Bull. Korean Chem. Soc. 2002, 23, 1635-1639.

97. Gupta, V.K.; Agarwal, S. PVC based 5,10,15,20-tetrakis (4-methoxyphenyl) porphyrinatocobalt (II) membrane potentiometric sensor for arsenite. Talanta 2005, 65, 730-734.

98. Seo, H.R.; Lee, H.K.; Jeon, S. Improved Thiocyanate-Selective Electrode Based on Tetra(trimethylphenyl)-porphyrinato Manganese(III) Chloride: The Electronic and pH Effects. Bull. Korean Chem. Soc. 2004, 25, 1484-1488.

99. Lin, X.M.; Umezawa, K.; Tohda, K.; Furuta, H.; Sessler, J.L.; Umezawa, Y. Potentiometric Responses of Expanded Porphyrin Incorporated Liquid Membrane Electrodes toward a Series of Inorganic and Organic Anions. Anal. Sci. 1998, 14, 99-108.

100. Amini, M.K.; Shahrokhian, S.; Tangestaninejad, S. PVC-Based Mn(III) Porphyrin MembraneCoated Graphite Electrode for Determination of Histidine. Anal. Chem. 1999, 71, 2502-2505.

101. Fagadar-Cosma, E.; Vlascici, D.; Fagadar-Cosma, G.; Bizerea, O.; Chiriac, A. The study of the electrochemical behaviour of metalo-porphyrins with $\mathrm{Co}(\mathrm{II})$ and $\mathrm{Co}(\mathrm{Ill})$. Nitrite-selective electrode based on [5,10,15,20-tetraphenyl-21H,23H-porphyrinato-N21, N22, N23, N24]Co(III) chloride. Rev. Chim. 2004, 55, 882-885.

102. Lee, H.K.; Song, K.; Seo, H.R.; Jeon, S. Nitrate-selective electrodes based on meso-tetrakis[(2arylphenylurea)-phenyl] porphyrins as neutral lipophilic ionophores. Talanta 2004, 62, 293-297.

103. Fakhari, A.R.; Alaghemand, M.; Shamsipur, M. Iron(III)-Selective Membrane Potentiometric Sensor Based on 5,10,15,20-Tetrakis-(pentafluorophenyl)-21H,23H-Porphyrin. Anal. Lett. 2001, 34, 1097-1106.

104. Malinski, T.; Ciszewski, A,; Fish, J.R. Conductive Polymeric Tetrakis(3-methoxy-4hydroxyphenyl)porphyrin Film Electrode for Trace Determination of Nickel. Anal. Chem. 1990, 62, 909-914.

105. Gupta, V.K.; Jain, A.K.; Singh, L.P.; Khurana, U. Porphyrins as carrier in PVC based membrane potentiometric sensors for nickel(II). Anal. Chim. Acta 1997, 355, 33-41.

106. Gupta, V.K.; Jain, A.K.; Maheshwari, G.; Lang, H.; Ishtaiwi, Z. Copper(II)-selective potentiometric sensors based on porphyrins in PVC matrix. Sens. Actuators B 2006, 117, 99-106.

107. Mazloum Ardakani, M.; Dehghani, H.; Jalayer, M.; Zare, H.R. Potentiometric Determination of Silver(I) by Selective Membrane Electrode Based on Derivative of Porphyrin. Anal. Sci. 2004, 20, 1667-1672.

108. Fakhari, A.R.; Shamsipur, M.; Ghanbari, Kh. Zn(II)-selective membrane electrode based on tetra(2-aminophenyl) porphyrin. Anal. Chim. Acta 2002, 460, 177-183.

109. Galowski, J.; Rieckemann, B.; Umland, F. Potassium-selective membrane electrodes based on the cryptand [2b2b2]. Fresenius J. Anal. Chem. 1981, 309, 343-346.

110. Cross, G.G.; Fyles, T.M.; Suresh, V.V. Coated-wire electrodes containing polymer immpbilized ionophores blended with poly(vinyl chloride). Talanta 1994, 41, 1589-1595.

111. Lukyanenk, N.G.; Titova, N.Y.; Nesterenko, N.L.; Kirichenko, T.I.; Scherbakov, S.V. Cation selective of poly(vinyl chloride) membrane based on cryptands with thiourea fragments. Anal. Chim. Acta 1992, 263, 169-173.

112. Amini, M.K.; Mazloum, M.; Ensafi, A.A. Lead selective membrane electrode using cryptand(222) neutral carrier. Fresenius J. Anal. Chem. 1999, 364, 690-693.

113. Srivastava, S.K.; Gupta, V.K.; Jain, S. PVC-based 2,2,2-cryptand sensor for zinc ions. Anal. Chem. 1996, 68, 1272-1275.

114. Pouretedal, H.R.; Shamsipur, M. A PVC-based cryptand C2(B)22 membrane potentiometric sensor for zinc(II). Fresenius J. Anal. Chem. 1998, 362, 415-418.

115. Alexandratos, S.D.; Stine, C.L. Synthesis of ion-selective polymer-supported crown ethers:a review. React. Funct. Polym. 2004, 60, 3-16. 
116. Greenwood, N.N.; Earnshaw, A. in: Chemistry of the Elements. Pergamon Press Inc., Tarrytown 1984, 105-110.

117. Fabre, B.; Simonet, J. Electroactive polymers containing crown ether or polyether ligands as cation-responsive materials. Coor. Chem. Rev. 1998, 178, 1211-1250.

118. Saalfrank, R.W.; Low, N.; Kareth, S.; Seitz, V.; Hampel, F.; Stalke, D.; Teichert, M. Crown ethers, double-decker, and sandwich complexes: Cation-mediated formation of metallatopomer coronates. Angew. Chem. Int. Ed. 1998, 37, 172-175.

119. Pearson, R.G. Hard and Soft Acids and Bases. J. Am. Chem. Soc. 1963, 85, 3533-3539.

120. Pearson, R.G. Acids and Bases. Science 1966, 151, 172-177.

121. Alexandratos, S.D. Polymer-supported reagents with enhanced ionic recognition. Sep. Purif. Meth. 1992, 21, 1-22.

122. Zong, Z.; Dong, S.; Hu, Y.; Xu, Liu, W. Synthesis and complexation properties of polystyrene supported polymeric thiacrown ether. Eur. Polym. J. 1998, 34, 761-766.

123. Attiyat, A.S.; Christian, G.D.; Xie, R.Y.; Wen, X.W.; Bartsch, R. A. Comparative-evaluation of neutral and proton-ionizable crown ether compounds as lithium ionophores in ion-selective electrodes and in solvent-extraction. Anal. Chem. 1988, 60, 2561-2564.

124. Kataky, R.; Nicholson, P.E.; Parker, D.; Covington, A.K. Comparative performance of 14crown-4 derivatives as lithium-selective electrodes. Analyst 1991, 116, 135-140.

125. Suzuki, K.; Yamada, H.; Sato, K.; Watanabe, K.; Hisamoto, H.; Tobe, Y.; Kobiro, K. Design and synthesis of highly selective ionophores for lithium ion based on 14-crown-4 derivatives for an ion-selective electrode. Anal. Chem. 1993, 65, 3404-3410.

126. Kobiro, K. New class of lithium ion selective crown ethers with bulky decalin subunits. Coord. Chem. Rev. 1996, 148, 135-149.

127. Zhou, X.Y.; Luo, Y.; Uo, Wu, C.T.; Zou, Z.F.; Hu, Q.Z. Sodium ion-selective membraneelectrode based on a new crown ether. Anal. Chim. Acta 1988, 212, 325-329.

128. Suzuki, K.; Hayashi, K.; Tohda, K.; Watanabe, K.; Ouchi, M.; Hakushi, T.; Inoue, Y. Sodiumion selective electrodes based on lipophilic 16-crown-5 derivatives. Anal. Lett. 1991, 24, 10851091.

129. Shibata, Y.; Miyagi, H. Anion interference in response of sodium ion-selective electrodes based on a bis(crown ether) compound. Nippon Kagaku Kaishi 1992, 1, 33-39.

130. Lukyanenko, N.G.; Titova, N.Y.; Karpinchik, O.S.; Melnik, O.T. Sodium-selective electrodes based on PVC membranes containing bis[(3N $\left.{ }^{+} 1\right)$-crown-N] ether derivatives. Anal. Chim. Acta 1992, 259, 145-148.

131. Kimura, K.; Yoshinaga, M.; Funaki, K.; Shibutani, Y.; Yakabe, K.; Shono, T.; Kasai, M.; Mizufune, H.; Tanaka, M. Effects of alpha-substituents on ion selectivity of bis(12-crown-4methyl) malonates as neutral carriers for sodium ion-selective electrodes. Anal. Sci. 1996, 12, 6770.

132. Kimura, K.; Yajima, S.; Takase, H.; Yokoyama, M.; Sakurai, Y. Sol-gel modification of pH electrode glass membranes for sensing anions and metal ions. Anal. Chem. 2001, 73, 1605-1609.

133. Moriuchi-Kawakami, T.; Aoki, R.; Morita, K.; Tsujioka, H.; Fujimori, k.; Shibutani, Y.; Shono, T. Conformational analysis of 12-crown-3 and sodium ion selectivity of electrodes based on bis(12-crown-3) derivatives with malonate spacers. Anal. Chim. Acta 2003, 480, 291-298.

134. Tavakkoli, N. Sodium ion-selective membrane electrode based on dibenzopyridino-18-crown-6. Bull. Korean Chem. Soc. 2004, 25, 1474-1476.

135. Willis, J.P.; Young, C.C.; Olsonmank, L.; Radle, L. The Clinical-evaluation of bis crown ether based potassium-ion selective electrodes. Clin. Chem. 1983, 29, 1193-1193.

136. Ogata, T.; Sakaki, T.; Yamagami, H.; Kawano, K. Determination of sodium and potassium in biological-fluids by ion-selective electrodes based on crown ether compounds. Clin. Chem. 1988, 34, 1236-1236.

137. An, H.Y.; Wu, Y.J.; Zhang, Z.J.; Izatt, R.M.; Bradshaw, J.S. The synthesis of bis(benzo-crown ether)s and their incorporation into potassium-selective PVC membrane electrodes. J. Inclus. Phenom. 1991, 11, 303-311. 
138. Luboch, E.; Cygan, A.; Biernat, J.F. Bis(benzocrown ether)s with polymethylene bridges and their application in ion-selective electrodes. Tetrahedron 1991, 47, 4101-4112.

139. Allen, J.R.; Cynkowski, T.; Desai, J.; Baghas, L.G. Crown-ether derivatives of anthraquinone as ionophores in ion-selective electrodes. Electroanalysis 1992, 4, 533-537.

140. Li, A.G.; Zhang, Z.J.; Wu, Y.J.; An, H.Y.; Izatt, R.M.; Bradshaw, J.S. The synthesis of bis(benzo-15-crown-5) derivatives and their use in potassium PVC membrane electrodes. $J$. Inclus. Phenom. 1993, 15, 317-327.

141. Brzozka, Z.; Lammerink, B.; Reinhoudt, D.N.; Ghidini, E.; Ungaro, R. Transduction of selective recognition by preorganized ionophores- $\mathrm{K}^{+}$selective of the different 1,3-diethoxycalix[4]arene crown-ether conformers. J. Chem. Soc. Perkin Trans. 2 1993, 2, 1037-1040

142. Ganjali, M.R.; Moghimi, A.; Buchanan, G.W.; Shamsipur, M. The synthesis of styrene/4 '-vinylbenzo-24-crown-8 copolymer and its use in potassium-ion selective electrodes. J. Inclus. Phenom. 1998, 30, 29-43.

143. Gyurcsanyi, R.E.; Nyback, A.S.; Toth, K.; Nagy, G.; Ivaska, A. Novel polypyrrole based allsolid-state potassium-selective microelectrodes. Analyst 1998, 123, 1339-1344.

144. Xia, Z.R.; Badr, I.H.A.; Plummer, S.L.; Cullen, L.; Bachas, L.G. Synthesis and evaluation of a bis(crown ether) ionophore with a conformationally constrained bridge in ion-selective electrodes. Anal. Sci. 1998, 14, 169-173.

145. Cho, H.Y.; Rha, S.G.; Chang, S.K.; Chung, T.D.; Cho, K.C.; Kim, H. New potassium- and cesium-selective ionophoric bis(crown ether)s derived from xanthene-4,5-dicarboxylic acid. $J$. Inclus. Phenom. 1998, 31, 119-129.

146. Yanagi, H.; Sakaki, T.; Ogata, T. Development of high-performance ion sensors based on the functions of crown ethers and synthetic bilayer membranes. Nippon Kagaku Kaishi 1999, 10, 629-636.

147. Heng, L.Y.; Hall, E.A.H. Taking the plasticizer out of methacrylic-acrylic membranes for $\mathrm{K}^{+}$selective electrodes. Electroanalysis 2000, 12, 187-193.

148. Heng, L.Y.; Hall, E.A.H. One-step synthesis of $\mathrm{K}^{+}$-selective methacrylic-acrylic copolymers containing grafted ionophore and requiring no plasticizer. Electroanalysis 2000, 12, 178-186.

149. Kimura, K.: Yajima, S.; Okamoto, K.; Yokoyama, M. Supported sol-gel-derived membranes for neutral carrier-type ion-selective electrodes. J. Mater. Chem. 2000, 10, 1819-1824.

150. Bereczki, R.; Gyurcsanyi, R.; Agai, B.; Toth, K. Synthesis and characterization of covalently immobilized bis-crown ether based potassium ionophore. Analyst 2005, 130, 63-70.

151. Sugihara, H.; Hiratani, K. 1,10-phenanthroline derivatives as ionophores for alkali metal ions. Coord. Chem. Rev. 1996, 148, 285-299.

152. Hyun, m. H.; Piao, M.H.; Cho, Y.J.; Shim, Y.B. Ionophores in rubidium ion-selective membrane electrodes. Electroanalysis 2004, 16, 1785-1790.

153. Kim, J.S.; Ohki, A.; Ueki, R.; Ishizuka, T.; Shimotashiro, T.; Maeda, S. Cesium-ion selective electrodes based on calix[4]arene dibenzocrown ethers. Talanta 1999, 43, 705-710.

154. Mahajan, R.K.; Kumar, M.; Sharma, V.; Kaur, I. Cesium ion selective electrode based on calix[4]crown ether-ester. Talanta 2003, 61, 757-757.

155. Sheu, H.C.; Shih, J.S. Organic ammonium ion selective electrodes based on 18-crown-6phosphotungstic acid precipitates. Anal. Chim. Acta 1996, 324, 125-134.

156. Shvedene, N.V.; Shishkanova, T.V.; Torocheshnikova, I.I.; Nazarova, I.A.; Baulin, V.E.; Zolotov, Y.A.; Pletnev, I.V. Phosphoryl containing podands as carriers in plasticized membrane electrodes selective to quaternary ammonium surfactants. J. Inclus. Phenom. 1998, 32, 9-21.

157. Moriuchi-Kawakami, T.; Nakazawa, S.; Ota, M.; Nishihira, M.; Hayashi, H.; Shibutani, Y.; Shono, T. Pyrazole-containing crown ethers as ionophores for $\mathrm{NH}_{4}{ }^{+}$-selective electrodes. Anal. Sci. 1998, 14, 1065-1068.

158. Kim, H.S.; Do, K.S.; Kim, K.S.; Shim, J.H.; Cha, G.S.; Nam, H. Ammonium ion binding property of naphtho-crown ethers containing thiazole as sub-cyclic unit. Bull. Korean Chem. Soc. 2004, 25, 1465-1470. 
159. Ganjali, M.R.; Moghimi, A.; Shamsipur, M. Beryllium-selective membrane electrode based on benzo-9-crown-3. Anal. Chem. 1998, 70, 5259-5263.

160. Ganjali, M.R.; Daftari, A.; Pourjavid, M.R.; Rastegar, M.F.; Moghimi, A. Novel Be(II) membrane electrode-based on a derivative of benzo-9-crown-3. Main Group Metal Chem. 2002, 25, 669-676.

161. Ganjali, M.R.; Daftari, A.; Faal-Rastegar, M.; Moghimi, A. Novel potentiometric sensor for monitoring beryllium based on naphto-9-crown-3. Anal. Sci. 2003, 19, 353-356.

162. Ganjali, M.R.; Akbar, V.; Norouzi, P.; Moghimi, A.; Sepehrifard, A. Be(II) graphite coated membrane sensor based on a recently synthesized benzo-9-crown-3 derivative. Electroanalysis 2005, 17, 895-900.

163. Ganjali, M.R.; Rahimi-Nasrabadi, M.; Maddah, B.; Moghimi, A.; Faal-Rastegar, M.; Borhany, S.; Namazian, M. Sub-micro level monitoring of beryllium ions with a novel beryllium sensor based on 2,6-diphenyl-4-benzo-9-crown-3-pyridine. Talanta 2004, 63, 899-906.

164. Ganjali, M.R.; Kiani, R.; Yousefi, M.; Faal-Rastegar, M. Novel potentiometric strontium membrane sensor based on dibenzo-30-crown-10. Anal. Lett. 2003, 36, 2123-2137.

165. Aghaie, H.; Giahi, A.; Monajjemi, M.; Arvand, A.; Nafissi, G.H.; Aghaie, M. Tin(II)-selective membrane potentiometric sensor using a crown ether as neutral carrier. Sens. Actuators B 2005, 107, 756-761.

166. Attiyat, A.S.; Christian, G.D.; Cason, C.V.; Bartsch, R.A. Benzo-18-crown-6 and its lariat ether derivatives as ionophores for potassium, strontium, and lead ion-selective electrodes. Electroanalysis 1992, 4, 51-56.

167. Sheen, S.R.; Shin, J.S. Lead(II) ion-selective electrodes based on crown ethers. Analyst 1992, 117, 1691-1695.

168. Srivastava, S.K.; Gupta, V.K.; Jain, S. Determination of lead using a poly(vinyl chloride)-based crown-ether membrane. Analyst 1995, 120, 495-498.

169. Mousavi, M.F.; Sahari, S.; Alizadeh, N.; Shamsipur, M. Lead ion-selective membrane electrode based on 1,10-dibenzyl-1,10-diaza-18-crown-6. Anal. Chim. Acta 2000, 414, 189-194.

170. Ganjali, M.R.; Roubollahi, A.; Mardan, A.R.; Hamzeloo, M.; Mogimi, A.; Shamsipur, M. Lead ion-selective electrode based on 4 '-vinylbenzo-l5-crown-5 homopolymer. Microchem. J. 1998, 60, 122-133.

171. Shamsipur, M.; Ganjali, M.; Rouhollahi, A. Lead-selective membrane potentiometric sensor based on an 18-membered thiacrown derivative. Anal. Sci. 2001, 17, 935-938.

172. Ganjali, M.R.; Hosseini, M.; Basiripour, F.; Javanbakht, M.; Hashemi, O.R.; Rastegar, M.F.; Shamsipur, M.; Buchanen, G.W. Novel coated-graphite membrane sensor based on N,N'dimethylcyanodiaza-18-crown-6 for the determination of ultra-trace amounts of lead. Anal. Chim. Acta 2002, 464, 181-186.

173. Saleh, M.B. Cationic surfactant ion-selective PVC membrane electrode containing macrocyclic diimine crown ether. Anal. Lett. 1999, 32, 2201-2215.

174. Bobacka, J.; Alaviuhkola, T.; Hietapelto, V.; Koskinen, H.; Lewenstam, A.; Lamsa, M.; Pursiainen, J.; Ivaska, A. Solid-contact ion-selective electrodes for aromatic cations based on picoordinating soft carriers. Talanta 2002, 58, 341-349.

175. Su, C.C.; Ueng, C.H.; Liu, L.K. Characteristics of lariat crown ether-copper(II) ion-selective electrodes. J. Chin. Chem. Soc. 2001, 48, 733-738.

176. Kuckling, D.; Pareek, P. Synthesis of transition-metal-ion-selective poly(N-isopropylacrylamide) hydrogels by the incorporation of an aza crown ether. J. Polym. Sci. Part A: Polym. Chem. 2003, 41, 1594-1602.

177. Casabo, J.; Flor, T.; Romero, m.I.; Teixidor, F.; Perezjimenez, C. Silver-selective membrane electrodes using acyclic dithia benzene drivative neutral carriers-comparision with related macrocyclic-compounds. Anal. Chim. Acta 1994, 294, 207-213.

178. Casabo, J.; Teixidor, F.; Escriche, L.; Vinas, C.; Perezjimenez, C. Silver-selective electrodes based on supported liquid membranes. Adv. Mater. 1995, 7, 238-243. 
179. Siswanta, D.; Nagatsuka, K.; Yamada, N.; Kumakura, K.; Hisamoto, H.; Shichi, Y.; Toshima, K.; Suzuki, K. Structural ion selectivity of thia crown ether compounds with a bulky block subunit and their application as an ion-sensing component for an ion-selective electrode. Anal. Chem. 1996, 68, 4166-4172.

180. Su, C.C.; Chang, M.C.; Liu, L.K. New $\mathrm{Ag}^{+}-$and $\mathrm{Pb}^{2+}$-selective electrodes with lariat crown ethers as ionophores. Anal. Chim. Acta 2001, 432, 261-267.

181. Gupta, V.K.; Al Khayat, M.; Minocha, A.; Kumar, P. Zinc(II)-selective sensors based on dibenzo-24-crown-8 in PVC matrix. Anal. Chim. Acta 2005, 532, 153-158.

182. Gupta, V.K.; Chandra, S.; Mangla, R. Dicyclohexano-18-crown-6 as active material in PVC matrix membrane for the fabrication of cadmium selective potentiometric sensor. Electrochim. Acta 2002, 47, 1579-1586.

183. Gupta, V.K.; Jain, S.; Khurana, U.A. PVC-based pentathia-15-crown-5 membrane potentiometric sensor for mercury(II). Electroanalysis 1997, 9, 478-480.

184. Fakhari, A.R.; Ganjali, M.R.; Shamsipur, M. PVC-based hexathia-18-crown-6-tetraone sensor for mercury(II) ions. Anal. Chem. 1997, 69, 3693-3696.

185. Javanbakht, M.; Ganjali, M.R.; Eshghi, H.; Sharghi, H.; Shamsipur, M. Mercury(II) ion-selective electrode based on dibenzodiazathia-18-crown-6-dione. Electroanalysis 1999, 11, 81-84.

186. Lee, S.S.; Ahn, M.K.; Park, S.B. Silver(I)-selective membrane electrodes based on mono- to quadridentate podands. Analyst 1998, 123, 383-386.

187. Hayashita, T.; Qing, D.; Minagawa, M.; Lee, J.C.; Ku, C.H.; Teramae, N. Highly selective recognition of lead ion in water by a podand fluoroionophore/g-cyclodextrin complex sensor. Chem. Commun. 2003, 17, 2160-2161.

188. Yan, Z.; Fan, Y.; Gao, Q.; Lu, H.; Hou, H. Tripodal compound 1,1,1-tris( $N$-ethyl- $N$ phenylamino-carboxylmethoxymethyl) propane as an ionophore for alkali and alkaline earth metal cations-selective electrode. Talanta 2002, 57, 81-88.

189. Kim, Y. K.; Ha, J.; Cha, G. S.; Ahn, K. H. Synthesis of tripodal trifluoroacetophenone derivatives and their evaluation as ion-selective electrode membranes. Bull. Korean Chem. Soc. 2002, 23, 1420-1424.

190. Berrocal, M.J.; Cruz, A.; Badr, H.A.; Bachas, L.G. Tripodal Ionophore with Sulfate Recognition Properties for Anion-Selective Electrodes. Anal. Chem. 2000, 72, 5295-5299.

191. Alizadeh, N.; Ershad, S.; Naeimi, H.; Sharghi, H.; Shamsipur, M. Copper(II)-selective membrane electrode based on a recently synthesized naphthol-derivative, Schiff's base. Fresenius J. Anal. Chem. 1999, 365, 511-515.

192. Gupta, V.K.; D'Arc, M.J. Performance evaluation of copper ion selective electrode based on cyanocopolymers. Sens. Actuators B 2000, 62, 171-176.

193. Poursaberi, T.; Hajiagha-Babaei, L.; Yousefi, M.; Rouhani, S.; Shamsipur, M.; Kargar-Razi, M.; Moghimi, A.; Aghabozorg, H.; Ganjali, M.R. The synthesis of a new thiophene-derivative Schiff's base and its use in preparation of copper-ion selective electrodes. Electroanalysis 2001, 13, 1513-1517.

194. Ganjali, M.R.; Poursaberi, T.; Yousefi, M.; Rouhani, S.; Hajiagha-Babaei, L.; Kargar-Razi, M.; Moghimi, A.; Aghabozorg, H.; Shamsipur, M. Highly selective and sensitive copper(II) membrane coated graphite electrode based on a recently synthesized Schiff's base. Anal. Chim. Acta 2001, 440, 81-87.

195. Mashhadizadeh, M.H.; Sheikhshoaie, I. Mercury(II) ion-selective polymeric membrane sensor based on a recently synthesized Schiff base. Talanta 2003, 60, 73-80.

196. Ganjali, M.R.; Emami, M.; Rezapour, M.; Shamsipur, M.; Maddah, M.; Salavat,-Niasari, M.; Hosseini, M.; Talebpour, Z. Novel gadolinium poly(vinyl chloride) membrane sensor based on a new S-N Schiff's base. Anal. Chim. Acta 2003, 495, 51-59.

197. Ganjali, M.R.; Emami, M.; Salavat,-Niasari, M.; Yousefi, M. Determination of trace amounts of $\mathrm{Cr}(\mathrm{III})$ in presence of $\mathrm{Cr}(\mathrm{VI})$ by a novel potentiometric membrane sensor based on a new tridentate S,N,O Schiff's base. Anal. Lett. 2003, 36, 2735-2747. 
198. Ganjali, M.R.; Daftari, A.; Norouzi, P.; Salavat,-Niasari, M. Novel Y(III) PVC-based membrane microelectrode based on a new S-N Schiff's base. Anal. Lett. 2003, 36, 1511-1522.

199. Ganjali, M.R.; Ravanshad, J.; Hosseini, M.; Salavati-Niasari, M.; Pourjavid, M.R.; Baezzat, M.R. Novel Dy(III) sensor based on a new bis-pyrolidene schiff's base. Electroanalysis 2004, 16, 1771-1776.

200. Shamsipur, M.; Saeidi, M.; Yari, A.; Yaganeh-Faal, A.; Mashhadizadeh, M.H.; Azimi, G.; Naeimi, H.; Sharghi, H. $\mathrm{UO}_{2}{ }^{2+}$ ion-selective membrane electrode based on a naphthol-derivative Schiff's base 2,2'-[1,2-ethandiylbis (nitriloethylidene)] bis(1-naphthalene). Bull. Korean Chem. Soc. 2004, 25, 629-633.

201. Ganjali, M.R.; Qomi, M.; Daftari, A.; Norouzi, P.; Salavat-Niasari, M.; Rabbani, M. Novel lanthanum(III) membrane sensor based on a new N-S Schiff's base. Sens. Actuators B 2004, 98, 92-96.

202. Shamsipur, M.; Ershad, S.; Samadi, N.; Esmaeilbeig, A.R.; Kia, R.; Abdolmaleki, A. Polymeric membrane lanthanum(III)-selective electrode based on N,N'-adipylbis(5-plenylazo salicylaldehyde hydrazone). Electroanalysis 2005, 17, 1828-1834.

203. Ganjali, M.R.; Matloobi, P.; Ghorbani, M.; Norouzi, P.; Salavat,-Niasari, M. La(III) selective membrane sensor based on a new N-N Schiff's base. Bull. Korean Chem. Soc. 2005, 26, 38-42.

204. Ganjali, M.R.; Ghesmi, A.; Hosseini, M.; Pourjavid, M.R.; Rezapour, M.; Shamsipur, M.; Salavati-Niasari, M. Novel terbium(III) sensor based on a new bis-pyrrolidene Schiff's base. Sens. Actuators B 2005, 105, 334-339.

205. Ganjali, M.R.; Dodangeh, M.; Ghorbani, H.; Norouzi, P.; Adib, M. PPb level monitoring of Dy(III) ions by a highly sensitive and selective Dy(III) sensor based on a new asymmetrical Schiff's bas. Anal. Lett. 2006, 39, 495-506.

206. Saleh, M.B.; Soliman, E.M.; Gaber, A.A.A.; Ahmed, S.A.A novel Hg(II) PVC membrane sensor based on simple ionophore ethylenediamine bis-thiophenecarboxaldehyde. Anal. Lett. 2006, 39, 659-673.

207. Ganjali, M.R.; Norouzi, P.; Daftari, A.; Faridbod, F.; Salavati-Niasari, M. Fabrication of a highly selective $\mathrm{Eu}(\mathrm{III})$ membrane sensor based on a new S-N hexadentates Schiff's base. Sens. Actuators B 2006 in Press.

208. Ganjali, M.R.; Tamaddon, A.; Norouzi, P.; Adib, M. Novel Lu(III) membrane sensor based on a new asymmetrically S-N Schiff's base. Sens. Actuators B 2006, 120, 194-199.

209. Sun, C.J.; Sun, X.X.; Aboul-Enein, H.Y. Potentiometric, enantioselective electrode responsive to propranolol enantiomers based on a lipophilic beta-cyclodextrin. Anal. Lett. 2004, 37, 22592266.

210. Shamsipur, M.; Jalali, F.; Ershad, S. Preparation of a diclofenac potentiometric sensor and its application to pharmaceutical analysis and to drug recovery from biological fluids. J. Pharm. Biomed. Anal. 2005, 37, 943-947.

211. El-Kosasy, A.M.; Shehata, M.A.; Hassan, N.Y.; Fayed, A.S.; El-Zeany, B.A. Membrane electrodes for the determination of glutathione. Talanta 2005, 66, 746-754.

212. Fukui, H.; Kaminaga, A.; Maeda, T.; Hayakawa, K. Preparation of surfactant anion-selective electrodes with different selectivity coefficients and a trial to determine each component in binary surfactant mixtures. Anal. Chim. Acta 2003, 481, 221-228.

213. Lima, J.L.F.C.; Montenegro, M.C.B.S.M. Dopamine ion-selective electrode for potentiometry in pharmaceutical preparations. Mikrochim. Acta 1999, 131, 187-190.

214. Li, X.W.; Yang, B.L.; Wu, Y.Y.; Lin, H.Y. Determination of atropine in injection with betacyclodextrin modified ion sensitive field effect transistor sensor. Sensors 2005, 5, 604-612.

215. Kelani, K.M. Selective potentiometric determination of zolpidem hemitartrate in tablets and biological fluids by using polymeric membrane electrodes. JAOAC Intern.l 2004, 87, 1309-1318.

216. Mahajan, R.K.; Kaur, I.; Bakshi, M.S. Cationic surfactant-selective potentiometric sensors based on neutral ion-pair carrier complexes. J. Surf. Deterg. 2004, 7, 131-134.

217. Missel, P.J. Coated-wire ion-selective electrodes for levobetaxolol. Langmuir 1999, 15, 71227124. 
218. Odashima, K.; Hashimoto, H.; Umezawa, Y. Potentiometric discrimination of organic amines by liquid membrane electrodes based on a long alkyl chain derivative of beta-cyclodextrin. Mikrochim. Acta 1994, 113, 223-238.

219. Peyre, V.; Baillet, S.; Letellier, P. Ion-selective electrode for dodecyldimethylamine oxide: A "twice-Nernstian" slope for the determination of a neural component. Anal. Chem. 2000, 72, 2377-2382.

220. Zhang, G.; Wang, X.; Shi, X.; Sun, T. b-Cyclodextrin-ferrocene inclusion complex modified carbon paste electrode for amperometric determination of ascorbic acid. Talanta 2000, 53, 10191025.

221. Gong, F.Ch.; Zhang, X.B.; Guo, C.Ch.; Shen, G.L.; Yu, R.Q. Amperometric metronidazole sensor based on the supermolecular recognition by metalloporphyrin incorporated in carbon paste electrode. Sensors 2003, 3, 91-100.

222. Damos, F.S.; Sotomayer, M.D.T.; Kubota, L.T.; Tanaka, S.M.C.N.; Tanaka, A.A. Iron(III) tetra( $N$-methyl-4-pyridyl)-porphyrin as a biomimetic catalyst of horseradish peroxidase on the electrode surface: An amperometric sensor for phenolic compound eterminations. Analyst 2003, 128, 255-259.

223. Quintino, M.S.M.; Winnischofer, H.; Araki, K.; Toma, H.; Angnes, E.L. Cobalt oxide/tetraruthenated cobalt-porphyrin composite for hydrogen peroxide amperometric sensors. Analyst 2005, 130, 221-226.

224. Quintino, M.S.M.; Winnischofer, H.; Nakamura, M.; Araki, K.; Toma, H.; Angnes, E.L. Amperometric sensor for glucose based on electrochemically polymerized tetraruthenated nickel-porphyrin. Analytica Chimica Acta 2005, 539, 215-222.

225. Yang, D.W.; Gong, F.C.; Cao, Z. Amperometric dimetridazole sensor using glycosylated metalloporphyrin as a recognition element. Sens. Actuators B 2006, 114, 152-157.

226. Santos,W.J.R.; Sousa, A.; Luz, L.R.C.S.; Damos, F.S.; Kubota, L.T.; Tanaka, A.A.; Tanaka, S.M.C.N. Amperometric sensor for nitrite using a glassy carbon electrode modified with alternating layers of iron(III) tetra-( $N$-methyl-4-pyridyl)-porphyrin and cobalt(II) tetrasulfonated phthalocyanine. Talanta 2006, 70, 588-594.

(c) 2006 by MDPI (http://www.mdpi.org). Reproduction is permitted for noncommercial purposes. 